\title{
The N170 as a marker of Reading Proficiency
}

\author{
Inaugural-Dissertation \\ in der Fakultät Humanwissenschaft \\ der Otto-Friedrich-Universität Bamberg
}

Vorgelegt von

Ulrike Kagel

aus

Parchim

Bamberg, den 20.11.2019

Tag der mündlichen Prüfung: 25.04.2020

Dekan: Universitätsprofessor Dr. Jörg Wolstein.

Erstgutachter: Universitätsprofessor Dr. Jascha Rüsseler

Zweitgutachter: Universitätsprofessor Dr. Claus-Christian Carbon

URN: urn:nbn:de:bvb:473-irb-488426

DOI: https://doi.org/10.20378/irb-48842

Dieses Werk ist als freie Onlineversion über das Forschungsinformationssystem (FIS; https://fis.uni-bamberg.de) der Universität Bamberg erreichbar. Das Werk steht unter der CC-Lizenz CC-BY. (c) (i) 


\title{
Dedication
}

\author{
I thank
}

My family, who supported me all my life,

Dr. Klaus Kagel, who inspired me,

and

Dr. C. Hoffmann,

I also thank Prof. Dr. Jascha Rüsseler for his support. 


\section{Contents}

Dedication..........................................................................................................................................

1 Introduction ..............................................................................................................

1.1 Overview of language-related event-related potentials (ERPs) ............................ 5

2 The N170 - A Marker for Reading Proficiency? .................................................... 8

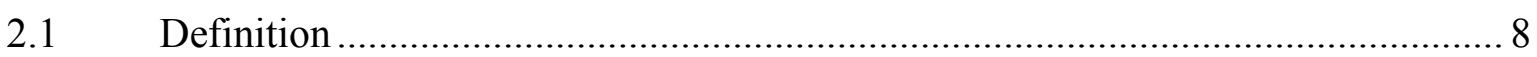

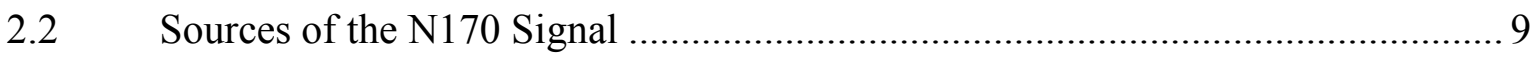

2.2.1 The N170 and Word Specificity ……………………...................................... 10

2.2.2 Studies of Fast vs. Slow Readers ........................................................................ 13

3 Other ERP-Markers for Reading Problems ..................................................... 14

$3.1 \quad$ The Mismatch Negativity (MMN) ................................................................. 14

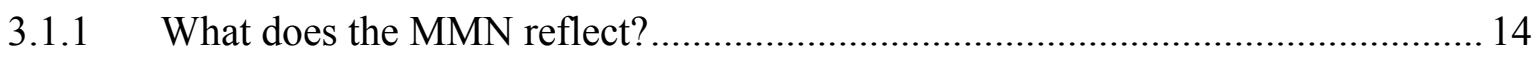

3.1.2 Is the MMN a possible marker for reading problems? ........................................ 16

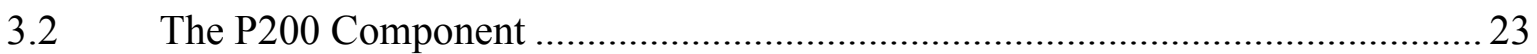

3.2.1 What does the P200 reflect? .......................................................................... 23

3.2.2 Why is this component a possible biological marker for reading problems? ....... 24

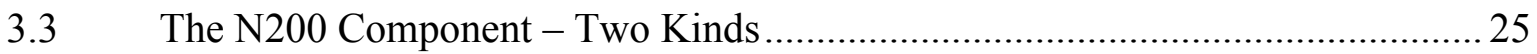

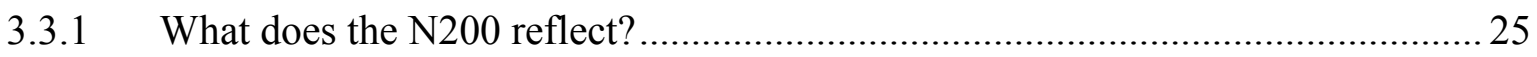

3.3.2 Is the N200 a possible marker for reading problems? ......................................... 26

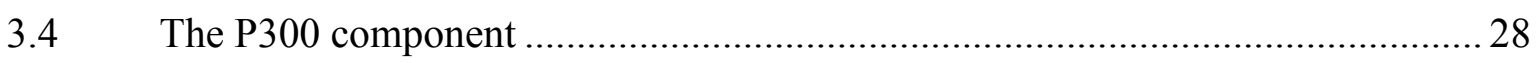

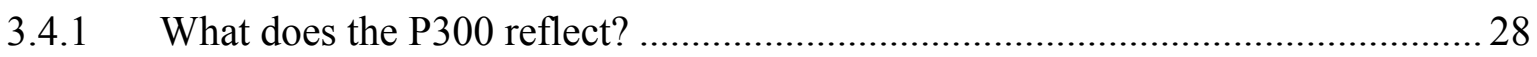

3.4.2 Is the $\mathrm{P} 300$ a possible marker for reading problems? ……………………….......... 30

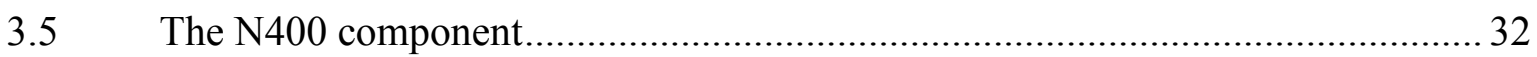

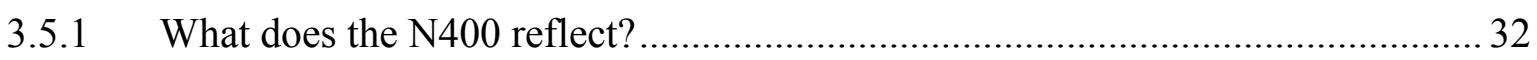

3.5.2 Is the $\mathrm{N} 400$ a possible marker for reading problems? .............................................. 32

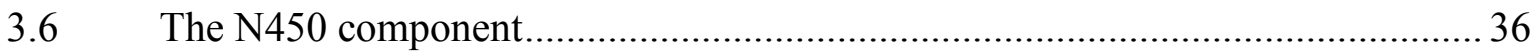

3.6.1 A short excursion: A Component that shows Differences between Rhyming and

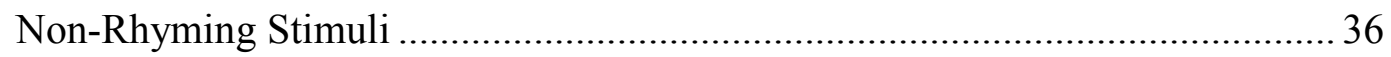

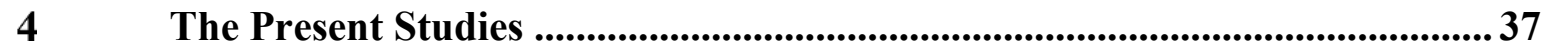

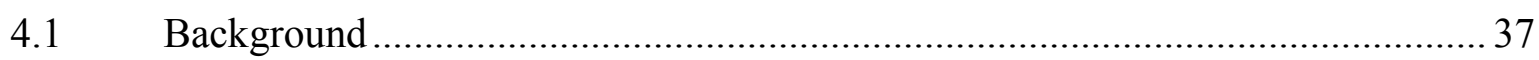

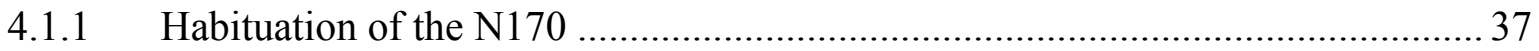

4.2 Experiment 1: The Habituation of the N170 in Adults.........................................38

4.3 Experiment 2: The Habituation of the N170 in Children ....................................5 5

4.4 Experiment 3: A Test of the Phonological Mapping Hypothesis .......................... 57

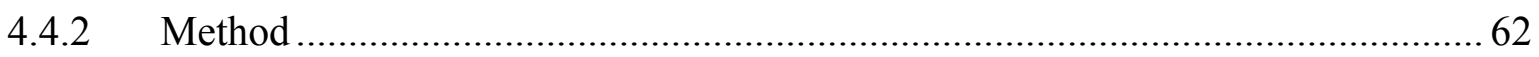

4.4.3 General Discussion ................................................................................ 86

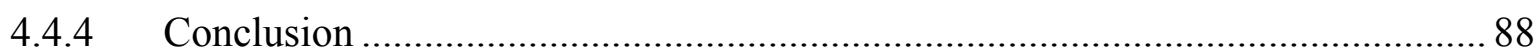




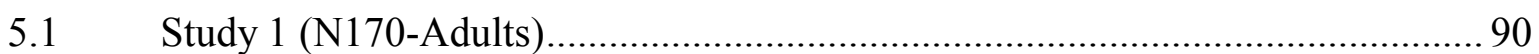

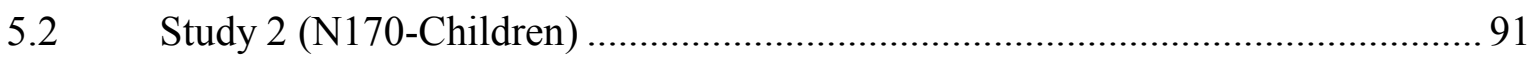

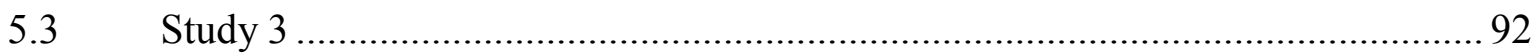

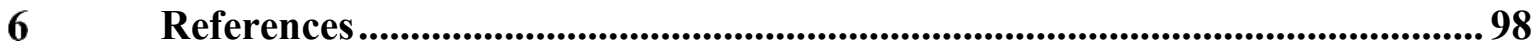




\section{Introduction}

The major aim of the thesis is to investigate a new biological marker for reading proficiency. One typical marker for dyslexia is the mismatch negativity (MMN) of the auditory event-related brain potential. In the present studies I shall explore a marker that is more reading-specific: the N170 component (also called N1). This component is more reading specific because it responds to and is modulated by visual stimuli depending on the expertise of the reader with a specific stimulus class such as words or faces. In contrast, the MMN is primarily sensitive to deviant auditory stimuli in an otherwise consistent series of auditory events.

The first two studies examined whether there is a correlation between habituation of the N170 and reading speed in adult normal readers and $2^{\text {nd }}$ graders. The ongoing habituation of the N170 signal represents the automatization of the reading process. In a third study rhymes were used to explore the relation between N170 laterality, phonological abilities (rhyming) and reading ability/speed.

\subsection{Overview of language-related event-related potentials (ERPs)}

Visual stimuli like faces, pictures of objects and words elicit the N170 component after $150 \mathrm{~ms}$ to $200 \mathrm{~ms}$ in temporo-parietal regions while real visual objects rather activate temporaloccipital regions. The N170 is investigated in order to analyze a print-specific ERP. Other typical language-related components also appear depending on the task. The MMN appears around 100-200 ms post-stimulus and is an auditory evoked potential that is thought to be a good candidate as a biomarker for reading difficulties (see Section 3.1). I will review research on the early left anterior negativity (ELAN) which basically represents automatized processing of syntactic structure (parsing) (Hahne \& Friederici, 1999). I will also review research on the P200 component that peaks at about $150-275 \mathrm{~ms}$ and which is investigated primarily in the auditory domain. The N400 reflects the processing of semantic information while the P300 reveals insights in tasks that require an intentional discrimination response (see Figure 1 and Figure 2). 


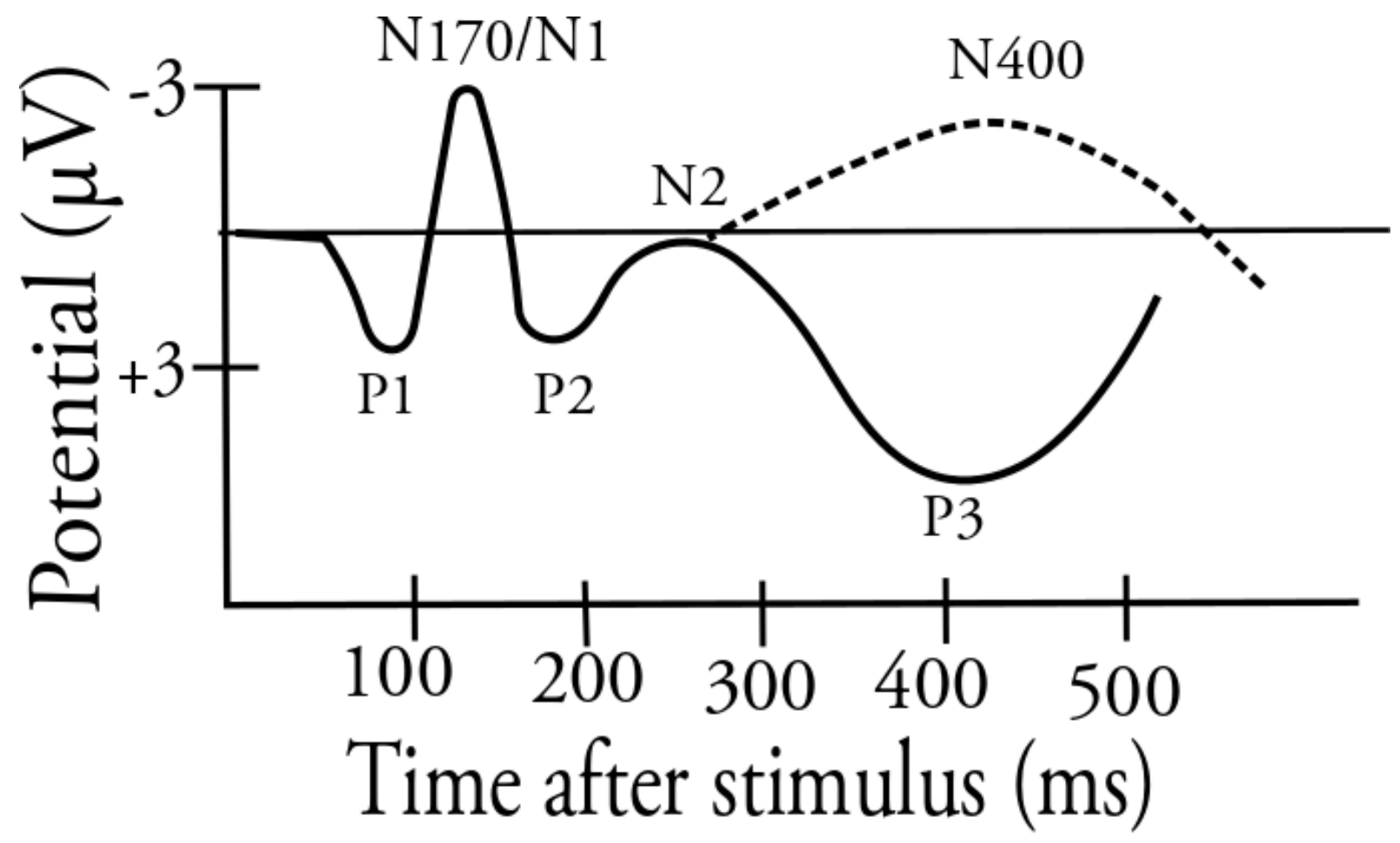

Figure 1: A schematic overview of some language-related potentials.

In the next sections the different language-associated ERPs and their relation to dyslexia or specific language impairment (SLI) are reviewed. 


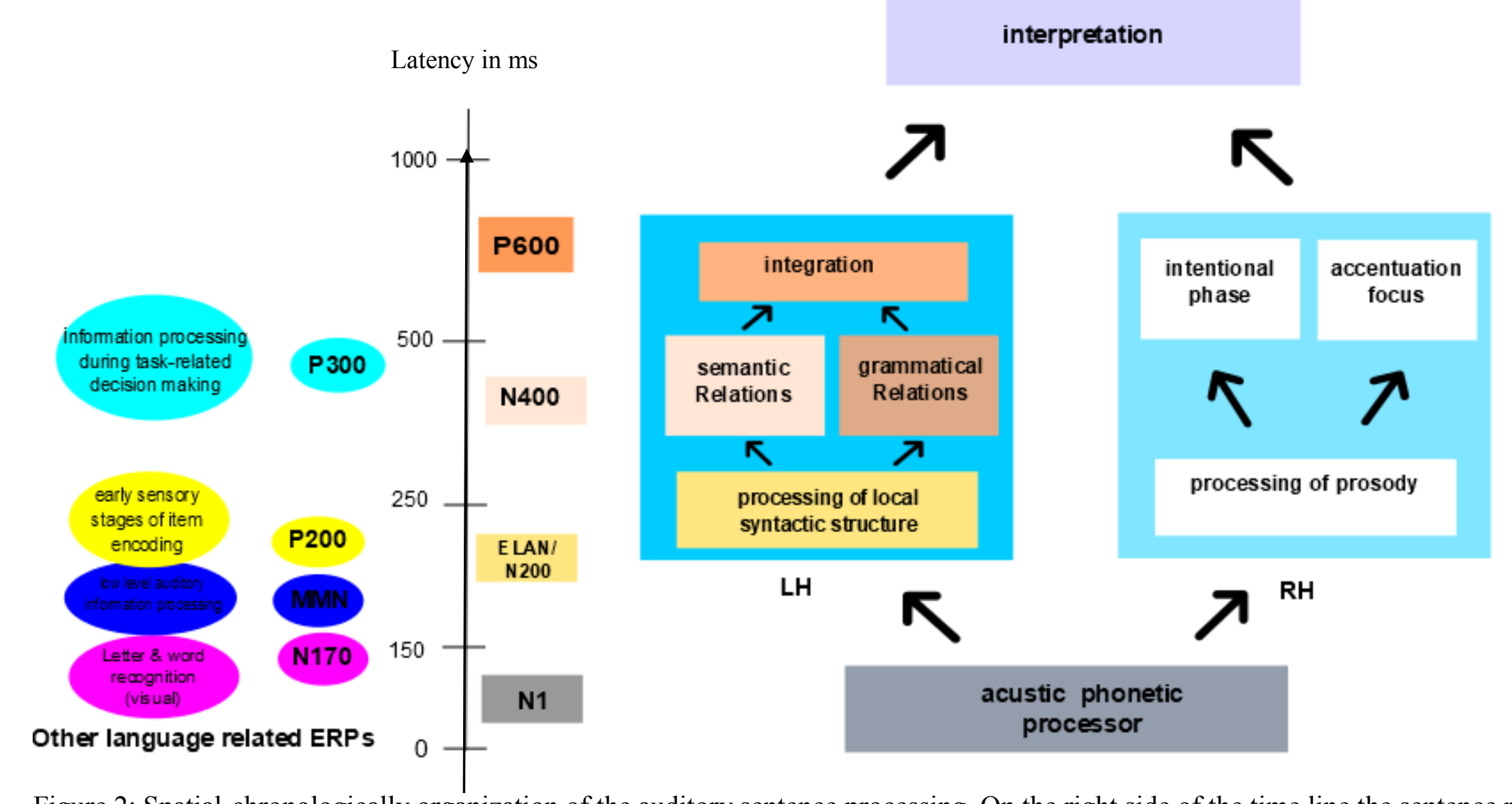

Figure 2: Spatial-chronologically organization of the auditory sentence processing. On the right side of the time line the sentence processing model of Angela Friederici (Friederici, 2002) is depicted. On the left side, other language related ERPs and their function are summarized in regards to the time line. Figure adapted from Jäncke (2013), Lehrbuch Kognitive Neurowissenschaften, p.637. 


\section{$2 \quad$ The N170 - A Marker for Reading Proficiency?}

\subsection{Definition}

The N170 is a negative deflection of the event-related brain potential that is elicited by visual stimuli at temporo-parietal electrodes with a maximum amplitude 150-200 ms post-stimulus. It is evoked by visual stimuli in general and is prone to the expertise of the observer. The N170 amplitude was found to be larger, if experts were looking at stimuli that were more familiar to them than others. That means, as an example, that the N170 evoked by pictures of animals is higher for animal experts vs. non-experts (Tanaka \& Curran, 2001) and can be modulated, to take an example from another study, by the expertise of car-experts (Gauthier, Curran, Curby, \& Collins, 2003). The present doctoral thesis addresses the N170 component that is elicited by words or letters, i.e. it is sensitive to the tuning for print and visual print expertise. 


\subsection{Sources of the N170 Signal}

ERP and magnetoencephalographic (MEG) data of Tarkiainen et al (1999) and in the study by Maurer et al (2005b) found that there is print-specific activation in parts of the occipitotemporal cortex. FMRI data support this hypothesis and found sensitivity to word-like stimuli in the fusiform gyrus - the so-called visual word form area (VWFA).
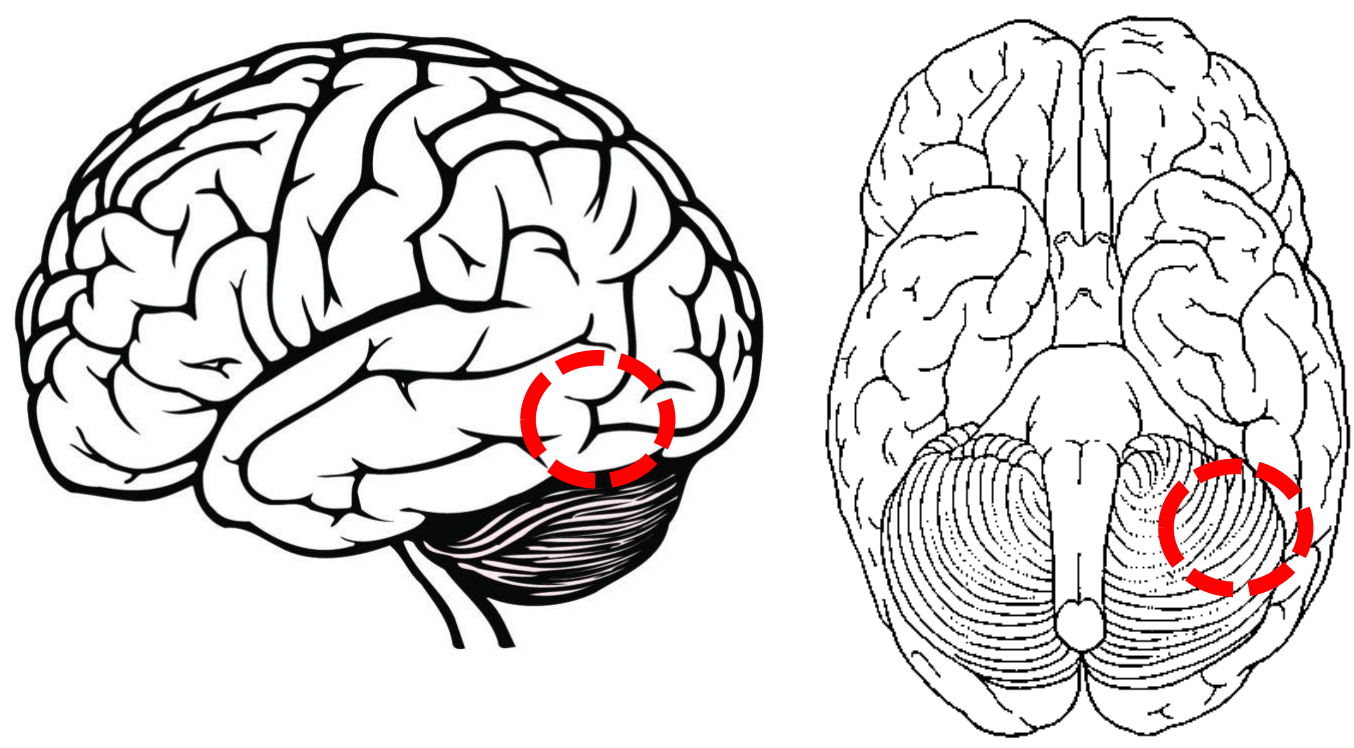

Figure 3 left: Lateral view of the left hemisphere. The indicated area shows the position of the VWFA. Reprinted from list of brain pictures In Venngage. Retrieved January 29, 2018 from: https://infograph.venngage.com/p/212935/12-major-landmarks-of-the-brain; Figure 3 right: Horizontal view of the brain, sight from beyond, again the VWFA is indicated by a red circle, please note that the VWFA is located below the cerebellum. Reprinted from a list of figures of the brain. Retrieved January 29, 2018 from: https://faculty.washington.edu/chudler/gif/colorb9.gif. 


\subsubsection{The N170 and Word Specificity}

Early reading-specific processes seem to be a form of perceptual expertise. Bentin, MouchetantRostaing, Giard, Echallier, and Pernier (1999) found that the N170 is larger in the left hemisphere for orthographic stimuli compared to non-orthographic stimuli like symbols. It was also found that the N170 is more left lateralized for native Japanese speakers compared to monolingual English speakers who were presented a new script (the Japanese scripts). Compared to the Japanese participants, the English participants showed a bilateral N170 activation pattern for the novel script in the grand averages amplitude (words vs. novel words). This reflects that the N170 is not specific to the alphabetic systems (Maurer, Zevin, \& McCandliss, 2008). Additionally, researchers found that the N170 is almost not evident in preschool kindergarten children, but increases in amplitude when children have approximately two years of reading training in school (Maurer et al., 2006) and is still present in adults (Maurer, Brem, Bucher, \& Brandeis, 2005). Zhao, Li, Zhao, Gaspar, and Weng (2015) showed that even short training sessions of Chinese characters modulate the N170 in preliterate children. Boltzmann and Rüsseler (2013) showed that adult functional illiterates display an N170 that is not different for orthographic and non-orthographic stimuli. However, when they learned to read fluently, the N170 amplitude became larger for orthographic stimuli, and the amplitudegain of the N170 for orthographic stimuli correlated positively with the gain in reading ability. Thus, the N170 that is evoked by orthographic stimuli like words or letters can be considered to reflect early specialized neural processing for print that arises through training of reading The N170 correlates with the ability to read and, thus, might be used as a marker for reading proficiency and as a predictor for reading problems. For example, Zhao et al. (2015) found that the N170 amplitude increases after a short visual identification training of Chinese characters in preschoolers. The mean amplitude increase was observed in the right hemisphere.

Maurer et al (2005b) examined children that were not able to read but had letter and word knowledge. The study was designed to investigate whether there are signs of a fast specialization for letter strings (i.e. words and other letter strings). Additionally, the authors compared the processing of word and symbol strings in adults versus children. The results showed that the N170 did not differ between letter and symbol strings in children which were not able to read. Furthermore, children with low letter knowledge had a letter string specialization, i.e. N170-amplitude was larger for words compared to symbols. This could be caused by a previously acquired visual familiarity with letter stings. In another study, Maurer et al (2011) found in a longitudinal study that the N170 deficit for tuning in dyslexic children persists until approximately 5th grade (with a developmental delay). Nevertheless, the N170 
tuning deficit was present in the beginning- when dyslexic children learn to read. Similar results were found in other studies (Grossi et al 2001; Taylor \& Keenan, 1999; Holcomb et al, 1992; Kok \& Rooijakkers, 1985). Furthermore, Mahé, Bonnefond, Gavens, Dufour and DoignonCamus (2012) found that dyslexics exhibit superior N170 tuning for print compared to healthy controls. These studies show that the N170 component evoked by words or letter strings is an index for the ability to read. It is very specific for print tuning and represents clearly defined features of reading.

\section{Better reading ability leads to a larger left-lateralization of the N170}

Typically, the N170 has been shown to be lateralized slightly to the left in the context of reading (Cao et al., 2013; Maurer et al., 2006; Maurer, Blau, Yoncheva, \& McCandliss, 2010; Maurer, Schulz, Brem, der Mark et al., 2011). However, left lateralization of the N170 has been shown to be lacking in children who cannot read. In those children the phonological mapping skills are not yet developed (Kast, Elmer, Jancke, \& Meyer, 2010; Maurer et al., 2006; Maurer et al., 2007). These results demonstrate that the N170 component could be an index for early phonological mapping that develops shortly after familiarization with print (Maurer \& McCandliss, 2007b). In line with this idea, Tong et al. (2016) found that younger children ( $M=7.7$ years) had a bilateral N170 response, while older and more experienced children ( $M=9.4$ years) had a more left lateralized N170 signal (mean amplitude).

Mahé, Bonnefond, Gavens, Dufour and Doignon-Camus (2012) found that dyslexics process verbal and nonverbal printed material similarly which suggests that these participants had no specific visual tuning for printed language. The print tuning of the N170 component was investigated in a lexical decision task with symbol strings and four sets of word-like stimuli. The authors found that there was a tuning for healthy controls but not for dyslexic adults. Tuning was indexed by calculating the differences of the mean N170 amplitudes for letter vs. non-letter stimuli. Furthermore, Mahé, Bonnefond and Doignon-Camus (2013) compared controls, dyslexic adults and poor readers that were reading-matched with the same kind of stimuli as in Mahé et al. (2012) to demonstrate that dyslexia is linked with the hallmark that there is a specific lack of tuning. Like control readers, poor readers showed more pronounced left occipitotemporal negativities in contrast to dyslexics (in absolute mean amplitudes). To summarize, N170 left-lateralization seems to reflect expertise for phonological processing of visually presented letters or words that is compromised in dyslexia. Thus, left-lateralization of the N170 evoked by words, pseudowords or letters might be a useful marker of reading abilities. 
There are few studies leading the way to an N170 component that is a usable biological marker for reading ability. It is - as described above- very sensitive to impairments of the reading ability in adults and children. A very positive feature of this component is that it actually develops with the children's ability to read. As they evolve from a beginner to fluent reader the N170 can be observed to take the shape of an inverted U-curve (Maurer et al., 2006; Tong et al., 2016; see figure 5). When the child learns to read, the N170 grows. When the child develops to a fluent, eloquent reader the N170 lowers again:

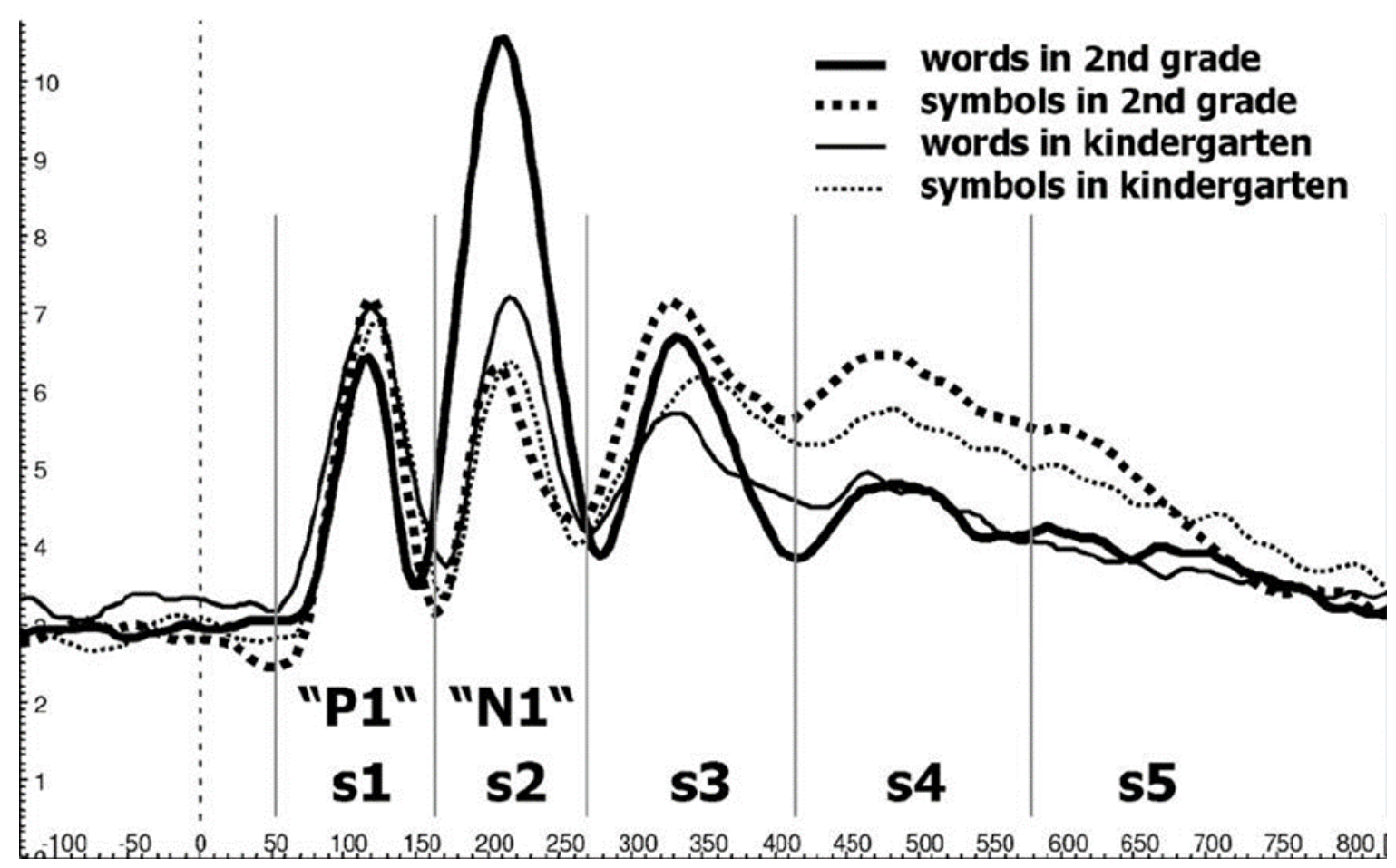

Figure 4: Development of the N170 in kindergarten children and children and second graders. Reprinted from "Coarse neural tuning for print peaks when children learn to read" adapted figure of Maurer, 2006, NeuroImage, Volume 33 (2), 749-758. 


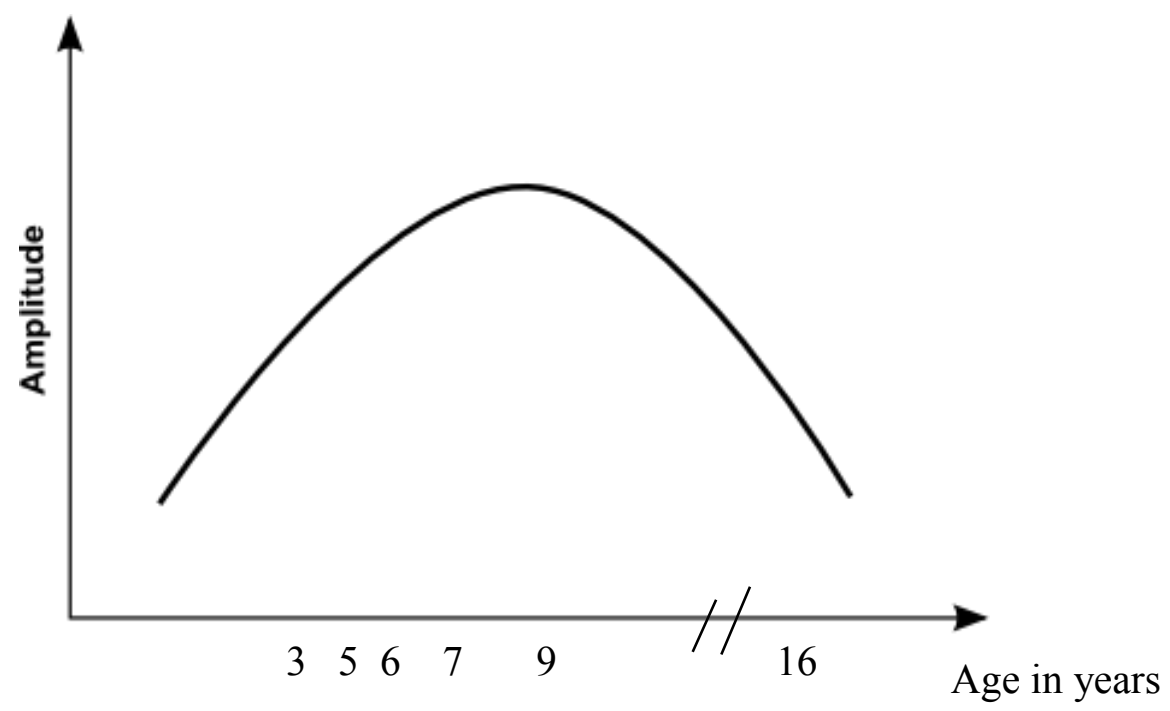

Figure 5: Approximated N170 amplitude over the life span based on publication by Maurer (2006). The amplitude probably rises until the age of 9/10 years and then lowers with age.

Next, I will look at the few studies that investigated the automatization process in reading and used the N170 component to examine such processes. Such studies look at the habituation of the N170 to repeated exposure to the same printed stimuli (see figure 4 and 5).

\subsubsection{Studies of Fast vs. Slow Readers}

Reading might be more automatized in fast readers and may be reflected in a faster habituation / adaptation of the N170 amplitude with increasing reading ability. Korinth, Sommer, and Breznitz (2013) presented single letters to slow and fast readers. They observed an interesting pattern in fast readers only: a double peak - two subcomponents - in the time window from $160 \mathrm{~ms}$ to $200 \mathrm{~ms}$. These subcomponents are temporally and topographically distinct. Furthermore, they studied adaptation effects, i.e., a reduction of N170 absolute mean amplitude after multiple presentations of the same letter. Adaptation effects were weaker for slow compared to fast readers. However, in a more recent study with Hebrew readers, Korinth and Breznitz (2014) did not find a difference in N170 habituation of slow and fast readers.

Taken together, these results indicate that (1) the N170 amplitude increases with better reading ability; (2) better reading ability leads to a larger left-lateralization of the N170 and (3) the habituation / adaptation of the N170 amplitude might be more pronounced with increasing reading ability. These results show that the N170 might be a useful biological marker of reading ability. In the next section I recapitulate findings from other language related ERP components which show that the N170 might be a better marker for reading problems. 


\section{Other ERP-Markers for Reading Problems}

These studies aim to find a marker for the reading ability that can be used for individual diagnostic decisions/risk predictions. Previous studies have also tried to find an index for reading problems using ERPs other than the N170 as a relevant ERP for individual diagnostic decision making with regards to developmental reading difficulties. In the following sections other ERPs than the N170 are reviewed in relation with reading problems.

\subsection{The Mismatch Negativity (MMN)}

In the following section the MMN and its applications is described quite thoroughly, compared to other ERPs. The reason is that the MMN has an important position as a biological marker of reading problems.

\subsubsection{What does the MMN reflect?}

The MMN of the auditory evoked potential is elicited by deviant stimuli interspersed in a sequence of otherwise physically identical sounds even if these are not attended to (Näätänen et al., 1978). The MMN represents the early, low-level stages of auditory information processing at the subcortical and cortical levels (Escera, Leung, \& Grimm, 2014). It can be used to study reading problems in children or infants, because the subject does not have to attend to the stimuli. This makes it especially attractive in studying infants or patients who have problems in communicating or performing tasks. MMN usually peaks $100-200 \mathrm{~ms}$ after the onset of the deviant stimulus with a maximum amplitude over frontal and central scalp locations. It has been described for unexpected changes for a range of stimulus attributes like a decrement in stimulus duration, frequency or intensity changes or changes of the spatial location of stimulus origin (for a recent review, see Bartha-Doering, Deuster, Giordano, Am Zehnhoff-Dinnesen, \& Dobel, 2015). These and other results have led to the conclusion that the MMN is generated by a discriminative process that detects any change in a sequence of sounds by using memory traces established by the previous auditory stimulation (Fishman, 2014). In many studies, the MMN has been found to be of lower amplitude or even absent in dyslexics (for a review, see Bishop, 2007; Kujala \& Näätänen, 2001). This has led researchers to explore the potential of the MMN as a marker for reading difficulties (Hämäläinen, Salminen, \& Leppänen, 2013; Lohvansuu et al., 2014; Lyytinen, Erskine, Hämäläinen, Torppa, \& Ronimus, 2015). 
Some studies show that the MMN can also be used to test the phonological system of the auditory cortex (Cheour et al., 1998; Dehaene-Lambertz, 1997; Näätänen et al., 1997; Rinne et al., 1999; Shtyrov, Kujala, Palva, Ilmoniemi, \& Näätänen, 2000). Näätänen et al. (1997) compared vowel processing in Estonian and Finnish participants by using four vowels, /e/, /ö/, and /o/ that were shared by these two languages and /o/ which belongs to Estonian, but not Finnish. The researchers found that in Estonian, the deviant /ö/, / $\tilde{\mathrm{o}} /$ and /o/ elicited MMNs that were increasingly larger as the physical difference between the standard and the deviant vowel increased. In Finns, the MMN showed another but similar amplitude behavior with the exception that there was an amplitude attenuation for the Estonian /õ/, which suggests that there was no phonological representation (or long-term memory trace) for this vowel. A source localization with MEG indicated that the MMNm (the magnetic equivalent of the MMN) was enhanced for the native-language phoneme in the left temporal cortex as compared to the nonnative language phoneme, for which the MMNm was small in both hemispheres. There is quite a large amount of evidence that the MMN can serve as an index of learning-associated neural plasticity. This has been shown for non-speech and speech stimuli as well as in learning situations in the laboratory and in natural conditions (Kraus et al., 1995; Kujala et al., 2001; Menning, Roberts, \& Pantev, 2000; Näätänen, Schröger, Karakas, Tervaniemi, \& Päävilainen, 1993; Tremblay, Kraus, \& McGee, 1998b; Winkler et al., 1999). As an example, Näätänen and colleagues (Näätänen \& Alho, 1995) showed that the MMN gradually emerged in those participants who learned to discriminate complex spectro-temporal sound patterns, but not in those who did not learn them. Kraus et al. (1995) and Tremblay, Kraus, and McGee (1998a) got similar results by investigating the discrimination learning of speech contrasts that were initially impossible to discriminate for their participants with the MMN being elicited when participants learned to discriminate the speech contrasts.

These examples demonstrate that the MMN reflects auditory processing, a function that might be compromised in developmental dyslexia. Thus, the MMN has been studied in developmental dyslexia to explore its usability as a biomarker for reading problems. 


\subsubsection{Is the MMN a possible marker for reading problems?}

\subsubsection{MMN and dyslexia or SLI}

The MMN is used quite often used to investigate dyslexia or other language problems like specific language impairment (SLI).

\subsection{MMN to Speech Stimuli}

Bishop (2007) summarized eleven studies that investigated the rapid auditory temporal processing (RATP; Tallal, 1980) theory. The RATP hypothesizes that dyslexic readers have difficulties in processing rapidly changing auditory stimuli. Rapid stimulus discrimination is necessary to distinguish, for example, /d/ and /p/. Difficulties in distinguishing these sounds might lead to weak phonological representations and, in turn, to problems with graphemephoneme mapping when starting to learn to read and write. Examples for speech stimuli used in these MMN-studies are: /da/ vs. /ga/and/ba/ vs. /ga/.

Most studies that examined differences between normal and dyslexic readers with speech stimuli reported small to middle effect sizes ranging from 0 to 0.5 (i.e. Alonso-Búa, Díaz, \& Ferraces, 2006; Bradlow et al., 1999; Heim et al., 2000; Paul, Bott, Heim, Wienbruch, \& Elbert, 2006). Only three studies had large effect sizes for specific and different time windows over which the MMN was computed for the studies (Schulte-Körne et al., 1998; Schulte-Körne, Deimel, Bartling, \& Remschmidt, 2001; Sharma et al., 2006). Notable in regard to the effect sizes in studies with speech stimuli is that only the stimuli /da/ vs. /ga/elicited an effect size in which the confidence intervals did not include zero. Two studies found effect sizes around 0.50.8 (Sharma et al., 2006; Uwer, Albrecht, \& Suchodoletz, 2002). To summarize, most confidence intervals of the effect sizes include zero. Only some studies found reliable differences in auditory processing between dyslexic and normal readers. 


\subsection{MMN to Non-speech Auditory Stimuli (that involve temporal processing)}

For non-speech stimuli the MMN review found similar effect sizes. Most studies report an effect size between 0 to 0.5 (i.e. Alonso-Búa et al., 2006; Baldeweg et al., 1999; Kujala, Lovio, Lepistö, Laasonen, \& Näätänen, 2006; Uwer, Albrecht, \& Suchodoletz, 2002). Larger effect sizes were obtained in some studies (two out of seven studies: Korpilahti \& Lang, 1994; Stoodley, Hill, Stein, \& Bishop, 2006). Examples for stimuli are duration deviants or different frequency pattern changes that differ in temporal characteristics. Taken together, for studies using non- speech stimuli, there are few studies (4) with the effect sizes in which the confidence intervals do not include zero.

Korpilahti and Lang (1994) observed effect sizes (Cohen's d $~ 0.7$ vs. 0.9) for the duration deviants 50 vs. $500 \mathrm{~ms}$ compared to 50 vs. $110 \mathrm{~ms}$ (the duration deviant varied from 50-300 $\mathrm{ms}$ ). Both effect sizes were different from zero. Another study (Stoodley, Hill, Stein, \& Bishop, 2006) used pure tones as the standard stimuli and modulated tones as the deviant. Stoodley et al. (2006) found only large to very large effects sizes around d $\sim 1$ with the $20 \mathrm{~Hz}$-modulated deviants in an early (150-300 ms) and late time window (300-500 ms) and had confidence intervals which did not include zero. Studies with non-speech auditory stimuli also do not display a coherent picture. The review displays mixed results for the possibility of the MMN being a suitable candidate for a biological marker for reading problems for non-speech auditory stimuli.

\subsection{MMN to Frequency Deviants}

The previous studies used tone stimuli where standards and deviants differ in frequency. Here, stronger differences between the normal and clinical group were observed in the reviewed studies. Small effect sizes were found by Schulte-Körne, Deimel, Bartling, and Remschmidt (1999), Schulte-Körne, Deimel, Bartling, and Remschmidt (2001) and Uwer et al. (2002), while medium effect sizes were presented by Heim et al. (2000), Lachmann, Berti, Kujala, and Schröger (2005) and Sharma et al., 2006. Compared to the other kind of stimuli, there was quite a large portion of the studies that had very strong effect sizes that range from approx.1.5 up to 2 (Korpilahti \& Lang, 1994; Holopainen et al. 1997, 1998; Baldeweg et al., 1999). 
Table 1: Overview of effect sizes and studies in Bishop's review (2007).

Studies with Frequency Stimuli

Calculated Effect Size (Cohen's d)

- Schulte-Körne et al. (1999)

Small $(\sim 0.1-0.5)$

- Schulte-Körne et al. (2001)

- Uwer et al. (2002)

- Heim et al. (2000)

Medium ( 0.6)

- Lachmann et al. (2005)

- Sharma et al. (2006)

- Korpilahti and Lang (1994)

Large $(\sim 1.5-2)$

- Holopainen, Korpilahti, Juottonen, Lang, and Sillanpää (1997)

- Holopainen, Korpilahti, Juottonen, Lang, \& Sillanpää, 1998

- Baldeweg, Richardson, Watkins, Foale, and Gruzelier (1999)

When reviewing the studies with different stimuli, only research with frequency deviants show explicitly lower amplitudes for dyslexia, the other mentioned stimuli (speech stimuli, nonspeech auditory stimuli) do not demonstrate such results in a convincing way.

\subsubsection{The MMN for early dyslexia identification}

In developmental impairments like dyslexia, it would be helpful if the disorder is identified before any major developmental delays appear and interventions could be introduced. Additionally, interventions would then be more effective because the plasticity of the brain is higher in such early developmental stages (Paterson, Heim, Friedman, Choudhury, \& Benasich, 2006). It is well known that there is a strong genetic component in the case of dyslexia (Hallgren, 1950; Rutter, Tizard, and Whitmore, 1970; Bishop \& Snowling, 2004; Liu, Wu, Zhou, \& Gong, 2019). It is important to develop early indices of the disorder in infants with relatives that are at risk. In the Jyväskylä longitudinal study on dyslexia (Finland) the perceptual dysfunctions of infants with a genetically elevated risk for dyslexia were evaluated and it follows up the development of these infants. Results of Leppänen, Pihko, Eklund, and Lyytinen (1999) showed that the central auditory processing in infants with genetic risk differed from that in control children. The authors used a pseudo-word /ata/ as standard stimulus. 
Additionally, two deviant stimuli (/atta/), one having a small and the other a larger increment in the duration of the stop consonant - the silent gap corresponding to the occlusion stage of the stop consonant - were presented. The duration changes are phonetically relevant in the Finnish language because they can alter the meaning of a word. Leppänen and colleagues (1999) found several differences in the electrophysiological responses of the two groups as newborn babies. The duration changes elicited MMN-type responses which differed both in amplitude and scalp distribution between the at-risk and control children. The small duration difference between the deviant and the standard stimulus elicited an MMN in the control children, but not in the at-risk children, whereas the larger duration difference elicited an MMN in both groups. Nevertheless, the MMN was smaller in the at-risk compared to the control group over the left hemisphere, whereas no group differences were found over the right hemisphere. This suggests a decreased discrimination accuracy of the duration of speech stimuli in the at-risk infants. Furthermore, the results show a dysfunction of the left hemisphere in the at-risk children which is consistent with several previous studies indicating functional and structural abnormalities in the left hemisphere in dyslexia (Raschle, Zuk, \& Gaab, 2012). Additionally, a significant correlation between the behavioral measures and the MMN was found. A comparison of the MMN laterality and the infants' head-turning responses to duration deviants indicated that a stronger left-hemisphere dominance correlated with better behavioral discrimination of the deviant stimuli (more head turns in response to the occurrence of the deviant). These results suggest that with the MMN, dysfunctions of the phonological and auditory processing in dyslexia can be determined in infants even if they are only six months of age.

Taken together the review of Bishop (2007) displays an ambiguous research situation (until 2007) for the MMN in relation to language impairment. Effect sizes are varying strongly or are non-existent. Besides the missing effect sizes, the review encountered some problems: The age of the participants ranges from five years until in adult age and also the sample sizes varied a lot in the review. Additionally, other characteristics like stimulus construction and presentation are quite different across the studies. The mother tongues of the participants differ a lot. They include English, Finnish, German, Mandarin and Norwegian which all have different characteristics. The following section presents some studies that were published after 2007.

\subsubsection{MMN to speech stimuli}

A very (developmentally) early $\mathrm{MMN}$ is called the mismatch response (MMR) which is frontally positive in young children but in adults it is frontally negative and called the MMN. In 17 month old infants, van Zuijen et al. (2012) found that the MMR correlates with language 
comprehension and with word and pseudo-word reading fluency in second grade. The authors interpreted this result as a better temporal auditory processing and as a precursor of language comprehension. They also found a correlation between preliterate expressive language abilities and reading fluency. This is in line with the results of Lovio, Näätänen, and Kujala (2010). The authors found a reduced MMN in children with a risk for dyslexia through having at least one dyslexic parent. The reduced MMN was found in the conditions vowel, vowel-duration, consonant, and intensity changes. In another study, Neuhoff et al. (2012) found three separate MMN components to speech stimuli. The late MMN was diminished in children with dyslexia and their unaffected siblings compared to the control group, while the other two components did not show any group differences.

\subsubsection{MMN to Frequency Deviants}

For frequency stimuli, Rinker et al. (2007) found, beside reversed activity in the hemispheres, an absent MMN2 in the second recorded time window. Children with SLI seem to have a deficit in frequency discrimination. The authors reported that this is especially the case for tones below $750 \mathrm{~Hz}$ and for a frequency difference of $50 \mathrm{~Hz}$. Similar results were found by Ahmmed, Clarke, and Adams (2008) who examined both individual and grand averaged amplitudes of the MMN. The results show that in terms of grand average, the control group can distinguish deviant tones that only differ from the standard tone by between $2 \%$ and $5 \%$ in order to generate an MMN response while children with SLI have smaller MMN with the same deviant tone separation. The results suggest that children with SLI need a frequency separation of at least $10 \%$ in order to generate an MMN that is similar to the control group. It might be that children with SLI have a deficit in the mechanism of generating a similar MMN. The authors identified two SLI subgroups with a high and low score in the Auditory Fusion Test-Revised (high score=HAG, low score $=\mathrm{LAG})$. The authors examined the grand average $\mathrm{MMN}$ for $5 \%$ and $10 \%$ contrasts for the subgroups and found that a significant difference for the HAG group while there was no MMN present in the 5\% contrast for this group. There was no grand average MMN for all kinds of contrast deviants for the LAG subgroup which leads to the conclusion that these groups have poor neural responses generating only a small MMN. Again (like in the frequency studies before 2007) the MMN to frequency deviants show that the MMN is a rather good marker for reading difficulties. 
Table 2: Overview over some recent studies (2007-2015) that examine the MMN in regards to reading or language problems. Note: F=frequency; $\mathrm{T}=$ temporal (non-speech); $\mathrm{S}=$ speech, *at least 1 dyslexic parent.

\begin{tabular}{|c|c|c|c|c|c|c|c|c|c|}
\hline ID & Citation & $\begin{array}{l}\text { Clinical } \\
\text { group }\end{array}$ & Age & Language & Clinical & Control & $\begin{array}{l}\text { Deviant } \\
\text { epochs }\end{array}$ & Stimuli & Results \\
\hline 1 & $\begin{array}{l}\text { Tuomainen } \\
\text { et a.1 } 2015\end{array}$ & $\begin{array}{l}\text { Dyslexic } \\
\& \\
\text { SLI }\end{array}$ & $14-25$ & English & $\begin{array}{l}11 \text { dys. } \\
\& \\
11 \text { SLI }\end{array}$ & 12 & not reported & $\mathrm{S}, \mathrm{T}$ & $\begin{array}{l}\text { - SLI needed more repetitions than the dysl.\& control in } \\
\text { order to show an MMN }\end{array}$ \\
\hline 2 & $\begin{array}{l}\text { Neuhoff et } \\
\text { al. } 2012\end{array}$ & $\begin{array}{l}\text { Dyslexic } \\
\& \\
\text { unaffected } \\
\text { siblings }\end{array}$ & $\begin{array}{l}10-15 \\
\text { years }\end{array}$ & German & $\begin{array}{l}105 \text { dys. } \\
\& \\
105 \text { sibl. }\end{array}$ & 15 & $15 \%$ & $\mathrm{~S}$ & $\begin{array}{l}\text { - first two MMN components did not differentiate the } \\
\text { groups } \\
\text { - late MMN component }(300-700 \mathrm{~ms}) \text { revealed } \\
\text { significant group differences } \\
\text { - mean area of the late MMN was attenuated in dysl. and } \\
\text { their unaffected siblings compared to control children }\end{array}$ \\
\hline 3 & $\begin{array}{l}\text { Zuijen et } \\
\text { al. } 2012\end{array}$ & $\begin{array}{l}\text { At risk of } \\
\text { dyslexia * }\end{array}$ & $\begin{array}{l}17 \\
\text { month }\end{array}$ & Dutch & 12 & 12 & $17 \%$ & $\mathrm{~T}$ & $\begin{array}{l}\text { - control children could detect the temporal change as } \\
\text { indicated by a mismatch response (MMR) } \\
\text { - MMR was not observed in at-risk children } \\
\text { - fronto-central MMR amplitude correlated with } \\
\text { preliterate language comprehension and later word } \\
\text { reading fluency } \\
\text { o not with phonological awareness }\end{array}$ \\
\hline
\end{tabular}

Table continued on next page 


\begin{tabular}{|c|c|c|c|c|c|c|c|c|c|}
\hline ID & Citation & $\begin{array}{l}\text { Clinical } \\
\text { group }\end{array}$ & Age & Language & Clinical & Control & $\begin{array}{l}\text { Deviant } \\
\text { epochs }\end{array}$ & Stimuli & Results \\
\hline 4 & $\begin{array}{l}\text { Lovio et al. } \\
2010\end{array}$ & $\begin{array}{l}\text { At risk of } \\
\text { dyslexia* }\end{array}$ & $6-7$ & Finnish & 10 & 9 & $\begin{array}{l}10 \% \text {, but } 2 \\
\text { deviants } \\
\text { were } \\
\text { alternating }\end{array}$ & $\mathrm{S}$ & $\begin{array}{l}\text { - amplitudes of MMN were smaller for the vowel, vowel- } \\
\text { duration, consonant, and intensity deviants in children } \\
\text { at risk for dyslexia }\end{array}$ \\
\hline 5 & $\begin{array}{l}\text { Rinker et } \\
\text { al. } 2007\end{array}$ & SLI & $7-11$ & German & 13 & 13 & not reported & $\mathrm{T}$ & $\begin{array}{l}\text { - Reversed hemispheric activity in SLI } \\
\text { - In } 2^{\text {nd }} \text { time window MMN2 was absent for the children } \\
\text { with SLI }\end{array}$ \\
\hline 6 & $\begin{array}{l}\text { Ahmmed } \\
\text { et al. } 2008\end{array}$ & SLI & $7-11$ & English & 19 & 19 & $\begin{array}{l}15 \% \text {, but } 3 \\
\text { deviant } \\
\text { frequencies }\end{array}$ & $\mathrm{T}$ & $\begin{array}{l}\text { - SLI who had poor temporal processing abilities } \\
\text { generated a positive mismatch response ( } 2 \% \text { ISIs } \\
\text { difference) } \\
\text { - good temporal processing abilities generated only P- } \\
\text { MMR in response to contrasts up to } 10 \% \text { ISIs }\end{array}$ \\
\hline 7 & $\begin{array}{l}\text { Schaadt et } \\
\text { al } 2019\end{array}$ & Dyslexic & $\begin{array}{l}\text { Mean } \\
\text { age } 9\end{array}$ & German & 16 & 19 & $\begin{array}{l}\text { Uni-modal } \\
\text { vs. } \\
\text { Bimodal } \\
\text { speech }\end{array}$ & $\mathrm{S}$ & $\begin{array}{l}\text { - reduced MMR with later onset to visual-auditory speech } \\
\text { information in children with spelling problems } \\
\text { compared to children without spelling problems } \\
\text { - comparing bimodal and monomodal speech perception: } \\
\text { children without spelling problems showed significantly } \\
\text { larger responses in the visual-auditory experiment } \\
\text { compared to the visual-only response, whereas children } \\
\text { with spelling problems did not. }\end{array}$ \\
\hline
\end{tabular}


Taken together, the MMN of the event-related brain potential seems to be a good predictor of reading difficulties. However, it seems not to be reading specific, i.e. the MMN is also compromised in SLI and in auditory processing deficits that do not lead to reading problems. Thus, it might be useful to look for a more specific biological index of reading expertise.

\subsection{The P200 Component}

\subsubsection{What does the $\mathbf{P 2 0 0}$ reflect?}

Shaul (2008) describes the possible relationship between the auditory P200 component and dyslexia. The auditory P200 has a fronto-central scalp distribution that peaks at the vertex (Hyde, 1997; for a review; Oades, Dittmann-Balcar, \& Zerbin, 1997). Other studies used pure tones and found that the P200 amplitude has strong parietal distributions. Contrarily, standard stimuli show maximum amplitudes at parieto-central sites (Dunn, Gomes, \& Sebastian, 1996). Other authors (e.g. Oades et al., 1997) found that auditory P200 maxima are rather posterior in children, but are more centrally localized in adults when they were presented a three-tone auditory oddball task. This suggests that the P200 shifts anteriorly to the vertex with increasing age. The same authors also found that amplitudes increased with age, and that the component latencies decrease at lateral sites with increasing age. In contrast, other authors found different maturing of the P200 component: Martin and Lovegrove (1988) found that the N100-P200 increased up to the age of 14 years, but Johnson (1989) found no such change. Licht, Bakker, Kok, and Bouma (1992) found a decreasing P240 from grade one to three. Oades et al. (1997) assumed that these inconsistent results might show that P200 measures are unreliable for reflecting developmental changes.

The visual P200 has been studied less well. Nevertheless, visual potentials in non-linguistics tasks in children have been conducted by Hennighausen, Remschmidt, and Warnke (1994). The authors used pattern reversals and found that the P200 appeared earliest at the occipital sites (75-225 ms) and then moved towards the central and frontal sites (170-265 ms).

Using word-stimuli, Hagoort and Kutas (1995) found that the P200 component appears in response to both visually and aurally presented words at around 180-250 ms. Visually, the P200 can be observed across the head, but is larger over the fronto-central sites. The P200 is larger when it is presented visually compared to an aural presentation (Hagoort \& Kutas, 1995, 2000). 
Studies suggest that the P200 is not just an exogenous component, but might also relate to endogenous or cognitive processing (Dunn, Dunn, Languis, \& Andrews, 1998; McDonough, Warren, \& Don, 1992). The P200 is also thought to be an index of feature detection (Luck \& Hillyard, 1994), selective attention (e.g. Hackley, Woldorff, \& Hillyard, 1990; Schulte-Körne,

Bartling, Deimel, \& Remschmidt, 2004b), and other early sensory stages of item encoding (Dunn et al., 1998). Other research shows that a P200-like component is thought to be linked with short-term memory storage (e.g. Chapman, McCrary, \& Chapman, 1978), retrieval (Chapman et al., 1978; Friedman, Vaughan, \& Erlenmeyer-Kimling, 1981; Taylor, Smith, \& Iron, 1990) and working memory functions (Raney, 1993; Smith, 1993; Stelmack, Saxe, NoldyCullum, Campbell, \& Armitage, 1988). There has been the idea among researchers that the anterior and posterior P200 components represent different aspects of stimulus feature detection and encoding. Some research assumes that P200s might be differentiated on the bases of their source location. Dunn et al. (1998) suggested that frontal P200 components may represent partial or complete word retrieval from long-term memory into working memory.

In language research, a study by Dambacher, Kliegl, Hofmann, and Jacobs (2006) investigated the effects of frequency, predictability and position of words in word-by-word sentencereading. They found that the P200 component was larger for words at the beginning and end of a sentence compared to words that were in the middle of a sentence, which shows that those words are accessed quickly and independent of the context information.

\subsubsection{Why is this component a possible biological marker for reading problems?}

\subsubsection{P200 and dyslexia}

Shaul (2008) states that only a handful of studies have been published on the P200 component in regard to dyslexics, but the available data shows that probably a similar pattern may characterize young and adult dyslexics at the linguistic level in visually presented stimuli. Harter, Diering, and Wood (1988) found smaller P200 amplitudes in the left hemisphere compared to the right hemisphere in dyslexic children during a letter recognition task using an intra-location selective attention paradigm. Naylor, Wood, and Harter (1995) report similar results for adult readers. The authors found evidence for a smaller P200 in the left hemisphere in dyslexic adults who used the same task. Participants showed a general reduction in the positivity beginning at around $150 \mathrm{~ms}$ until $500 \mathrm{~ms}$. Nevertheless, adult dyslexics seem to have a more diffuse, bilateral reduction of ERP responses. Schulte-Körne et al. (2004b) did not find any differences in the P200 amplitude and latency in dyslexic children while another study 
(Taroyan, 2015) found longer latencies for dyslexics. In another study by Schulte-Körne, Bartling, Deimel, and Remschmidt (2004a) the researchers investigated in-motion-onset visual evoked potentials (i.e. P100, P200) in order to examine the magnocellular deficit theory and found reduced amplitudes for the P100 and the P200 in dyslexic children. Furthermore, they found that the group difference for the P200 becomes larger if the stimuli moved faster. Meng, Tian, Jian, and Zhou (2007) found no differences between normally reading and dyslexic Chinese children in homophonic, orthographic and baseline conditions (for Chinese characters).

One disadvantage of the P200 is that it has a similar pattern for children and adults as well. This is not very suitable for looking at the development of the component. Furthermore, consistent relationships between reading ability and P200 amplitude or latency have not been found in the very few studies that investigated this issue. Thus, it remains unclear whether the P200 component might be useful as a biomarker of reading ability. Only few recent studies investigated the relationships between the P200 and language disorders.

\subsection{The N200 Component - Two Kinds}

\subsubsection{What does the $\mathrm{N} 200$ reflect?}

\subsubsection{Attention-sensitive N200}

The N200 is a negative component peaking at around 200-350 ms and usually appears at frontocentral sites (Oades et al., 1997). Research on the visual N200 in children that used pattern reversal stimuli in which the participants were required to fixate but not to respond, has shown that this component is occipitally distributed at $190-440 \mathrm{~ms}$, the central sites at $215-260 \mathrm{~ms}$, and the frontal sites at about 205-390 ms (Hennighausen et al., 1994). Research on the auditory modality suggests that this component peaks fronto-centrally at the Fz electrode when using a two-tone oddball paradigm (Enoki, Sanada, Yoshinaga, Oka, \& Ohtahara, 1993; Johnstone, Barry, Anderson, \& Coyle, 1996a). When the auditory N200 was elicited by a three-tone task the researchers found that N200 amplitudes and latencies tend to decrease with age and show a right bias from about 14 years of age. In this age range, a larger midline activation to common versus rare tones also develops. Frontal maxima appear for non-target processing at all ages, but only become apparent for target processing around age 17. Oades et al. (1997) found that N200 latencies are longer at frontal compared to posterior electrode sites. The N200 is usually considered to reflect processing that is associated with focused attention, stimulus classification and discrimination (Näätänen \& Picton, 1987; Ritter, Simson, Vaughan, \& Macht, 1982; 
Vaughan Jr \& Kurtzberg, 1992) and it might also be evoked in unattended situations (Picton, 1995).

Studies showed that the N200 amplitude increases with task difficulty and in response to deviant stimuli. Latency seem to be shorter during focused attention compared to diffuse attention and latencies are shorter after deviant compared to standard stimuli (Oades et al., 1997; Oades, Zerbin, \& Dittmann-Balcar, 1995). Other research shows that the N200 component is the first index of target detection (Potts, Hirayasu, O'Donnell, Shenton, \& McCarley, 1998). Studies that used word paradigms showed that the N200 may be elicited by physically unexpected stimuli (for discussion, see Deacon, Breton, Ritter, \& Vaughan, 1991; Herning, Speer, \& Jones, 1987; Polich, 1985).

Researchers assume that the N200 is associated with "mismatch detection", which is typically sensory (see Niznikiewicz \& Squires, 1996; for a review). This view is supported by research showing that the N200 is related to the degree of mismatch between a stimulus template of a neuronal model (Näätänen \& Picton, 1986; Ritter et al., 1982). Further research on visual spatial attention and letter target detection shows that the N200 may reflect an early, partly automatic process of template matching (Wijers, Lange, Mulder \& Mulder 1997).

\subsubsection{Is the $\mathrm{N200}$ a possible marker for reading problems?}

The following section reviews some results that show the connection between the N200 and reading or language related problems.

\subsubsection{N200 and dyslexia}

There are only a few reports about the N200 in dyslexic readers. Those studies usually find that N200 latencies occur later in dyslexic readers compared to typical readers, but there were no amplitude differences detected. This applied to visual and auditory tasks. In the auditory modality Fawcett, Chattopadhyay, Kandler, Jarrat, Nicolson, and Proctor (1993b) found evidence of longer N200 latencies in dyslexic children in response to tones in an oddball paradigm. The majority of studies used visual stimuli, such as Taylor and Keenan (1990) who found a later N200 in dyslexics with visual processing impairment in response to linguistic (letters, words and non-words) and nonlinguistic stimuli (symbols). Neville, Coffey, Holcomb, and Tallal (1993) used a visual recognition paradigm and found attenuated N200 latencies in dyslexics. In another study (Taylor \& Keenan, 1999), three visual target tasks were presented to dyslexic children who had an auditory processing deficit and to typically reading children. The detection tasks included an orthographic task where targets were letters with closed loops, 
a phonological task in which targets were letters that rhymed with $\mathrm{v}$, and semantic tasks where 3-letter animal names were presented. The authors found longer latencies in the semantic task in dyslexic children compared to typically reading children. Bergmann, Hutzler, Klimesch, and Wimmer (2005) found no latency changes in several ERPs, except a small one for the N200 in dyslexic readers (13 ms). Instead of finding a reduced N220 they found an enhanced component for words (and a tendency for letter strings) right after a reduced contingent negative variation $(\mathrm{CNV})$. The authors interpret this pattern as a slow response of brain regions (left posterior areas) that are involved in a compensatory visual letter string processing.

\subsubsection{The Magnocellular Theory and the $\mathbf{N 2 0 0}$}

The magnocellular theory proposes that the magnocellular dysfunction is not only restricted to the visual pathways but also includes auditory and tactile modalities (for an overview see review by Stein , 2018). Some studies found evidence for the magnocellular theory and dyslexia (see review by Stein, 2018) some did not. One study that found evidence for the magnocellulardorsal pathway deficit in dyslexia was the study by Jednorog, Marchewka, Tacikowski, Heim, \& Grabowska (2011). They investigated whether coherent vs. incoherent motion modulates the amplitude of N200 in a similar way in dyslexic and in control children. They found higher N200 amplitudes for coherent compared to random motion in the right hemisphere for controls but not for dyslexics. To summarize, it is possible to show a magnocellular deficit with the corresponding paradigm, but the evidence is mixed.

\subsubsection{Language - Related N200 (or ELAN- Early Left Anterior Negativity)}

In several studies, it has been found that phrase-structure violations trigger early negative deflections of the brain waves in the left frontal region. Both groups of participants showed this effect between 200-400 ms post critical word onset. No major differences in the distribution of the ELAN between the two groups were detected, but the ELAN peaked significantly earlier in the dyslexic group. The ELAN has been assumed to reflect a highly automatized processing phase of syntactic parsing (Hahne \& Friederici, 1999). The results of the present study indicate that dyslexic individuals also make use of this very early mechanism and that they detect these violations even faster than the controls (Rispens, 2004). 


\subsection{The P300 component}

\subsubsection{What does the $\mathbf{P 3 0 0}$ reflect?}

The P300 is a positive-going ERP-component that peaks around 280-600 ms after stimulus presentation. It is distributed centro-parietally and appears in tasks that require active discrimination (i.e. oddball paradigms) (Dunn et al., 1998; Wilson, Swain, \& Ullsperger, 1998). In passive procedures, such as tasks that do not require an intentional discrimination response, P300-like waveforms seem to have a frontal-central scalp distribution, and can occur much earlier or later than $300 \mathrm{~ms}$, and typically habituate over relatively few trials (Polich, 1989; Polich \& Heine, 1996). Some research shows that the distribution of the P300 tends to be more symmetrical with increasing age, as evidenced by a significant increase in the ratio of the P300 at $\mathrm{Fz}$ to $\mathrm{Pz}$ (e.g., Johnstone, Barry, Anderson, \& Coyle, 1996b). This is the case for auditory (Friedman \& Simpson, 1994; Iragui, Kutas, MItchiner \& Hillyard, 1993; Johnstone et al., 1996b) and visual (Molenaar, Wijker, \& Molen, 1989) tasks. Even though the auditory and the visual P300 component show similar, but not identical, scalp distributions, the P300 seems to be smaller and shorter in latency in auditory responses compared to the visual P300 (Polich $\&$ Heine, 1996). Other studies found that language stimuli elicit a larger P300 over the left hemisphere (McCarthy \& Nobre, 1993; Nobre \& McCarthy, 1995). The P300 is adjusted as a function of psychological parameters that reflect information processing of stimuli (Erez \& Pratt, 1992). Therefore, authors suggest that the P300 is an index of central information processing during task-related decision making (Palmer, Nasman, \& Wilson, 1994). Different processes that are associated with the $\mathrm{P} 300$ are the dynamic updating of information in working memory (Donchin \& Isreal, 1980; Fitzgerald \& Picton, 1983), cognitive resource allocation and task involvement (Kramer, Strayer, \& Buckley, 1991), and mental effort, or workload (Humphrey \& Kramer, 1994; Wilson et al., 1998). The P300 latency is assumed to represent higher-order cognitive processes such as stimulus evaluation and categorization (Polich, 1987; Polich \& Heine, 1996). It has been assumed that the P300 latency is a temporal measure of neural activity underlying the speed of attentional allocation and immediate memory operations (Cohen \& Polich, 1997; Polich \& Heine, 1996). The amplitude of the P300 is thought to be related to task relevance (Hillyard \& Picton, 1987), and probability, or expectancy (Comerchero \& Polich, 1999; Duncan-Johnson \& Donchin, 1982; Gehring, Gratton, Coles, \& Donchin, 1992; Johnson, 1988) of the eliciting stimulus. Another feature of the P300 is the sensitivity to task/decision difficulty (Palmer et al., 1994). As an example: P300 amplitudes are larger and latencies are longer during oddball as opposed to single-stimulus recognition (Polich \& Heine, 1996). The P300 seems to be inversely related to decision confidence (Hillyard, Squires, Bauer, 
\& Lindsay, 1971; Ruchkin, Sutton, \& Stega, 1980), decision difficulty and stimulus discriminability (Johnson, 1986).

When using word stimuli, it was found that word type might affect the P300. Nobre and McCarthy (1995) found that, compared to other word types, exemplars elicited a larger P300 with a maximal amplitude over parietal sites. The amplitude and distribution were not different in other word types. It was also found that the P300 amplitude is larger for non-rhyming than rhyming stimuli (Ackerman, Dykman, \& Oglesby, 1994; Bonte \& Blomert, 2004; Molfese, Fletcher, \& Denton, 2013).

Some researchers differentiated between $\mathrm{P} 300 \mathrm{a}$ and $\mathrm{P} 300 \mathrm{~b}$ components. These two components are thought to differ in brain sources and physiological correlates (Cycowicz, Friedman, \& Rothstein, 1996). Usually, auditory or visual P300b have a central/ parietal distribution with a latency of about 280-350 ms. P300a components typically have a fronto-central distribution and have a relatively short peak latency and habituate quickly (Comerchero \& Polich, 1999; Dunn et al., 1998; Knight, 1996; Squires, Squires, \& Hillyard, 1975). Both modalities elicit a frontal-central maximum P300 (or P300a) when novel stimuli appear, while frequent non-target stimuli elicit a central-parietal P300 (or P300b) (Comerchero \& Polich, 1999; Verbaten, Huyben, \& Kemner, 1997). In typical participants, the P300a is elicited primarily by novel stimuli which suggests that it might be associated with passive shifts of attention, or the orienting response (Comerchero \& Polich, 1999; Cycowicz et al., 1996; Halgren \& Marinkovic, 1995; Halgren, Marinkovic, \& Chauvel, 1998). Further research underlines the view that the P300a may be more closely related to attentional processes and the P300b with categorization (Comerchero \& Polich, 1999). The same authors showed that the ease of perceptual discrimination influences the P300a and P300b. The participants had to respond to a target with a button press in three-stimulus auditory and visual paradigms. The target stimulus was frequently occurring, and the non-target stimulus was infrequently occurring. Auditory stimuli were tones, and the visual stimuli were solid blue shapes. The results show that however difficult the discrimination was, the target stimulus in both modalities elicited a P300 that peaked over parietal sites. When the perceptual discrimination between the target and nontarget was difficult (i.e. the target was very similar to the standard), the P300b amplitude attenuated and latency lengthened in response to target stimuli. The non-target stimuli in difficult discrimination conditions in both modalities elicited a P300 that was largest over the frontal sites and whose latency was much shorter than the latency for targets. For this reason, the P300 elicited by infrequent occurring non-targets in both modalities was very similar to the 
P300a found in "novel" stimulus paradigms. The authors assume that these results can show that frontal lobe functions - such as attentional focus - are related with the P300a.

\subsubsection{Is the $\mathbf{P} 300$ a possible marker for reading problems?}

\subsubsection{The P300 component and dyslexia}

Many researchers found that the P300 has smaller amplitudes and longer latencies in response to both linguistic and nonlinguistic auditory and visual stimuli in dyslexics (Barnea, Lamm, Epstein, \& Pratt, 1994; Duncan et al., 1994; Erez \& Pratt, 1992; Fawcett et al., 1993; Harter, Anllo-Vento, Wood, \& Schroeder, 1988; Harter, Diering et al., 1988; Holcomb, Ackerman, \& Dykman, 1985, 1986; Johannes, Mangun, \& Münte, 1994a; Taylor \& Keenan, 1990, 1990, 1999). In a more recent study using an auditory oddball paradigm with a dyslexic group of children, Papagiannopoulou and Lagopoulos (2017) observed that the amplitude of the P300 in central regions was reduced and the latency was delayed over all brain regions, but most pronounced frontally. This effect was found even though the performance in reaction times was comparable.

In the auditory modality, some researchers found smaller, but longer P300 components in dyslexic children while using simple auditory stimuli (Holcomb et al., 1986; Lovrich \& Stamm, 1983). Other authors found a reversed pattern (Fawcett, Chattopadhyay, Kandler, Jarrat, Nicolson, \& Proctor, 1993a). The authors observed longer P300 latencies but no differences in P300 amplitudes to target tones among dyslexic adolescents performing a selective choice reaction oddball task.

Similar results have been found in the visual domain. Neville et al. (1993) found that language impaired, reading disabled children had smaller P300 amplitudes compared to typically reading children when visual stimuli in target detection tasks were presented to them. Duncan et al. (1994) observed attenuations in visual P300s in dyslexics compared to typically reading men with increasing task demands, but further analysis showed that group differences were accounted for by dyslexic readers with several symptoms of ADHD in their childhood. Other authors reported differences in P300 latencies such as Johannes, Mangun, and Münte (1994b), who examined visual P300s in dyslexics and typically reading children using a simple visual discrimination task. The authors found that while the P300 amplitude did not differ in the two groups, the P300 latencies were longer in dyslexics. Additionally, the component was distributed almost symmetrically over the two hemispheres in dyslexic readers, but was displayed predominantly in the left hemisphere in typical readers. 
Taylor and Keenan (1990) obtained the finding that dyslexics with a visual processing deficit show longer latencies of the P300 components in phonological and semantic tasks, but not in orthographic tasks. Rüsseler, Johannes, Kowalczuk, Wieringa, and Münte (2003) found, contrary to other evidence, that the latency of the P300 was not prolonged. These results can be explained as follows: Rüsseler et al. (2003) investigated a group of high functional dyslexics with a minimum IQ of 110. The researchers acquired this sample in order to exclude comorbidities and isolate the cognitive core of dyslexia. The results can be explained by those deviations. Additionally, the P300 was rather posteriorly distributed in dyslexic readers. The research group even found an enhancement of P300 amplitude with a frontal distribution for standard stimuli for the dyslexic sample. An enlargement of a P300a amplitude was found in another study by Rüsseler, Kowalczuk, Johannes, Wieringa, and Münte (2002) that investigated the ERPs to novel stimuli in dyslexics compared to the control group.

Current research mainly supports the basic findings: longer P300 latencies and smaller P300 amplitudes for dyslexic compared to normal readers. Such findings have been reported for children (Fawcett et al., 1993; Oliveira, Murphy, \& Schochat, 2013; Ortiz Alonso, Navarro, \& Vila Abad, 1990) as well as for adults (Breznitz \& Leikin, 2000; Shiran \& Breznitz, 2011).

However, P300 amplitude and latency differences are observed in all conditions with impaired information processing. P300 latency prolongation and diminished amplitudes are not specific to reading difficulties. Thus, P300 seems not to be a good candidate for a biomarker of reading problems. 


\subsection{The N400 component}

\subsubsection{What does the $\mathrm{N} 400$ reflect?}

The N400 is a negative-going ERP-component that is typically elicited 300-500 ms post-onset with a slightly right-lateralized centro-parietal maximum. It seems to reflect the extent to which a word is semantically primed. For example, a word that is semantically expected elicits a reduced N400 component (Hillyard \& Kutas, 1983; Kiehl, Laurens, \& Liddle, 2002). The N400 seems to be prone to attention, because there are larger N400 amplitudes in response to attended, but not for unattended words. For attended words, the component appears to be smaller for semantically primed/repeated words (McCarthy \& Nobre, 1993). Contrarily, it does not appear to change in response to the physical characteristics of stimuli (see Nobre \& McCarthy, 1995; for review). The N400 seems to be elicited by all stimuli that have a semantic representation: Pictures (Holcomb \& McPherson, 1994), pseudo-words and pseudo-objects also elicit a N400like component (Bentin, 1987, 1989; Bentin, Allison, Puce, Perez, \& McCarthy, 1996; Holcomb \& McPherson, 1994; Rugg \& Doyle, 1992; van Petten \& Kutas, 1991). Pseudo-words elicit a similar or a larger N400 than the N400 for words. It does not matter if the words are spoken or printed (Bentin, 1987, 1989; Holcomb \& Neville, 1990; Rugg, 1987). Contrarily, phonologically or orthographically illegal non-words do not produce this ERP (Holcomb $\&$ Neville, 1990-for further information see review by Kutas and Federmeier , 2011).

It was found that the N400 is different in word-list tasks compared to sentence tasks. In word tasks, the component has a more anterior distribution, with largest amplitudes over the frontal or central sites (Bentin, 1987; McCarthy \& Nobre, 1993; Boddy, 1986). In sentence tasks, the N400 seems to be highest over centro-parietal regions of the scalp, and a bit larger and prolonged over the right as compared to the left hemisphere (Kutas, van Petten, \& Besson, 1988).

\subsubsection{Is the $\mathrm{N} 400$ a possible marker for reading problems?}

\subsubsection{Dyslexia and the $\mathbf{N} 400$ component}

Schulz et al. (2008) conducted a combined study with fMRI and ERP analysis. The participants were children that had to read simple sentences with semantically congruous or incongruous endings. Sometimes the control group and the dyslexic group had to judge those simple sentences. FMRI and ERPs were recorded while they were reading the sentences as well as during the semantic processing task. For sentences, the authors investigated the response to all words in a sentence; and for semantic processing the authors contrasted responses to 
incongruous and congruous sentence endings. The analysis for semantic processing revealed an activation in left-hemispheric regions of frontal and superior temporal cortex and an N400 effect after 240 ms with a stable left anterior source location. Dyslexic children exhibited a decreased activation for sentence reading in inferior parietal and frontal regions, and for semantic processing in inferior parietal regions, and during the N400 effect. The authors suggest that semantic impairment during sentence reading reduces dyslexic children's responses in left anterior brain regions that the N400 is based upon. It also modulates the consistent BOLD response in left inferior parietal regions (Schulz et al., 2008).

The N400 has been found to differ in dyslexics compared to typical readers. Lovrich, Cheng, Velting, and Kazmerski (1997) investigated regular and reading impaired students that had to complete an auditory rhyme decision and a semantic decision task. The authors found a larger negativity at around $480 \mathrm{~ms}$ in the rhyme decision task in impaired readers with a maximum at the $\mathrm{C} 3$ electrode. There were no differences in the semantic decision task in regard to the N400 component. Nevertheless, in within-group analyses, the N400 amplitude was larger for semantic tasks for regular readers only. Lovrich, Cheng, and Velting (1996) reported similar results. Similar results have been found in a study by Ackerman et al. (1994) who tested dyslexic children, slow readers and normally reading children with attention deficit disorder (ADD). Dyslexics showed a diminished N450 peak when they performed a visual rhyme decision task. Reading disabled children did not exhibit the N400 reduction for rhyming stimuli characteristic of regular readers. Another design was tested by McPherson, Ackerman, Oglesby, and Dykman (1996) who divided dyslexic adolescents into two subgroups: phonetic dyslexics (better decoders) and dysphonetics (poorer decoders). In the paradigm the subjects had to decide whether two sequentially presented pictures were objects with names that rhymed. Better decoders showed an N400 priming effect, whereas poorer decoders did not show such an effect. The priming effect was determined on the basis of the mean N450 of the rhyming targets subtracted from the non-rhyming targets. In a similar constructed follow-up study using the same subgroups disabled and regular readers were tested on visual and auditory rhyme decision tasks (McPherson, Ackerman, Holcomb, \& Dykman, 1998). The tasks used single syllable, real words. Miles and Stelmack (1994) conducted a study with learning disabled children (3 subgroups: reading disabled; arithmetic disabled; reading plus arithmetic disabled) and typical children. The reading disabled children exhibited an absence in the usual left hemispheric asymmetry of the frontal N450 amplitude to unprimed spoken words. But it is important to say that this was also true for arithmetic disabled and reading plus arithmetic disabled children. 
Rüsseler, Becker, Johannes, and Münte (2007) conducted a study in a special group of dyslexics: University students who were highly compensated dyslexics by the time they started their way at the university were tested in a visual semantic judgment task (house-window $\rightarrow$ are they semantically related?), a rhyme judgment task (house - mouse $\rightarrow$ do they rhyme?) and a gender judgment task (das Haus-the house- $\rightarrow$ Is the gender correct? (In German the word "the house" is of neutral gender.) The study showed that highly-compensated dyslexic readers do not only have phonological difficulties in written word processing but they also have problems in syntactic/gender and semantic integration processes: the behavioral data showed that normal readers responded faster than dyslexic participants in all three tasks. Additionally, in the rhyme judgment task it was found that all readers (dyslexics and normal) were faster in their responses compared to the other two tasks. In all of the tasks the incongruent words showed more negative-going ERPs of different distributions. The onset latencies of the negative effects were delayed in dyslexics compared to controls in the phonological and the gender judgment task, but not in the semantic judgment task. Between the two groups the peak amplitudes did not differ. The dyslexic groups showed longer-persisting incongruency effects in the phonological judgment and the semantic judgment task. All of the effects (phonological, syntactic/gender, semantical effect) were labeled "N400" even though they might have different distributions or are differently named. The phonological N400 had a delayed onset and persisted longer in adult dyslexics. This shows that even highly compensated adult dyslexics have difficulties with phonological processing of written words. This finding is in line with the finding of a phonological core deficit in developmental dyslexia (Goswami \& Bryant, 1994; Griffiths \& Snowling, 2002; Shaywitz, 1998). The semantic priming effect was normal in adult dyslexic readers and the onset latency was not delayed for dyslexics in the semantic judgment task. Furthermore, the N400 peak amplitude was similar in dyslexic and in normal readers as found in other studies (Bonte \& Blomert, 2004; Rüsseler, Probst, Johannes, \& Münte, 2003; SilvaPereyra et al., 2003). As in the phonological task, the semantic N400 persisted longer in dyslexics. Additionally, they needed longer to perform the semantic judgment task. It might be that dyslexic readers need more time and effort for semantic integration processes.

Regarding syntactic processing (gender task), Rüsseler et al. (2007) observed a delayed onset and a longer persistence of the N400. Additionally, the response times indicated syntactic processing difficulties in dyslexics. Furthermore, the normal readers showed a bilateral distribution of the negativity which Rüsseler et al. take as evidence for a contribution of prosodic right hemisphere processes (Rüsseler et al., 2007). In contrast, there was a strong left lateralization in dyslexic readers, which might be interpreted as reflecting the absence of a contribution of prosodic/phonological processes in the detection of phrase structure violations 
in dyslexics. This suggests an impairment of phonological processing which results in problems of automatic syntactic processing. Meng, Tian, Jian and Zhou (2007) found for Chinese dyslexic children in general no differences between experimental conditions. For the control group, the mean amplitudes were increasingly more negative-going over the baseline condition, orthographic and homophonic conditions (for Chinese characters). . In contrast, Hasko, Groth, Bruder, Bartling, and Schulte-Körne (2014) found that a training program increased the N400 component in dyslexic children. In the study by Jednoróg, Marchewka, Tacikowski, and Grabowska (2010) the amplitude for the N400 amplitude was enlarged in semantically and phonologically incongruent words relative to congruent words in control children. Dyslexic children showed distinguished priming effects depending on whether semantic or phonological primes were used. Semantic priming elicited an N400 effect comparable to controls, though delayed. In phonological priming, the dyslexics differed from controls in both the phonologically incongruent and congruent conditions showing reduced N400 amplitude in the incongruent and enhanced N400 in the congruent condition.

The N400 is impaired in dyslexics when the stimuli are presented visually but not when they are presented in the auditive modality. The N400 is also low in amplitude and later - or totally absent in other language disabilities, such as dementia or aphasic dysfunctions. For this reason, the N400 seems not to be a suited biological marker for reading problems. It rather reflects impairments of semantic integration which is delayed, but mostly intact in dyslexics. 


\subsection{The N450 component}

\subsubsection{A short excursion: A Component that shows Differences between Rhyming and Non-Rhyming Stimuli}

Studies that investigated phonological processing found an ERP component that is sensitive for the processing of phonological information in rhymes (Coch, Mitra, George, \& Berger, 2011). The component appears in a time range from $300 \mathrm{~ms}$ to $550 \mathrm{~ms}$ and peaks at around $400 \mathrm{~ms}$ to 450 ms (Coch, George, \& Berger, 2008; Coch, Hart, \& Mitra, 2008; Rugg, 1984a, 1984b, 1984b).

Non-rhyming stimuli elicited a larger N450 than rhyming stimuli, primarily in the right hemisphere and in the medial posterior part or the brain (Coch, George et al., 2008; Grossi, Coch, Coffey-Corina, Holcomb, \& Neville, 2001; Rugg, 1984a, 1984b; Rugg \& Barrett, 1987). The N450 component is depending on age. In second graders, a N450 rhyme effect is already found in posterior brain regions. This effect was also observed in kindergarteners but it was not as distinct as in $2^{\text {nd }}$ graders. Authors concluded that the N450 effect develops with reading and writing acquisition (Wagensveld, van Alphen, Segers, Hagoort, \& Verhoeven, 2013). The posterior rhyme effect seems to remain stable in the local distribution and onset across different age ranges, which shows that comparable neuronal systems are involved in the processing of phonological material across all age groups (Coch et al., 2011; Grossi et al., 2001).

The N450 component is sensitive to rhyming word pairs, but not for word pairs that have phonological similarities or no phonological similarity (Wagensveld, Segers, van Alphen, Hagoort, \& Verhoeven, 2012). The N450 rhyme effect was also found for single lower-letters or capital-letters (Coch, George et al., 2008; Coch, Hart et al., 2008). Even in beginning readers the rhyme effect appears with the processing of single letters and is comparable to the rhyme effect of adults (Coch et al., 2011). The N450 component is more positive in a one-back-task if the preceding letter rhymes with the following one (i.e. e and b). This is true for implicit as well as for explicit rhyming decisions (Stevens, McIlraith, Rusk, Niermeyer, \& Waller, 2013). 


\section{The Present Studies}

\subsection{Background}

\subsubsection{Habituation of the N170}

Habituation is an attenuation of neural activity and results from repeated stimulus presentation; other names for this phenomenon are repetition suppression, neural priming, decremental responses, mnemonic filtering and adaptation. The habituation effect was found for words, faces (Cao et al., 2013; Cao, Jiang, Li, \& He, 2014; Cao, Ma, \& Qi, 2015) and letters (Korinth, Sommer, \& Breznitz, 2013).

Korinth et al. (2013) found two distinct subcomponents of the N170 and a correlation between reading speed and the extent of habituation. According to Cao et al. (2014) it is possible to find habituation effects for alphabetic and non-alphabetic words. Importantly, he observed that objects of expertise (e.g. words, faces) can produce N170 habituation effects but that does not happen with other objects (e.g., houses). Similar results were found in another study by Cao et al. (2015). The main limitations of previous studies were that the authors used only complex stimuli such as words. In addition, most studies were using English stimuli. English has a very opaque orthography while German is quite transparent. It is important to study other languages in order to replicate findings in those languages.

In contrast to previous studies, the following studies used letters as stimulus material in order to be able to evaluate the stimuli on children. If letters are suitable for children in the second grade, the stimuli also could be used for kindergarten children who have limited knowledge of words, but enough expertise in letter recognition. Three blocks were used in order to investigate the habituation of the N170 over time. The whole experiment was split in three thirds (or blocks: A, B, C) to observe a possible decrease of the signal. In order to determine habituation, the ERPs were visually inspected. The biggest amplitude difference could be found between the first block's mean amplitude (the first third, Block A) and the second block (the second third, Block B). The mean amplitude of Block B was smaller (as a result of habitation), that's why the mean amplitude of Block B was subtracted from the amplitude of Block A. In the end, these differences were correlated with the reading speed of adults and children. 


\subsection{Experiment 1: The Habituation of the N170 in Adults}

\subsubsection{Participants}

Thirty-nine neurologically healthy participants (assessed by questioning and by a standard form, 24 women, 2 bimanual, all others right-handed, age: $M=25.08$ years, $S D=6.4$ years) participated in the study. All were students at the University of Bamberg, native speakers of German or bilingual ( $n=3$; German and another language) and had normal or corrected to normal vision assessed by questioning the participants. Participants were paid $10 €$ per hour or received course credit for their participation if needed. The study protocol was conducted in accordance with the declaration of Helsinki (1964) and approved by the local ethics committee.

\subsubsection{Materials}

\subsection{The Saarbrücker Reading Test (Kerkhoff, Wimbauer, \& Reinhart, 2012)}

The Saarbrücker reading texts consist of six simple texts with 180 words each (Kerkhoff et al., 2012). The participants were instructed to read each text as fast and as accurate as possible aloud to the instructor. The reading time needed for each story and the numbers of mistakes were recorded.

4.2.1.2.2 Salzburger Reading Test, Version A (Hutzler \& Wimmer, personal communication) The Salzburger Reading Test requires the participant to read as many of 77 simple declaration sentences (silently) as possible in three minutes and mark each statement as correct of false. The Salzburger Reading Test is a test of reading comprehension and reading speed.

\subsection{Correlation of the two tests}

The two tests have a correlation of 0.49 (own calculations, 2017). Both Tests seem to measure at least partly different aspects of reading speed. They are especially dissimilar in detecting reading comprehension.

\subsubsection{Procedure and Design}

After the participants gave a written consent, they had to complete an experiment that consisted of five conditions: letters, words, pseudo-words, symbol strings and faces. All stimuli were presented in white on a black background. Stimuli subtended $3 \mathrm{~cm}$ x $5 \mathrm{~cm}$ (words, pseudo-words, symbol strings), $1 \mathrm{~cm} \times 1 \mathrm{~cm}$ (letters) or $7 \mathrm{~cm} \times 5 \mathrm{~cm}$ (faces) and were presented in the center of a computer monitor at a constant viewing distance of $70 \mathrm{~cm}$.

The different conditions consisted of the letters "a" (target) and "c", the words "Preis" (target) and "Spiel", the pseudo-words "'Kleuf" (target) and "Frand", the symbol strings 
$\square \triangle \triangle \square \square$ (target) and $\triangle \square \rho \diamond \bigcirc$, see Table 3. Two color photographs of a face of a female actor with a neutral emotional expression served as face stimuli, but the latter were not evaluated.

In each condition, 240 stimuli were presented (80\% standards, $20 \%$ targets). The ISI varied randomly between $600 \mathrm{~ms}$ and $1200 \mathrm{~ms}$. Each condition was split into three thirds (Block A, B and $\mathrm{C}$ ) in order to observe possible attenuations of the N170 component over time (habituation). The division into three blocks was not apparent for the participants. In each block, 64 standards and 16 targets were presented. Participants were instructed to press a button as fast as possible whenever a target stimulus was presented. The standard stimuli were not linked to a response. The five stimuli-conditions were presented in a randomized order (different for each participant; see Figure 6) .

Fifty percent of the participants had to respond with the right index finger, $50 \%$ used the left index finger. A Cedrus RB 830 response box (www.cedrus.com) was used to collect behavioral data. Presentation 17.0 software (neurobs.com) was used to deliver the stimuli and for recording the participants' responses. The whole session took 32 minutes. 


\begin{tabular}{|c|c|c|c|}
\hline & & $1^{\text {st }}$ Third (Block A) & \\
\hline+ & & Stimuli no. & $64 \times$ Standards \\
\hline & & & $16 \times$ Deviants \\
\hline & Standard/Deviant & ISI & 700-1200 ms (MW $950 \mathrm{~ms}$ ) (by chance) \\
\hline & & Condition pres. & $700 \mathrm{~ms}$ \\
\hline & & Maximum response & Dependent on ISI Interval: $600-1100 \mathrm{~ms}$ \\
\hline & & Total time & $109.8 \mathrm{~s} / 1.83 \mathrm{~min}($ Decimal $)$ \\
\hline & & $2^{\text {nd }}$ Third (Block B) & \\
\hline & & Stimuli no. & 64 Standards \\
\hline & & & 16 Deviants \\
\hline & & ISI & 700-1200 ms (MW $950 \mathrm{~ms}$ )(by chance) \\
\hline & Standard/Devian & Condition pres. & $700 \mathrm{~ms}$ \\
\hline & & Maximum response & Dependent on ISI Interval: $600-1100$ \\
\hline & & time & $\mathrm{ms}$ \\
\hline & & Total time & $109.8 \mathrm{~s} / 1.83 \mathrm{~min}($ Decimal $)$ \\
\hline & & $3^{\text {rd }}$ Third (Block C) & \\
\hline & & Stimuli no. & 64 Standards \\
\hline & & & 16 Deviants \\
\hline & & ISI & $700-1200 \mathrm{~ms}(M=950 \mathrm{~ms})($ by chance $)$ \\
\hline & & Condition pres. & $700 \mathrm{~ms}$ \\
\hline & & Maximum response & Dependent on ISI Interval: $600-1100 \mathrm{~ms}$ \\
\hline & & Total time & $109.8 \mathrm{~s} / 1.83 \mathrm{~min}$ (Decimal) \\
\hline Break: max. & inute & & \\
\hline Adults (stud & 8 minutes * & ates & \\
\hline Children (st & 2) 5 minutes & utes & \\
\hline
\end{tabular}

Figure 6: Schematic view of one trial for adults. Children had shorter trials. One trial is programmed in three thirds (Block A, B \& C). The mean amplitudes of those 3 blocks enabled analyzing the habituation. In the following table the standards and the deviants are listed, which were put in for the placeholder that are displayed in the figure as "Standard or Deviant". 
Table 3: Stimuli for adults and children.

\begin{tabular}{|c|c|c|c|c|}
\hline \multirow[t]{2}{*}{ Stimuli } & \multicolumn{2}{|l|}{ Adults } & \multicolumn{2}{|l|}{ Children } \\
\hline & Standard & Deviant & Standard & Deviant \\
\hline Letter & $\mathrm{a}$ & $\mathrm{c}$ & A & $\mathrm{C}$ \\
\hline Words & Preis & Spiel & PREIS & SPIEL \\
\hline Pseudo Word & Frand & Kleuf & FRAND & KLEUF \\
\hline Symbol(s) & $\square \triangle \triangle[$ & $\Delta \square Q$ & & \\
\hline
\end{tabular}




\subsubsection{Data Analysis and EEG Recordings}

ERPs were recorded from 28 electrode sites mounted in an elastic cap (Easycap GmbH, Herrsching, Germany) by means of sintered $\mathrm{Ag} / \mathrm{AgCl}$ electrodes. The following sites were used: FP1, FP2, F7, F3, FZ F4, F8, FC5, FCZ, FC6, T7, C3, CZ, C4, T8, Cp5, CP1, CP2, CP6, P7, P3, PZ, P4, P8, O1, O2, TP9, and TP10. Electrodes were placed according to the standard 1020-system (see Figure 7; Jasper, 1958).

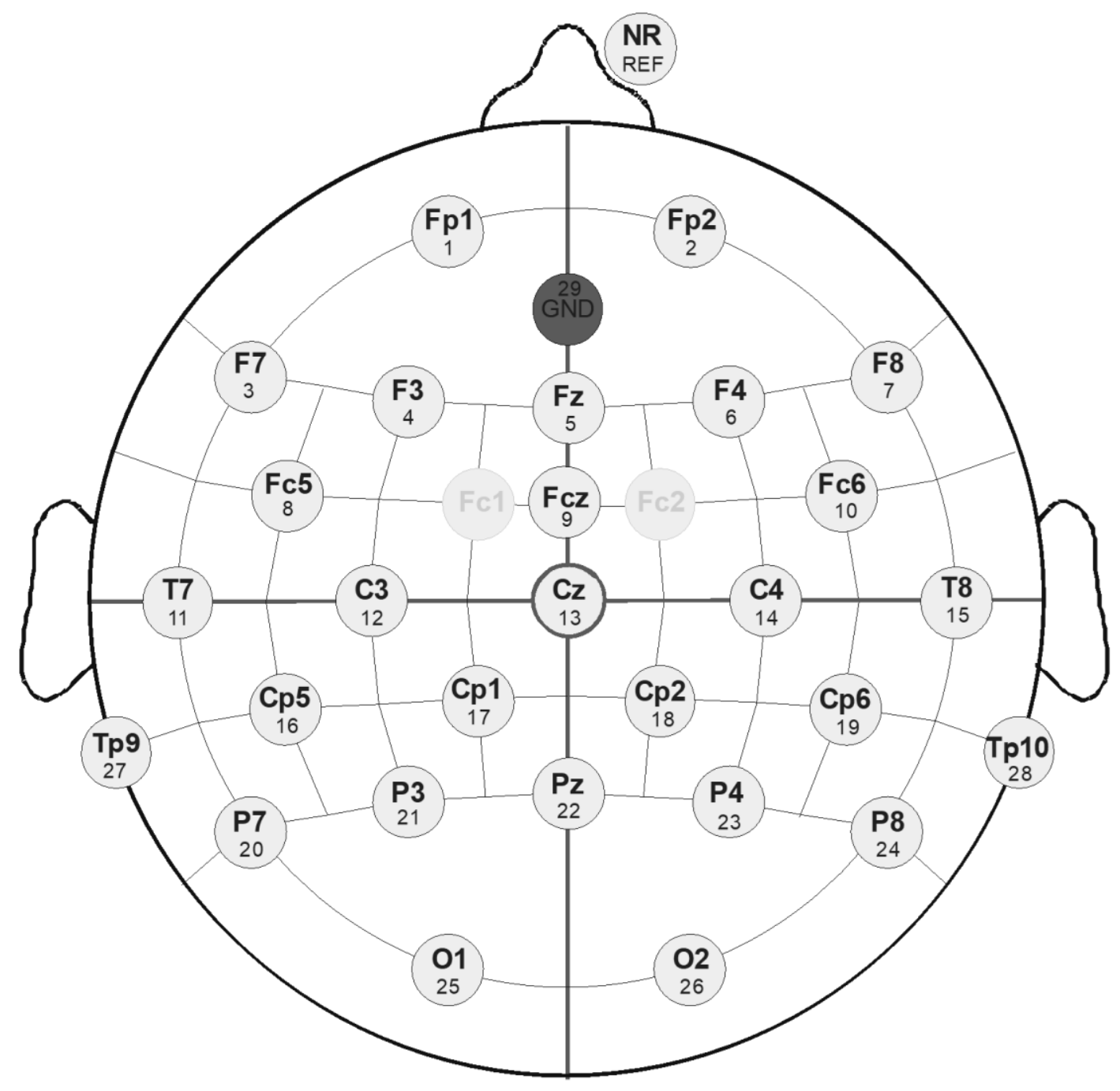

Figure 7: Graphic of the used electrodes (marked in fat script).

The ground electrode was placed on AFZ and the reference on the nose. Horizontal eye movements were recorded with two extra electrodes mounted at the right and left external canthus. Eye blinks were recorded with EOG.

All electrode impedances were maintained at or below $5 \mathrm{k} \Omega$. The electrophysiological signals were amplified with a bandpass ranging from 0.1 to $30 \mathrm{~Hz}$, digitized online with a $4 \mathrm{~ms}$ 
resolution (sampling rate of $250 \mathrm{~Hz}$ ) and stored on hard-disk for offline- analysis. A 32-channel BrainAmp DC amplifier (www.brainproducts.com) was used for EEG registration.

From the continuous EEG-signal, stimulus-locked epochs of $800 \mathrm{~ms}$ lengths starting $100 \mathrm{~ms}$ prior to stimulus onset were averaged for each condition and participant. Grand averages were formed separately for each condition and group. All stimuli requiring a response and standard trials with erroneous responses were discarded from further analysis. Thus, only standard stimuli without an (erroneous) response were analyzed. A pre-stimulus baseline of $100 \mathrm{~ms}$ was used for ERP computation. Ocular artifacts were corrected using the ICA-procedure as implemented in BrainVisionAnalyzer-software (www.brainproducts.com).

In a second step, all epochs with amplitudes exceeding + or $-80 \mu \mathrm{V}$ at any electrode were rejected from further analysis. The number of the trials which were taken into analysis ranged from 35 to 63 for adults and 20 to 30 for children.

After visual inspection, the strongest habituation was found between the first and the second block/third of the averages. For further statistical analysis the difference between the first and the second block average amplitude was calculated and correlated with the mean reading speed of the Saarbrücker reading speed test. Peaks were searched for the N170 component in the time range of $120 \mathrm{~ms}$ to $220 \mathrm{~ms}$ at electrode position $\mathrm{P} 7$ and $\mathrm{P} 8$. 


\subsubsection{Results}

\subsection{Behavioral measures}

Two groups were created according to reading speed: fast readers $(N=19)$ (cut off: $<300.49$ s time of all Saarbrücker Reading text) and slow readers $(N=20)$.

Two groups were formed on the basis of the Saarbrücker reading tests: The fastest 19 readers (of the Saarbrücker tests) and the slowest 20 participants were taken and assigned into either the slow readers group $(M=361.19 \mathrm{~s} ; S D=29.03 \mathrm{~s})$ or the fast readers group $(M=281.5 \mathrm{~s}$, $S D=19.40 \mathrm{~s})$, respectively.

Response times differed between the stimulus-conditions (letters: $M=406.12 \mathrm{~ms}, S D=40.51$; words: $M=42.36 \mathrm{~ms}, S D=44.32$; pseudo-words: $M=422.08 \mathrm{~ms}, S D=50.42$ ); Condition RT: $\mathrm{F}_{(2,74)}=3.74, p=.028, \eta^{2}=.09$. Planned contrasts show that the significant effect results from differences between letters and words $\left(\mathrm{F}_{(1,42)}=5.81, p=.021, \eta^{2}=.12\right)$ and between letters and pseudo-words $\left(\mathrm{F}_{(1,42)}=6.85, p=.013, \eta^{2}=.1402\right)$. The main effect for GROUP and the interaction GROUP $\times$ CONDITION was non-significant.

Mean response accuracy was very high for all conditions: Letters $(M=99.84 \%, S D=0.01)$, words $(M=99.54 \%, S D=0.02)$, pseudo-words $(M=99.54 \%, S D=0.02)$, with no significant variation between conditions or reader groups. False alarms were very low in occurrence $(M=1.2 \%$, $S D=0.07)$ and did not differ between groups or conditions.

\subsection{Event-related potential measures}

The ERPs show a negative peak at parietal electrodes after approximately $170 \mathrm{~ms}$ (see Figure 8). After massive repetition the signal decreased (habituation) especially between block A and block B.The data for the experiment was evaluated with an ANOVA with repeated measures. The factors were LATERALITY (left/P7 and right/P8), CONDITION (letters, words, pseusdowords) and TIME (block A represented the first third of the whole time window, block B the second third, block $\mathrm{C}$ the third third), peaks were searched for the N170 component in the time range of $120 \mathrm{~ms}$ to $220 \mathrm{~ms}$.

There was a significant effect of TIME (blocks): $\mathrm{F}_{(2,37)}=5.28, p=.01, \eta^{2}=.22$. Planned contrasts for P7 showed a significant difference between block $A$ and block $B\left(\mathrm{~F}_{(2,42)}=13.73, p<.01\right.$, $\eta^{2}=.95$ ), but no significant difference between block $A$ and block $C$ or block B and $C$ for any condition. For P8 the contrast showed no significant difference between block A and B but for block B vs. $\mathrm{C}\left(\mathrm{t}_{(2)}=6.43, p=.015, d=0.02\right)$. For CONDITION there was a tendency towards a 


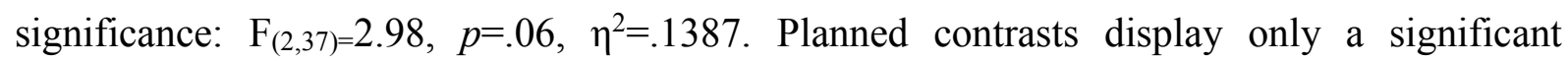
difference for P7 amplitudes between letters and words $\left(\mathrm{t}_{(38)}=7,85 p=.01, d=0.3\right)$ and letters vs. pseudo-Words $\left(\mathrm{t}_{(38)}=10, p<.01\right)$, but not between words and pseudo-Words. For P8 amplitudes, no significant differences were found.

Table 4: Mean Amplitudes for Letters, Words and Pseudo Words.

\begin{tabular}{lll}
\hline & P7 amplitudes in $\mu \mathrm{V}$ & P8 amplitudes in $\mu \mathrm{V}$ \\
\hline Letters & -3.31 & -3.21 \\
Words & -4.29 & -3.60 \\
Pseudo-Words & -4.39 & -3.34 \\
\hline
\end{tabular}

LATERALITY and GROUP also displayed a significant interaction $\mathrm{F}_{(1,37)}=5.82, p=.02, \eta^{2}=.14$. LATERALITY (electrode position) was significant: $\mathrm{F}_{(1,37)}=5.39, p=.03, \eta^{2}=.13$. and selected $\mathrm{t}$ tests showed that the N170 was significantly more left lateralized for fast readers $\left(\mathrm{t}_{(18)}=-2.42\right.$, $p=0.01$, while the amplitudes for slow readers did not show a significant difference.

Additionally, the interaction of LATERALITY and CONDITION was significant $\mathrm{F}_{(2,37)}=5.81$, $p<.01,, \eta^{2}=.24$. T-tests showed that letters did not differ in laterality, but words $\left(\mathrm{t}_{(38)}=-2.1\right.$, $p=.042, d=-0.33)$ and pseudo-words $\left(\mathrm{t}_{(38)}=-2.74, p=.01, d=-0.43\right)$ differed significantly. 
Slow Readers

Conditions P7

Letters

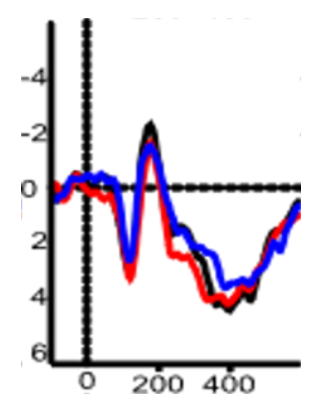

Words

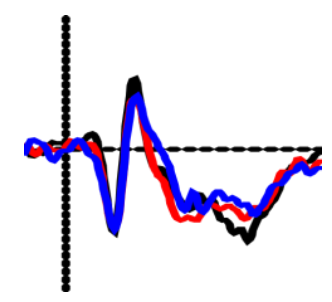

P8
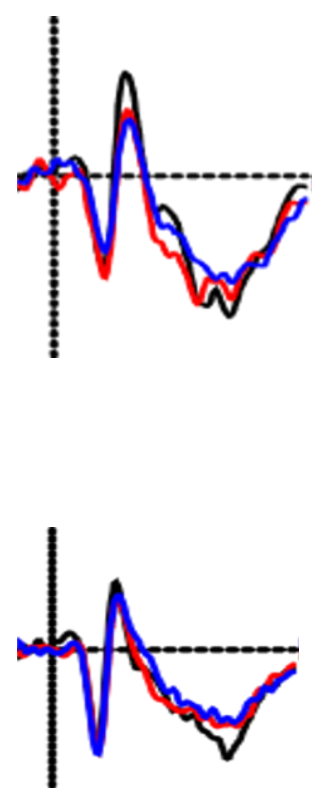

\section{Fast Readers}

P7

P8
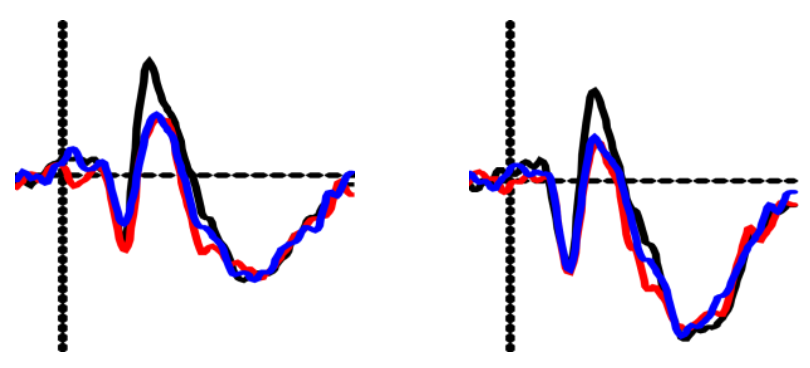

Legend

- Block A

- Block B

Block C

Figure continues on next page
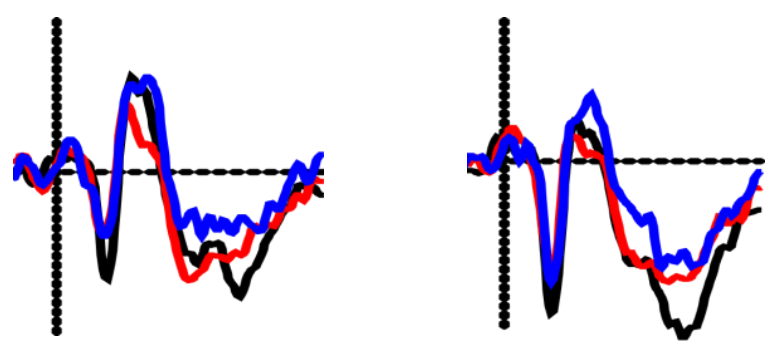

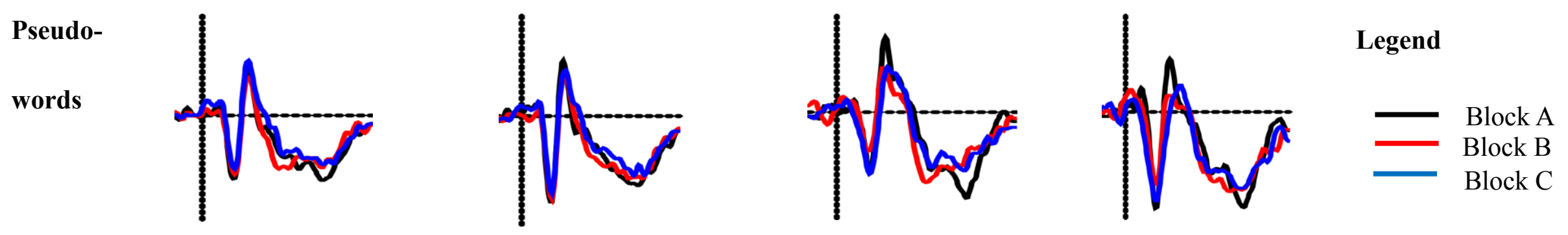

Figure 8: Adults: ERPs of Fast and Slow Readers at Electrode Positions P7/P8. 
In adults, the ANOVA (within subject) of the blocks (factor TIME) showed that habituation happens quickly $\left(\mathrm{F}_{(2,36)}=5.28, p=.01, \eta^{2}=.23\right)$ : Simple contrasts indicate a significant difference for all conditions/stimuli in mean amplitudes between block A $(M=-3.19, S D=3.07)$ and block $\mathrm{B}(M=-2.66, S D=3.06): \mathrm{t}_{(38)}=13.22, p<.01, d=.31$ and a tendency towards significance between block B $(M=-2.66, S D=3.06)$ and block C $(M=-3.05, S D=3.14): \mathrm{t}_{(38)}=3.69 p=.06 ., d=.01$

CONDITION X LATERALIZATION $\left(\mathrm{F}_{(1,37)}=5.81, p=.01, \eta^{2=} .74\right)$ : There is a significant difference of lateralization for the conditions word $\left(\mathrm{t}_{(38)}=-2.11, p=.04, d=.02\right)$ and pseudo-words $\left(\mathrm{t}_{(38)}=-2.7, p=.01, d=.19\right)$ in both kind of readers.

Repeated measures ANOVAs of the mean ERP amplitudes showed that fast and slow readers differed significantly in lateralization $\left(\mathrm{F}_{(1,37)}=5.81 ; p=.02, \eta^{2}=.14\right)$. Multiple dependent $\mathrm{t}$-tests of mean amplitudes at electrodes P7 vs. P8 revealed that fast readers showed a significant left lateralization (at P7: $M=-3.79, S D=2.91, \mathrm{P} 8: M=-2.74, S D=3.94, \mathrm{t}_{(18)}=-2.7, p=.01, d=-.64$ ) and slow readers showed no special lateralization for words (at P7: $M=-2.6, S D=2.91, \mathrm{P} 8: M=-2.78$, $\left.S D=2.78 ; \mathrm{t}_{(38)}=0.09, p=.93, d=0.02\right)$.

Additionally, there was a significant correlation of the difference of mean N170 amplitudes. This was the case for difference means of block A vs. block B in pseudo-words and the score of the Salzburger Reading Speed Test at electrode site P7 $(r=.33, p=.04)$. There was no significant correlation with reading speed for letters and words.

\subsubsection{Summary}

The habituation of the N170 in adult proficient readers could be shown, but it did not correlate significantly with the reading speed. Thus, it eventually is not a good indicator for the automatization of the reading process. 


\subsubsection{Discussion}

Massive repetition was used to analyze habituation to print stimuli. The automatization of reading was planned to be measured by determining the difference amplitude of block $\mathrm{A}$ and block B (habituation difference). This difference was then correlated with the reading speed.

The study with adult readers shows that the habituation of the N170 component is not suited for the identifications of reading problems, at least not in high performing students who were divided in two groups according to their reading speed (fast and slow). No general correlation etween reading speed and habituation of N170-amplitude was found. However, a habituation of the N170 component and a left lateralization tendency for words and pseudo-words was observed in fast and slow readers. The left lateralization specialization for word-like stimuli (i.e., words and pseudo-words) was statistically significant for fast readers, only. This finding might be explained with a stronger functional (and maybe structural) specialization of the left VWFA for fast readers, while for slow readers the distribution for letter, word and pseudo-word processing seem to be more undifferentiated.

There is few evidence in regard to neural adaptation effects and orthographic stimuli. The explanation is similar to Korinth's reasoning (of a missing subcomponent in slow readers) in his paper of 2013: Slower readers seem to lack a left lateralization at all, which could be caused by less pronounced string processing. The internal representation of the condition might not be necessarily of lower quality, but might be realized through an unproductive processing, which does not ignore redundant information. This inefficiency in a complex task such as reading might slow down processing in stages that follow visual processing. As in Korinth (2013) the behavioral measures of the present sample were not affected by the lack of lateralization, since the participants were only confronted with single letters, words, pseudo-words and symbols.

Results concerning the ERP measures were quite inconsistent. Only two correlations with reading speed measures were found in the sample of fast readers. These were the correlations of the N170 component with words and pseudo-words. For slow readers, no such correlations were found. One reason for the missing correlation of the N170 with the reading speed could be, that both groups of slow and fast readers were highly proficient readers (psychology students), who are used to read complex and long texts on a daily basis. Additionally, all performed equally well in the reading speed tests (small range in reading speed test scores). In terms of the extent of habituation, the amplitude decreased especially strong between the first and the second block. Nevertheless, no differences between fast and slow readers occurred. 


\subsection{Experiment 2: The Habituation of the N170 in Children}

\subsubsection{Participants}

Twenty-three children ( 8 girls) delivered decent data quality. The age range was from seven to nine years $(M=8.42, S D=0.59)$. All children were right-handed and had no known neurological or psychiatric diseases. All children were recruited in primary schools in or close to Bamberg, were native speakers of German and had normal or corrected to normal vision. Children received two cinema vouchers each. The parents signed the consent form and were present throughout data acquisition.

\subsubsection{Materials}

First, reading abilities were assessed. The One-Minute-Reading-Fluidity subtest of the Salzburger Lese- und Rechtschreibtest (SLRT II) was conducted. The children were instructed to read each word and pseudo-word list as fast and as accurate as possible aloud to the instructor. The children had one minute to read as many words or pseudo-words as possible. The amount of words was recorded.

The stimulus material of the study was written in capital letters for the children in order to facilitate reading for them. There were the letters " $A$ " (target) and " $C$ " (standard), the words "PREIS" (target) and "SPIEL", the pseudo-words "KLEUF" (target) and "FRAND", the single

symbols $P$ (target) and In each condition, 120 stimuli were presented (80\% standards, 20 $\%$ targets). The ISI varied randomly between $600 \mathrm{~ms}$ and $1200 \mathrm{~ms}$. Each condition was split into three thirds (Block A, B and C) in order to observe possible attenuations of the N170 component over time (habituation). The division into three blocks was not apparent for the participants. In each block 32 standards and 8 targets were presented in pseudo-random order (i.e. at least three standards had to occur after a target stimulus). The children were instructed to press a button as fast as possible whenever a target stimulus was shown. The standard stimuli were not linked to a response. The four stimulus-conditions were presented in randomized order (different for each participant). Fifty percent of the participants responded with the right index finger, 50\% used the left index finger. A Cedrus RB 830 response box (www.cedrus.com) was used to collect behavioral data. 


\subsection{Apparatus}

Presentation 17.0 software (neurobs.com) was used to deliver the stimuli and for recording the participants' responses.

\subsection{Procedure}

After the reading speed test, participants completed a task, in which the children were advised to react to one of two presented stimuli in a block (see section "Materials"). Four different stimuli were presented in separate blocks. Each block lasted about five minutes and breaks were taken between the blocks.

The experiment comprised of four stimulus-conditions: single letters, words, pseudo-words, and single symbols. All stimuli were presented in black on a grey background to go easy on the eyes of the children. Stimuli subtended $3 \mathrm{~cm} \times 5 \mathrm{~cm}$ (words, pseudo-words, single symbols), $1 \mathrm{~cm} \mathrm{x} 1 \mathrm{~cm}$ (letters) and were presented in the center of a computer monitor at a constant viewing distance of $70 \mathrm{~cm}$ after the children were seated on a children's' chair.

\subsection{EEG-recording and data analysis}

The ERPs showed a negative peak at parietal electrodes after approximately $170 \mathrm{~ms}$ (see Figure 8). After massive repetition there was no habituation.

Methods for EEG recording and data analysis were almost the same for both experiments (i.e. for children and adults). Except of TP9 and TP10 all, which were not recorded in children, electrode recordings were the same.

All electrode impedances were maintained at or below $5 \mathrm{k} \Omega$. The electrophysiological signals were amplified with a bandpass ranging from 0.1 to $30 \mathrm{~Hz}$, digitized online with a $4 \mathrm{~ms}$ resolution (sampling rate of $250 \mathrm{~Hz}$ ) and stored on hard-disk for offline- analysis. A 32-channel BrainAmp DC amplifier (www.brainproducts.com) was used for EEG registration.

From the continuous EEG-signal, stimulus-locked epochs of $800 \mathrm{~ms}$ lengths starting $100 \mathrm{~ms}$ prior to stimulus onset were averaged for each condition and participant. Grand averages were formed separately for each condition and group. All stimuli requiring a response and standard trials with erroneous responses were discarded from further analysis. Thus, only standard stimuli without an (erroneous) response were analyzed. A pre-stimulus baseline of $100 \mathrm{~ms}$ was used for ERP computation. Ocular artifacts were corrected using the ICA-procedure as implemented in BrainVisionAnalyzer-software (www.brainproducts.com). 
In a second step, all epochs with amplitudes exceeding + or $-80 \mu \mathrm{V}$ at any electrode were rejected from further analysis.

ERP peak amplitude and latency were determined at electrodes P7 and P8. A time-window of $150 \mathrm{~ms}$ to $250 \mathrm{~ms}$ was used. These data were submitted to two-way ANOVAs with factors (stimulus)-CONDITION (4 levels; letters, words, pseudo-words, single-symbol), TIME (3 levels: also called Block A, Block B, Block C) and LATERALITY (left[P7] vs. right[P8]). Where appropriate, the degrees of freedom in the ANOVAs were adjusted to control for violations of the sphericity assumption (Greenhouse-Geisser correction). Degrees of freedom are reported before, $p$-values after the correction.

\subsection{Results}

Mean response times (letters: $M=487.54 \mathrm{~ms}, S D=57.07$; words: $M=533.95 \mathrm{~ms}, S D=52.52$; pseudo-words: $M=537.64 \mathrm{~ms}, S D=76.91$; single symbols: $M=52.36 \mathrm{~ms}, S D=57.96)$ differed in the four stimulus-conditions, $\mathrm{F}_{(2,44)}=7.27, p=<.01, \eta^{2}=.33$. They did not differ for the 3 blocks: $\mathrm{F}_{(2,44)}=0.35, p=.7, \eta^{2}=.02$. Children's mean response accuracy was very high for all conditions (letters: $M=92.87 \%, S D=0.41$; words: $M=90.09 \%, S D=0.05$; pseudo-words: $M=89.31 \%$, $S D=0.05), \mathrm{F}_{(2,44)}=1.44, p=.24, \eta^{2}=.06$. In addition, they did not differ between blocks: $\mathrm{F}_{(2,44)}=1.44, p=.25, \eta^{2}=.06$. False alarms were low for all conditions: letters: $M=1.46 \%$, $S D=0.02$; words: $M=2.58 \%$; $S D=0.02$; pseudo-words; $M=3.18 \%, S D=0.03$; single symbol: $M=2.02 \%, S D=0.02 ; \mathrm{F}_{(2,44)}=4.55, p=.01, \eta^{2}=.18$.). 


\subsection{ERPs}

\section{Conditions $\quad$ P7}

Single

Letters

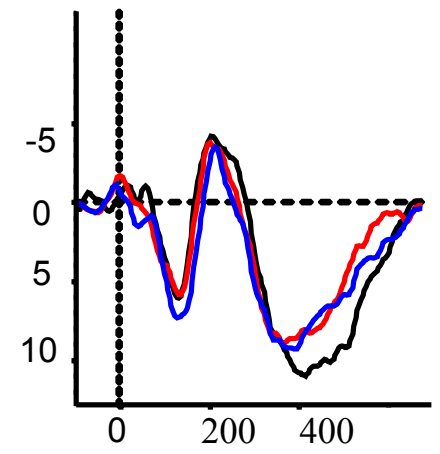

Words

Pseudo

words

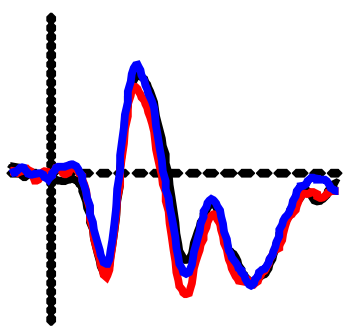

Single

Symbols

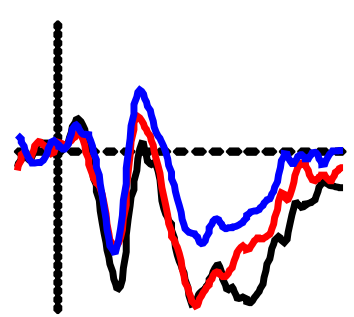

P8
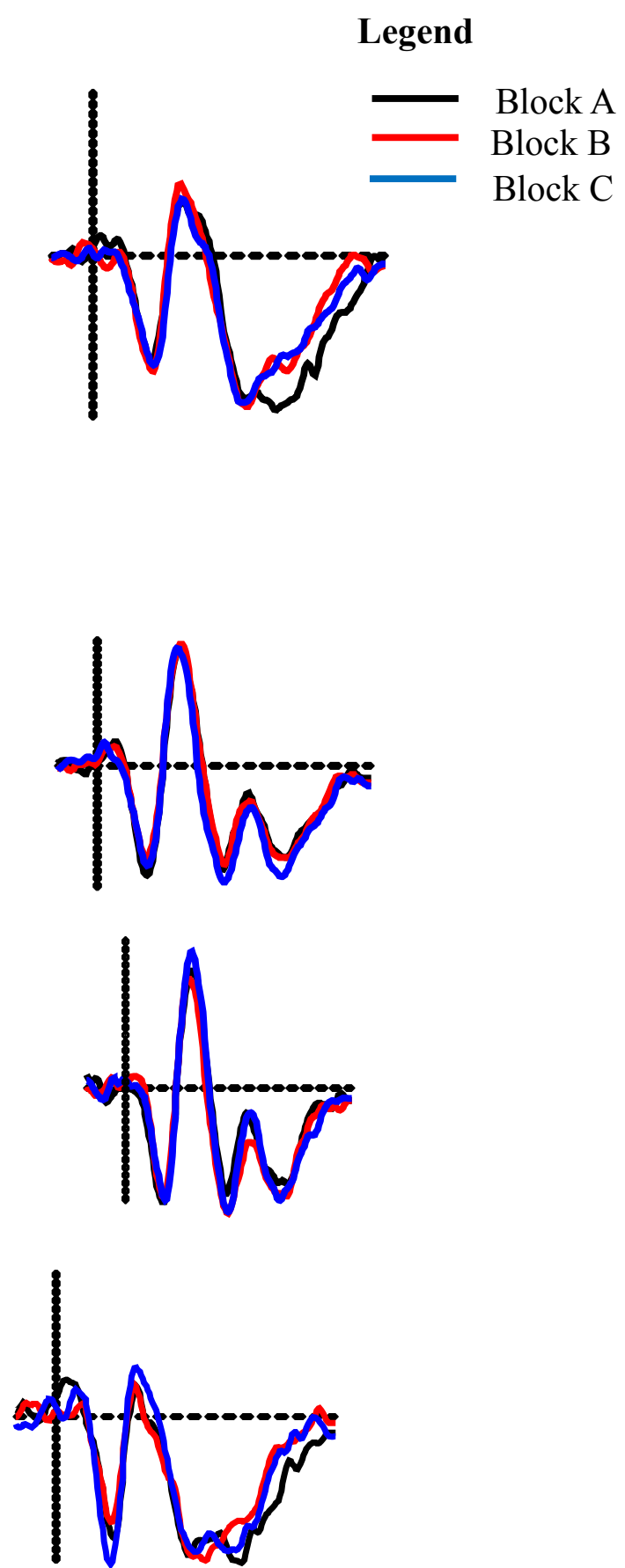

Figure 9: Children: ERPs at electrode positions P7/P8. 
Children did not show any habituation or effects in lateralization $\left(\mathrm{F}_{(1,21)}=2.42, p=.86 . \eta^{2}=.11\right)$. Neither there was any main effect for TIME (blocks): $\mathrm{F}_{(2,44)}=.36, p=.69, \eta^{2}=.02$ The same result (not-significant) was observed for the interaction effect BLOCK x CONDITION: $\mathrm{F}_{(4,84)}=0.76$, $p=.55$. In contrast to the adults, children did not show a correlation in reading speed of the SLRT II, because the main factor TIME (blocks) did not show a significant difference: $\mathrm{F}_{(2,44)}=.86$, $p=.73, \eta^{2}=.04$.

The repeated 3-way ANOVA (LATERALITY (2), CONDITION (4), TIME (3)) showed that conditions differed significantly $\left(\mathrm{F}_{(2,44)}=19.74 ; p<.01, \eta^{2}=.4845\right.$. $)$. There was a tendency for conditions to differ for hemispheres (LATERALITY x CONDITION: $\mathrm{F}_{(2,44)}=2,31 ; p=.09$, $\eta^{2}=.09$ ). They did not show any habituation or effects in lateralization.

\subsubsection{Discussion}

\subsection{Children}

In the age of six to eight years there is no habituation of the N170 for letters, words and pseudowords. Consequently, no significant correlation between reading speed and N170-amplitudedifference of block A vs. block B could be found. Nevertheless a study with dyslexic children would give important insight in regard to the expertise difference since the N170 arises in early reading acquisition (Maurer et al., 2006).

The lack of habituation in contrast to adults suggests that the ability to read is not yet automatized in children. Some studies even show that there is no adaptation of the signal but even an enhancement in amplitudes: in a review by, Nordt, Hoehl, and Weigelt (2016) the authors contrast the outcome of massive stimulus repetition: repetition suppression and repetition enhancement. In most cases the massive repetition of stimuli results in an adaption of the signal but sometimes an enhanced signal was observed. The authors interpreted the pattern as well-fitting to the assumption that repetition enhancement displays the formation of novel neural representations.

While there was a quick habituation for adults, children did not show a significant adaptation effect. Evidence provides support for a developmental change of perceptual expertise in reading. The visual word form area is developing over time in children and adults. Six to sevenyear-old children still show robust word-length effects, which slowly disappear over the years. Nevertheless they are still measurable in grade five (11-12 year old children) (Aghababian \& 
Nazir, 2000). Even though children early show an improved letter-string perception, those effects are limited to high-frequency words and do not spread to novel words or strings until ten to 13 years. In one study the N200 was mentioned. The ERP was used to measure reading expertise. The authors mention that a developmental study of this ERP shows similar patterns, which reveals that ten-year-old children produce a response that is similar to adult's high frequency words but that children fail to produce that response to pseudo-words (Posner \& McCandliss). The ongoing development of the visual word form area (VWFA) appears to be closely connected to the advancement of skill, rather than only being tied to simple maturation (Schlaggar \& McCandliss, 2007). Shaywitz et al. (2002) investigated fMRI responses in children aged between seven and 18 years with different reading abilities (impaired to highly performing). The activation levels of the VWFA and other related regions were positively correlated with standardized scores in grapheme-phoneme decoding abilities, even when the age was taken into account. Behavioral studies support the connection between decoding and enhancement of word recognition (Share, 1999).

Those findings are in line with our results showing that children do not habituate significantly. The amplitude did not attenuate from block A to block B (over time). The automatization reading process is not yet matured to a skilled stage. The results indicate that the habituation of the N170 component is not suited for a biological marker of the reading ability in children of this age.

\subsubsection{Discussion children and adults}

In these studies, massive repetition was used in children and adults to study habituation effetcs and the extent of reading automatization. In adults, a habituation of the N170 component and a left lateralization tendency for words and pseudo-words was observed in fast readers and slow readers, but there was only a significant difference for left lateralization specialization for fast readers (for pseudo-words). Children did not show any habituation (N170 amplitude difference between block A and B) or lateralization effects.

The data highlights the need to differentiate between two important characteristics: maturationrelated and age-independent variations in individual reading performance. As shown in Cao, Li, Zhao, Lin, and Weng (2011) young and therefore less proficient readers exhibited even at an early age larger left-lateralized amplitudes in seven-year old children than eleven year old children which stands in a contrast to the finding that six to nine year old children do not show a lateralization of any kind in the present study. Nevertheless, slow readers also did not show a 
left-lateralization. Whatsoever the adult samples represented a relatively homogenous age group $(M=25.08, S D=6.4)$, for which it can be assumed that maturation effects are probably completed. Therefore, larger amplitudes in the left hemisphere seem to relate to reading expertise only.

One limitation of previous studies is that the reported latencies are quite heterogenous. Korinth et al. (2013), for example, separated the N170 in two components: an early and a late one. It remains unclear how habituation happened in this manner. In Maurer et al. (2007) the N170 component peaked at about $200 \mathrm{~ms}$, while in Brem et al. (2004) the N170 was sampled between 148 and $160 \mathrm{~ms}$, which is an example of the high variability of N170 latencies.

The present results show that the N170 component is not a suitable biomarker for reading problems. Unfortunately, there is only one further study examining this effect. To summarize, there are not enough studies that look at reading-related N170 that handle this component as a biomarker. 


\subsection{Experiment 3: A Test of the Phonological Mapping Hypothesis}

\subsubsection{Background}

\subsection{The Phonological Mapping Hypothesis (PMH) and the N170}

Learning about the grapheme-phoneme relation is one of the most important processes that a successful reader acquires (i.e. grapheme-phoneme mapping). The grapheme-phoneme decoding of visual words has to be practiced regularly over the time of reading acquisition. In turn, reading acquisition leads - according to the phonological mapping hypothesis - to the predominant use of the left hemisphere for print decoding which manifests itself in the left lateralization of the N170 for written words (Maurer \& McCandliss, 2007b). McCandliss and Maurer (2007) hypothesize that the left hemisphere is mostly involved in phonological processes such as grapheme-phoneme mapping. This should be reflected in a left-lateralized N170 for words (i.e. amplitude of the N170 for words should be left lateralized and/or N170 amplitude of the difference between words and non-word stimuli should be left-lateralized). McCandliss and Maurer derived four assumptions from the phonological mapping hypothesis:

\section{(a) Left-lateralization of the $\mathrm{N170}$ reflects phonological mapping}

The phonological mapping hypothesis states that with the development of reading, left lateralization of the N170 follows because orthography links with phonological units (i.e. phonological mapping). Phonological processing predominantly happens in the left hemisphere, so with continuing practice with grapheme-phoneme relationships the N170 gets more and more left lateralized (Maurer \& McCandliss, 2007b). Sacchi and Laszlo (2016) predicted that individuals with greater phonological awareness should show a stronger left lateralization of visual word form processing. The study actually found that the higher the phonological awareness (but not vocabulary-knowledge), the greater the left N170 amplitude for word-like stimuli.

(b) If the phonological mapping hypothesis is correct, the left lateralization of the N170 should especially appear for scripts that use grapheme-phoneme conversion rules in contrast to logographic scripts, in which the left lateralized N170 should be less pronounced

A study by Kim, Yoon, and Park (2004) found that Korean participants who were taught both Chinese characters and written English showed a left lateralization for the N170 for English 
words and Korean words, but they displayed a bilateral N170 for Chinese characters. Korean and English are based on a script that converts sounds-to-letters, but Chinese is a logographic script in which symbols represent lexical morphemes (whole words).

\section{(c) According to the phonological mapping hypothesis, the N170 response should develop in children (and adults) when they gain expertise in reading}

In a previous part of this thesis the following cited studies were mentioned in another context. They were cited to highlight that the N170 amplitude appears specifically with words/print. In the following section (similar) studies are described to emphasize that the left-lateralization of the N170 develops while participants of those studies gain expertise in the context of reading.

This was shown in several studies by Maurer and colleagues (Maurer et al., 2006; Maurer et al., 2007; Maurer, Brem et al., 2005; Maurer, Schulz, Brem, van der Mark et al., 2011). For emphasizing the differences between pre-literate children and adults, Maurer, Brandeis, and McCandliss (2005) conducted a study in which kindergarten children were asked to detect repetitions of words, pseudo-words, symbols and pictures while EEG was recorded. While adults show a large difference between words and symbols on both occipito-temporal electrode sites -with a stronger left lateralization- children do not show this difference between symbols and words (Maurer, Brem et al., 2005a). Maurer et al (2005a) also found in the same study that these kindergarten children have letter knowledge, but still the results indicate that basic visual expertise with print and some letter knowledge are not enough to evoke the usual readingrelated N170 effect, even though the children could discriminate words from symbols and were able to name half of the alphabet. Additionally, the study demonstrated that a minimum of expertise is immanent. This interesting aspect was investigated further in another study of Maurer and colleagues in 2005(b). The researchers studied kindergarten children with high and low letter knowledge. The results revealed that children with low letter knowledge did not show a N170 specialization but children with high letter knowledge were revealed to have a weak specialization. Surprisingly, the topography was right lateralized and did not resemble the specialization of adults. This might be a pre-stage in the maturation of the N170 in contrast to the adult N170 fast visual specialization. The authors suggest that this pre-stage in kindergarten children is due to their letter knowledge or visual expertise with print (Maurer et al, 2005b). Even though the kindergarten children show a right lateralization, in contrast to the leftlateralized specialization of adults, children specialize nonetheless. Maurer and McCandliss (2007) take that as evidence supporting the phonological mapping hypothesis, which suggests that N170 responses develop in the progress of an increased mapping from letters to sounds. In 
2006, Maurer et al. repeated the measurements when the same children attended 2nd grade, and were able to read. A noticeable N170 specialization appeared in each child. Additionally, the topography became more left lateralized (Maurer \& McCandliss, 2006).

The N170 amplitude does not only differ between adults and children, but is also an indicator for adults and children that have reading problems. A typical reading disorder is dyslexia. Studies show that reading problems manifest themselves in a lower N170 amplitude. Nevertheless Maurer, Schulz, Brem, der Mark et al. (2011) showed that the N170 tuning deficit in dyslexic readers decreased from $2^{\text {nd }}$ to $5^{\text {th }}$ grade. In $2^{\text {nd }}$ grade the tuning deficit was very pronounced (Maurer et al., 2007) but in $5^{\text {th }}$ grade the difference between dyslexic and control children in terms of the word-symbol difference was no longer significant. It was close to significance only for occipito-temporal electrodes. The studies show that the N170 is changing over life but it can still serve as a predictor for reading improvement in dyslexia: FragaGonzalez et al. (2016) used the N170 as a predictor of reading improvement and reported a larger N170 for words in 'improvers' (dyslexics who benefited from reading fluency training) compared to 'non-improvers' (dyslexics who did not benefit).

Another way to show that expertise differences modulate the N170 amplitude is to expose participants to a reading training: Zhao, Li, Zhao, Gaspar and Weng (2015) showed that even short training units modulate the N170 in preliterate children, which was right-lateralized, though. Brem et al. (2010) found similar results in kindergarteners who received short grapheme-phoneme trainings. Consequently, the print-tuned N170 was considered to be an early specialized neural processing for print that arises through continuing training of reading.

The analysis of children's N170 development already gave promising results but we can also take a look at adults - especially at training studies that investigate adults who did not learn how to read in childhood but who received reading instructions in adulthood (illiterates). A study with illiterates conducted by Boltzmann and Rüsseler (2013) showed that the adult brain is still prone to plasticity. They found in functional illiterates that the word-related N170 increases after an intensive literacy training. The study demonstrates that a word-related N170 can still be modulated in adulthood through intensive literacy training.

To summarize, most evidence shows that the N170 actually develops in children or adults that are gaining more expertise in reading. The N170 seems to be a good instrument to track developmental changes in children or in adults who learn to read. 
(d) According to the phonological mapping hypothesis, dyslexic readers should show lower left lateralization for the reading-related N170, because a phonological core deficit is assumed with dyslexia

Dyslexia seems to include a specific lack of print tuning: in 2013, Mahé, Bonnefond and Doignon-Camus compared dyslexic adults, poor readers that were reading-matched and controls with the same kind of stimuli. The poor readers had no history of developmental dyslexia but had low socio-economic status and poor reading habits. Like control readers, poor readers showed more pronounced left occipito-temporal negativities, in contrast to the dyslexics. Helenius, Tarkiainen, Cornelissen, Hansen, and Salmelin (1999) instructed dyslexic adults to look at words and symbol strings in a magnetoencephalographic (MEG) study. The participants had to look at the stimuli cautiously and to report them if they were asked. Early visual responses were comparable in dyslexic and controls, but letter-string specific responses (approximate reported peak at around $150 \mathrm{~ms}$ ) were mainly found in the VWFA for typical adult readers and were not present in dyslexic readers.

In an MEG study, Tarkiainen (1999) observed that typically reading adults showed sources in the inferior occipito-temporal cortex which were preferably seen in the left hemisphere and differed between words and symbols at around $150 \mathrm{~ms}$. On the other hand dyslexic participants did not show such word-specific sources in that time range (Helenius et al., 1999). Another MEG study contributes similar results: words and pseudo-words activate sources in the left occipito-temporal cortex in normal readers between $100 \mathrm{~ms}$ and $200 \mathrm{~ms}$ but this activation is less pronounced in dyslexic readers (Salmelin, Service, Kiesila, Uutela, \& Salonen, 1996). Other studies do not show this pattern. Brandeis, Vitacco, and Steinhausen (1994) and Simos, Breier, Fletcher, Bergman, and Papanicolaou (2000), for example, did not find a difference between dyslexic children to age-matched controls in the N170 time range using MEG.

Altogether, some evidence shows that dyslexics have a lower reading-related N170 lateralization, but still some evidence does not verify this assumption. Considering the evidence, the N170, that is tuned to print, is an index that does not clearly identify manifested reading problems.

\subsubsection{Correlation of the $\mathrm{N} 170$ and $\mathbf{N 4 5 0}$}

Stevens et al. (2013) were the first to report a relation between the relative left lateralization of the N170 and the N450-rhyme component. They verified a neural specialization (N170) for the 
processing of single letters in adult fluent-reading participants, but it is different from the neural specialization of word processing, because it is bilateral for letters and not left lateralized as for words. For the implicit distinction between rhyme and non-rhyme a larger negative amplitude was discovered for the N450-rhyme component, if the stimulus (a letter) did not rhyme with the preceding letter. Other studies found similar evidence (Coch et al., 2011; Coch, Hart et al., 2008). Based on the results, Stevens et al. (2013) assume that the processing of letter labeling happens at a phonological level, when the participants are supposed to distinguish implicitly between rhyme and non-rhyme stimuli. They presume that there is an automatic association between orthography and phonology. Consequently, participants, who exhibit a greater N450effect in the same implicit processing task, also show a larger relative left-lateralization of the N170.

The purpose of the present study was to replicate and extend the results of Stevens et al. (2013). Stevens et al. (2013) only studied the relation of N170 left lateralization and the N450 rhyme effect using single letters. In the present study, single letters as well as words and pseudo-words were used. Furthermore, it seems important to verify results -obtained in an opaque language like English- in different languages. In the present study, German was studied (more transparent than English). Participants worked through six tasks. In the first and second block the participants were presented a sequence of letters. In the first block participants had to react to repeating letters and in block 2 they had to respond to appearing vowels by pressing a button. Thus, block 2 (vowel identification) requires more phonological processing compared to block 1 (detection of letter repetition). Consequently, there should be a stronger left-lateralization of the N170 in the vowel condition (block 2) which would represent a stronger automatic activation of the phonological representation for letters. In block 3 and 4, words were presented. The task in block 3 was to react to directly repeating words and in block 4 to pseudo-words that were mixed with real words. In blocks 5 and 6 symbol strings and single symbols were shown and participants were instructed to react to directly repeating stimuli. In all blocks involving letters, words or pseudo-words, some of the non-target stimuli were rhymes. it was hypothesized that rhymes evoke a larger N450 compared to non-rhymes reflecting the degree of phonological processing. 


\subsubsection{Method}

\subsubsection{Participants}

Twenty-six participants ( 24 female) were tested. The data sets of 22 participants were analyzed; one data set had to be excluded due to technical problems (to many artefacts) and three did not match the inclusion criteria because they reported neurological diseases. The inclusion criteria required that at least $80 \%$ of the 120 stimuli or $80 \%$ of the 60 Stimuli of the rhyme condition were useable for evaluation after artifact rejection of the ERP-trials.

The age range of the participants was between 20 and 34 years $(M=23.86$ years; $S D=4.36)$. Sixteen of the tested participants were Psychology majors. Three participants were other majors such as 'school psychology' combined with teaching degree or English studies. The other three participants were administrator, hotel manager and social security employee specialized in accident prevention. All 22 participants were right-handed and had normal or corrected eyesight assessed by a questioning form. No neurological diseases were reported. Twenty-one participants were German native speakers while one participant grew up bilingual (Polish and German).

\subsubsection{Materials}

Six blocks of stimuli were presented in a fixed order. Each block contained 240 stimuli. Fifty percent of the stimuli did not rhyme in block 1,3, 4, 5 and 6 (120 trials), while 50 percent rhymed. In block 2 vowels were presented that were preceded by single letters with either rhyming or non-rhyming single letter. Sixty stimuli rhymed to the previous condition. The stimulus was presented for $500 \mathrm{~ms}$ and the inter-stimulus interval (ISI) was $500 \mathrm{~ms}$ (the fixation cross was presented in this time). Figure 10 shows the sequence of such task block. 


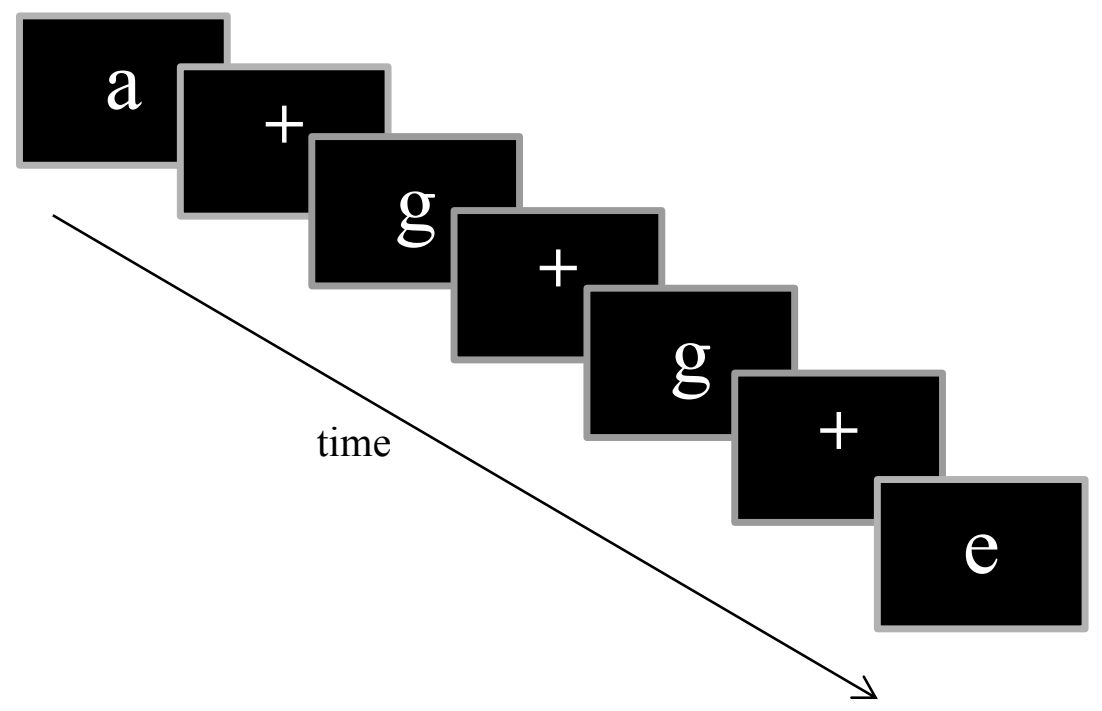

Figure 10: An example from the sequence of the condition material for task 1: Participants had to press a response key to an immediate repetition of a letter. Stimulus duration: 500 ms, ISI: $500 \mathrm{~ms}$.

In blocks 1 and 2, 22 of the 26 single letters were used as stimulus material. The lower letters a to $\mathrm{z}$, without $\mathrm{q}, \mathrm{r}, \mathrm{x}$, and $\mathrm{y}$, were included. The difference between the blocks was that the participants were supposed to react to immediate letter repetitions in block 1, whereas in block 2 they were asked to respond to vowels in order to activate a phonological representation. In block 3 , the participants saw 22 words and had to react to word repetitions. Word stimuli are presented in the appendix 5.3. In block 4, words and pseudo-words were presented: 22 stimuli from block 3 and seven new pseudo-words. Participants had to respond to the pseudo-words. In blocks 3 and 4, 60 stimuli were rhymes whereas all remaining stimuli were non-rhymes. In block 5, 22 symbol strings from the ASCII-symbols were generated. Those were put together from the symbols $\#, *, \&, \%, \S),(, /, \sim\},\{!, ?$, “and $\backslash$. Symbol-strings consisted of three to maximum five symbols (see Figure 11; all stimuli can be found in appendix 5.3). 


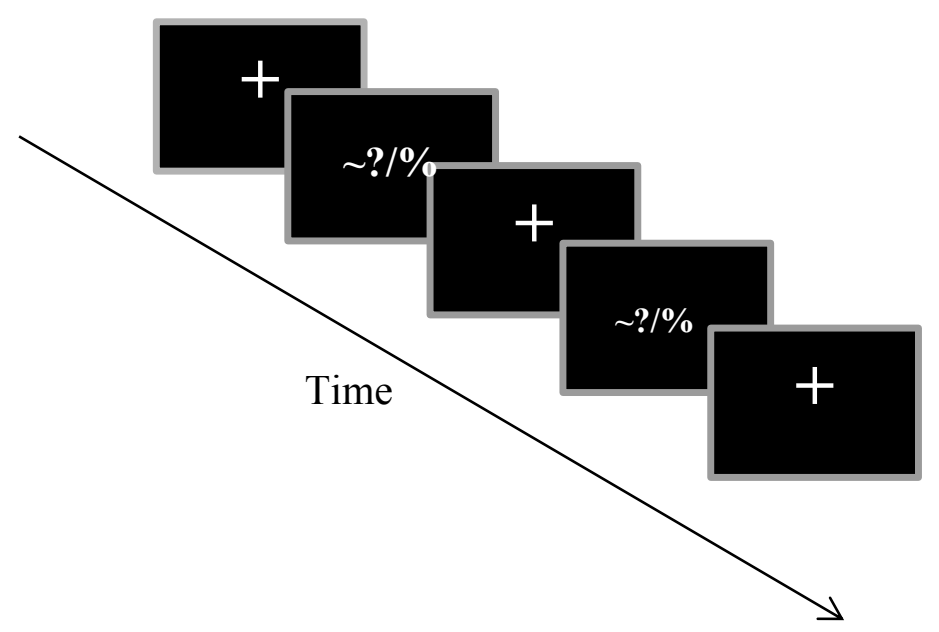

Figure 11: Schematic figure of a trial (symbol strings displayed): Participants had to press a response key to an immediate repetition of a letter. Stimulus duration: $500 \mathrm{~ms}$, ISI: $500 \mathrm{~ms}$.

In block 6 the participants saw 24 single symbols. The symbols originally were single letters that were cut with CorelDraw X7C maximum three times in order to create a new symbol. One example is shown in Figure 12.

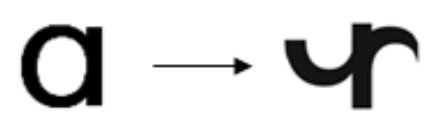

Figure 12: Symbol created symbol from a cut letter.

In blocks 5 and 6, participants had to respond to immediate stimulus repetitions. Due to the nature of the stimulus material, no rhymes were presented. All stimuli were presented in font size 32 with the font width of 300 and the font height of 100 pt. The stimuli were separated by a fixation cross. The font for the task block 1 to 5 was Arial and in block 6 Futura Lt. BT. All 
stimuli were presented in black on a white background in the center of a computer screen. Viewing distance was kept constant approximately $53 \mathrm{~cm}$.

\subsubsection{General Procedure}

Participants gave written and informed consent. Afterwards, two reading tests (Saarbrücker Reading Test, Salzburger Reading Test, see Experiment1, section 4.2.1.2) were administered. The participants absolved six different one-back-tasks. The tasks were split into six independent blocks (see section "Materials"), which were separated by a two-minute break. The participants were instructed to react to different stimuli (see Table 6).

Table 5: Overview over the blocks, the used stimuli and the task/ instructions.

\begin{tabular}{lll}
\hline Block & Stimuli & Task \\
\hline Block 1 & Single Letters & $\begin{array}{l}\text { "Please react to the repetition of } \\
\text { the letter." } \\
\text { "Please react to the vowel." }\end{array}$ \\
Block 2 & Single Letters & $\begin{array}{l}\text { "Please react to the word } \\
\text { repetition." } \\
\text { Block } 4\end{array}$ \\
Block 5 & Words & $\begin{array}{l}\text { "Please react to the pseudo-word." } \\
\text { "Please react to the repetition of } \\
\text { the symbol string." }\end{array}$ \\
Block 6 & Symbol Strings & $\begin{array}{l}\text { "Please react to the repetition of } \\
\text { the symbol." }\end{array}$ \\
\hline
\end{tabular}

\subsubsection{Data analysis and EEG recording}

The electrode positions FP1/2, F3/4, F7/8, Fz, FC5/6, T7/8, Cz, FCz, CP5/6, CP1/2, C3/4, P3/4, P7/8, Pz, O1/2, TP9/10 were recorded online with the "Vision Recorder" (Brain Products) and were analyzed offline with the "Vision Analyzer". The ground electrode was placed on AFZ and the reference on the nose. Horizontal eye movements were recorded with two extra electrodes mounted at the right and left external canthus. Eye blinks were recorded with FP1.

All electrode impedances were maintained at or below $5 \mathrm{k} \Omega$. The electrophysiological signals were amplified with a bandpass ranging from 0.1 to $30 \mathrm{~Hz}$, digitized online with a $4 \mathrm{~ms}$ resolution (sampling rate of $250 \mathrm{~Hz}$ ) and stored on hard-disk for offline- analysis. A 32-channel BrainAmp DC amplifier (www.brainproducts.com) was used for EEG registration. 
From the continuous EEG-signal, stimulus-locked epochs of $800 \mathrm{~ms}$ lengths starting $100 \mathrm{~ms}$ prior to stimulus onset were formed. All stimuli requiring a response and trials with erroneous responses were discarded from further analysis. Thus, only stimuli without an (erroneous) response were analyzed. A pre-stimulus baseline of $100 \mathrm{~ms}$ was used for ERP computation. Ocular artifacts were corrected using the ICA-procedure as implemented in BrainVisionAnalyzer-software (www.brainproducts.com).

In a second step, all epochs with amplitudes exceeding + or $-80 \mu \mathrm{V}$ at any electrode were rejected from further analysis. Averages were computed for non-rhymes and rhymes.

Peaks were searched for the N170 component in the time range of $120 \mathrm{~ms}$ to $220 \mathrm{~ms}$ and for the N450 component in the time window of $350 \mathrm{~ms}$ to $500 \mathrm{~ms}$. For the N170, peak latency and mean amplitude were analyzed whereas for the N450, mean amplitude between $350 \mathrm{~ms}$ and 500 ms served as dependent variable. The N170 component was analyzed at the P7/P8 positions, the N450 component was best observed at FCz, C3, C4, Cz, Pz, Cp1 and Cp2.

\subsubsection{Results}

\subsection{Behavioral Data}

Accuracy was very high for all conditions (letter repetition: $M=98.1 \%(S D=3.72)$, letter-vowel condition: $M=99.72 \% \quad(S D=1.41)$, words: $M=97.91 \% \quad(S D=5.14)$, pseudo-words words: $M=96.84 \%(S D=4.21)$, symbol strings: $M=95.11 \%(S D=7.65)$, single symbols: $M=96.62 \%$ $(S D=5.69)$. A one-way ANOVA for the error rates with six levels for stimulus-condition confirmed significant differences in the number of correct responses between conditions $\left(\mathrm{F}_{(1,21)}=15.99 ; p<.001, \eta^{2}=.4323\right)$. Planned contrasts of correct responses were significant between letter (repetition) vs. letter (vowel) $\left(\mathrm{t}_{(42)}=2.76 ; p=.01 ; d=0.86\right)$, letter (vowel) vs. word (repetition) $\left(\mathrm{t}_{(42)}=-3.07 ; p<.01 ; d=-1,12\right)$, word (repetition) vs. pseudo-word $\left(\mathrm{t}_{(42)}=-2.05 ; p=.043\right.$, $d=1.16)$, pseudo-word vs. symbol (repetition) $\left(\mathrm{t}_{(42)}=-2.35 ; p=.02 ; d=1.02\right)$, symbol (repetition) vs. single symbol (repetition) $\left(\mathrm{t}_{(42)}=-2.51 ; p=.01 ; d=-0.13\right)$ and between single symbol (repetition) vs. letter (repetition) $\left(\mathrm{t}_{(42)}=-2.21 ; p=.03 ; d=-0.12\right)$.

False alarms were very low. The mean of all conditions was 4.7 percent $(S D=3.73)$. False alarms for the conditions were: letter (repetition) $M=4.17 \%(S D=2.17)$, letter (vowel) $M=1.44 \%$ $(S D=1.94)$, word (repetition) $M=3.79 \%(S D=1.8)$, pseudo word $M=8.4 \%(S D=5.7)$, symbol (repetition) $M=6.14 \%(S D=3.18)$ and single symbol (repetition) $M=4.25 \%(S D=1.83)$. Planned contrasts of false alarms showed a significant difference between letter (repetition) vs. 
letter $\left(\right.$ vowel) $\left(\mathrm{t}_{(42)}=-2.92 ; p<.01, d=.45\right)$, letter (vowel) vs. word (repetition) $\left(\mathrm{t}_{(42)}=2.51\right.$; $p=.01, d=.38$ ), word (repetition) vs. pseudo-word $\left(\mathrm{t}_{(42)}=4.95 ; p<.01, d=.75\right)$, pseudo-word vs. symbol (repetition) $\left(\mathrm{t}_{(42)}=-2.43 ; p=.02\right)$ and symbol (repetition) vs. single symbol (repetition)

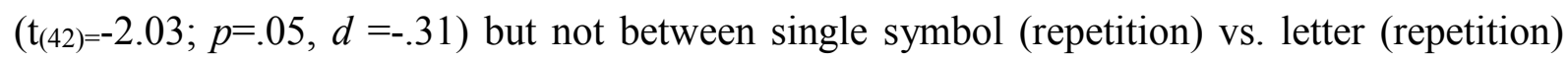
$\left(\mathrm{t}_{(42)}=-.081 ; p=.94, d=-.12\right)$.

The mean response time for letter (repetition) was $374.45 \mathrm{~ms}(S D=35.19)$, for letter (vowel) $405.71 \mathrm{~ms}(S D=23.58)$, for word (repetition) $378.53 \mathrm{~ms}(S D=29.52)$, pseudo-words $413.45 \mathrm{~ms}$ $(S D=29.81)$, symbol (repetition) $383.81 \mathrm{~ms}(S D=33.01)$ and single symbol (repetition) 378.93 ms $(S D=33.77)$. An ANOVA with one factor (CONDITION) and six factor levels (letter repetition, letter-vowel, word repetition, pseudo-word in words, symbol repetition, single symbol repetition) for response time was conducted, which was highly significant $\left(\mathrm{F}_{(1,21)}=6.01\right.$, $p<.000, \eta^{2}=.22$ ). Planned contrasts show that the conditions letter (repetition) and letter (vowel) differed significantly $\left(\mathrm{t}_{(126)}=3.3, p<.01\right)$, as well as letter (vowel) vs. word (repetition) $\left(\mathrm{t}_{(126)}=-\right.$ 2.82, $p=.01, d=-.25$ ); word (repetition) vs. pseudo-word $\mathrm{t}_{(126)}=3.67, p<.01, d=.33$; pseudoword vs. symbol (repetition) $\left(\mathrm{t}_{(126)}=3.24, p<.01, d=.29\right)$. No significant difference was found for symbol (repetition) vs. single symbol (repetition) and letter (repetition) vs. single symbol (repetition).

\subsection{ERP data}

The general waveform of the ERP showed a positivity peaking after approximately $100 \mathrm{~ms}$ to $220 \mathrm{~ms}$ at posterior electrodes, an N170 maximal at P7/P8 and a large positivity between 250 $\mathrm{ms}$ and $600 \mathrm{~ms}$. The N450 effect was most pronounced at $\mathrm{FCz}$ and $\mathrm{Cz}$ in the letter (vowel) and word (repetition) conditions. The N170 differed between the conditions. The positivity between $250 \mathrm{~ms}$ and $600 \mathrm{~ms}$ was maximal at central and parietal electrodes and differed for rhymes and non-rhymes (more negative for non-rhymes, i.e. N450 effect). These electrodes were used for computing t-tests for dependent samples.

\subsection{The N450 Rhyme Effect}

The first aim is to show that there was more phonological activation triggered in the second block (letter/vowel) compared to the first block (letter/repetition). Therefore, a three-way ANOVA of mean N450 amplitude with factors CONDITION (4 levels: single letters; single 
letters detect vowels; words; words in pseudo-words), ELECTRODE (7 levels: FCz, C3, Cz, C4, CP1, CP2 and Pz) and RHYME (2 levels: Rhyme vs. Non-Rhyme) was conducted.

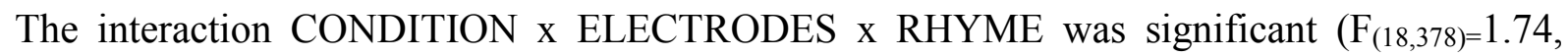

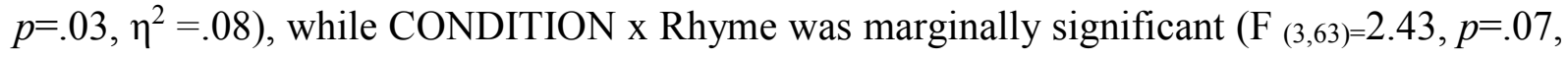
$\eta^{2}=.1$ ). Also highly significant was the interaction ELECTRODE $x$ RHYME (F $\left.(6,126)=6.49, p<.01, \eta^{2}=.24\right)$. The main effect RHYME was not significant, while the main effects

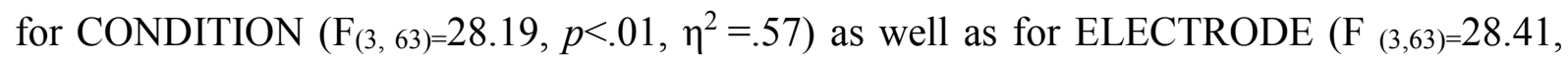
$p<.01, \eta^{2}=.58$ ) were significant. Multiple t-tests in table 4 show significant differences between rhyme and non-rhyme only for letter/vowel and word/repetition conditions. 
Table 6: T-test for the different electrodes and conditions: rhyme vs. non-rhyme:

\begin{tabular}{|c|c|c|c|c|c|c|c|}
\hline Electrode & $\begin{array}{l}\text { Rhyme vs. } \\
\text { non-rhyme }\end{array}$ & $\begin{array}{l}\text { Mean } \\
\text { difference in } \\
\text { amplitude in } \\
\mu \mathrm{V}\end{array}$ & $S D$ & T-Value & $d f$ & $\begin{array}{l}p \\
\text { (two-tailed) }\end{array}$ & $d$ \\
\hline \multirow[t]{4}{*}{$\mathrm{FCz}$} & $\begin{array}{l}\text { Letters } \\
+ \text { Letter } \\
\text { (Repetition) }\end{array}$ & $<0.01$ & 1.94 & $<0.01$ & 21 & 0.99 & $<.01$ \\
\hline & $\begin{array}{l}\text { Letter } \\
\text { + Letter } \\
\text { (Vowel) }\end{array}$ & -1.31 & 2.69 & -2.29 & 21 & 0.03 & -.45 \\
\hline & $\begin{array}{l}\text { Word } \\
+ \text { Word } \\
\text { (Repetition) }\end{array}$ & -1 & 2.06 & -2.28 & 21 & 0.03 & -.63 \\
\hline & $\begin{array}{l}\text { Word } \\
+ \text { Word } \\
\text { (Pseudo } \\
\text { Word) }\end{array}$ & 0.44 & 2.01 & 1.03 & 21 & 0.32 & .23 \\
\hline \multirow[t]{4}{*}{$\mathrm{C} 3$} & $\begin{array}{l}\text { Letters } \\
+ \text { Letter } \\
\text { (Repetition) }\end{array}$ & -0.06 & 1.7 & -0.18 & 21 & 0.86 & -.04 \\
\hline & $\begin{array}{l}\text { Letter } \\
\text { + Letter } \\
\text { (Vowel) }\end{array}$ & -0.6 & 2.24 & -1.22 & 21 & 0.24 & -.27 \\
\hline & $\begin{array}{l}\text { Word } \\
+ \text { Word } \\
\text { (Repetition) }\end{array}$ & -0.36 & 1.87 & -0.91 & 21 & 0.38 & -.2 \\
\hline & $\begin{array}{l}\text { Word } \\
+ \text { Word } \\
\text { (Pseudo } \\
\text { Word) }\end{array}$ & 0.49 & 1.64 & 1.39 & 21 & 0.18 & -.31 \\
\hline
\end{tabular}




\begin{tabular}{|c|c|c|c|c|c|c|c|}
\hline Electrode & $\begin{array}{l}\text { Rhyme vs. } \\
\text { Non Rhyme }\end{array}$ & $\begin{array}{l}\text { Mean Difference } \\
\text { Amplitude in } \mu \mathrm{V}\end{array}$ & $S D$ & T-Value & $d f$ & $\begin{array}{l}p \\
\text { (2-tailed) }\end{array}$ & $d$ \\
\hline \multirow[t]{4}{*}{$\mathrm{Cz}$} & $\begin{array}{l}\text { Letters } \\
\text { + Letter } \\
\text { (Repetition) }\end{array}$ & -0.22 & 1.96 & $\begin{array}{l}-0.53 \\
\end{array}$ & 21 & 0.6 & -.11 \\
\hline & $\begin{array}{l}\text { Letter + Letter } \\
\text { (Vowel) }\end{array}$ & -1.45 & 2.76 & -2.49 & 21 & 0.02 & -.56 \\
\hline & $\begin{array}{l}\text { Word + Word } \\
\text { (Repetition) }\end{array}$ & -1.08 & 2.09 & -2.42 & 21 & 0.03 & -.56 \\
\hline & $\begin{array}{l}\text { Word + Word } \\
\text { (Pseudo Word) }\end{array}$ & 0.31 & 2.06 & 0.7 & 21 & 0.49 & .16 \\
\hline \multirow[t]{4}{*}{$\mathrm{C} 4$} & $\begin{array}{l}\text { Letters }+ \\
\text { Letter } \\
\text { (Repetition) }\end{array}$ & -0.01 & 1.8 & -0.03 & 21 & 0.98 & $<.01$ \\
\hline & $\begin{array}{l}\text { Letter + Letter } \\
\text { (Vowel) }\end{array}$ & -0.99 & 2.16 & -2.14 & 21 & 0.04 & -.47 \\
\hline & $\begin{array}{l}\text { Word + Word } \\
\text { (Repetition) }\end{array}$ & -0.62 & 1.94 & -1.5 & 21 & 0.15 & -.34 \\
\hline & $\begin{array}{l}\text { Word + Word } \\
\text { (Pseudo Word) }\end{array}$ & 0.36 & 1.82 & 0.93 & 21 & 0.37 & .21 \\
\hline
\end{tabular}




\begin{tabular}{|c|c|c|c|c|c|c|c|}
\hline Electrode & $\begin{array}{l}\text { Rhyme vs. Non } \\
\text { Rhyme }\end{array}$ & $\begin{array}{l}\text { Mean Difference } \\
\text { Amplitude in } \mu \mathrm{V}\end{array}$ & $S D$ & T-Value & $d f$ & $\begin{array}{l}p \\
\text { (2-tailed) }\end{array}$ & $d$ \\
\hline \multirow[t]{4}{*}{ CP1 } & $\begin{array}{l}\text { Letters } \\
\text { + Letter } \\
\text { (Repetition) }\end{array}$ & -0.19 & 1.87 & -0.49 & 21 & 0.62 & -.11 \\
\hline & $\begin{array}{l}\text { Letter + Letter } \\
\text { (Vowel) }\end{array}$ & -0.89 & 2.49 & -1.66 & 21 & 0.11 & -.37 \\
\hline & $\begin{array}{l}\text { Word + Word } \\
\text { (Repetition) }\end{array}$ & -0.99 & 2.16 & -2.14 & 21 & 0.04 & -.48 \\
\hline & $\begin{array}{l}\text { Word + Word } \\
\text { (Pseudo Word) }\end{array}$ & 0.19 & 1.91 & 0.48 & 21 & 0.64 & .11 \\
\hline \multirow[t]{4}{*}{ CP2 } & $\begin{array}{l}\text { Letters } \\
\text { + Letter } \\
\text { (Repetition) }\end{array}$ & -0.21 & 1.89 & -0.51 & 21 & 0.62 & .11 \\
\hline & $\begin{array}{l}\text { Letter + Letter } \\
\text { (Vowel) }\end{array}$ & -1.14 & 2.45 & -2.18 & 21 & 0.04 & -.49 \\
\hline & $\begin{array}{l}\text { Word + Word } \\
\text { (Repetition) }\end{array}$ & -0.95 & 2.23 & -2 & 21 & 0.06 & -.49 \\
\hline & $\begin{array}{l}\text { Word + Word } \\
\text { (Pseudo Word) }\end{array}$ & 0.14 & 1.99 & 0.33 & 21 & 0.74 & .07 \\
\hline \multirow[t]{4}{*}{$\mathrm{Pz}$} & $\begin{array}{l}\text { Letters + Letter } \\
\text { (Repetition) }\end{array}$ & -0.29 & 1.86 & -0.72 & 21 & 0.48 & -.16 \\
\hline & $\begin{array}{l}\text { Letter + Letter } \\
\text { (Vowel) }\end{array}$ & -0.74 & 2.55 & -1.35 & 21 & 0.19 & -.3 \\
\hline & $\begin{array}{l}\text { Word + Word } \\
\text { (Repetition) }\end{array}$ & -1.21 & 2.42 & -2.34 & 21 & 0.03 & -.52 \\
\hline & $\begin{array}{l}\text { Word + Word } \\
\text { (Pseudo Word) }\end{array}$ & 0.21 & 2.07 & 0.49 & 21 & 0.63 & -.11 \\
\hline
\end{tabular}


The following figures show the different topographies for the different conditions (rhyme vs. non-rhyme):13) letter repetition 14) letter $\rightarrow$ vowel 15) word repetition16) word/pseudo-word.
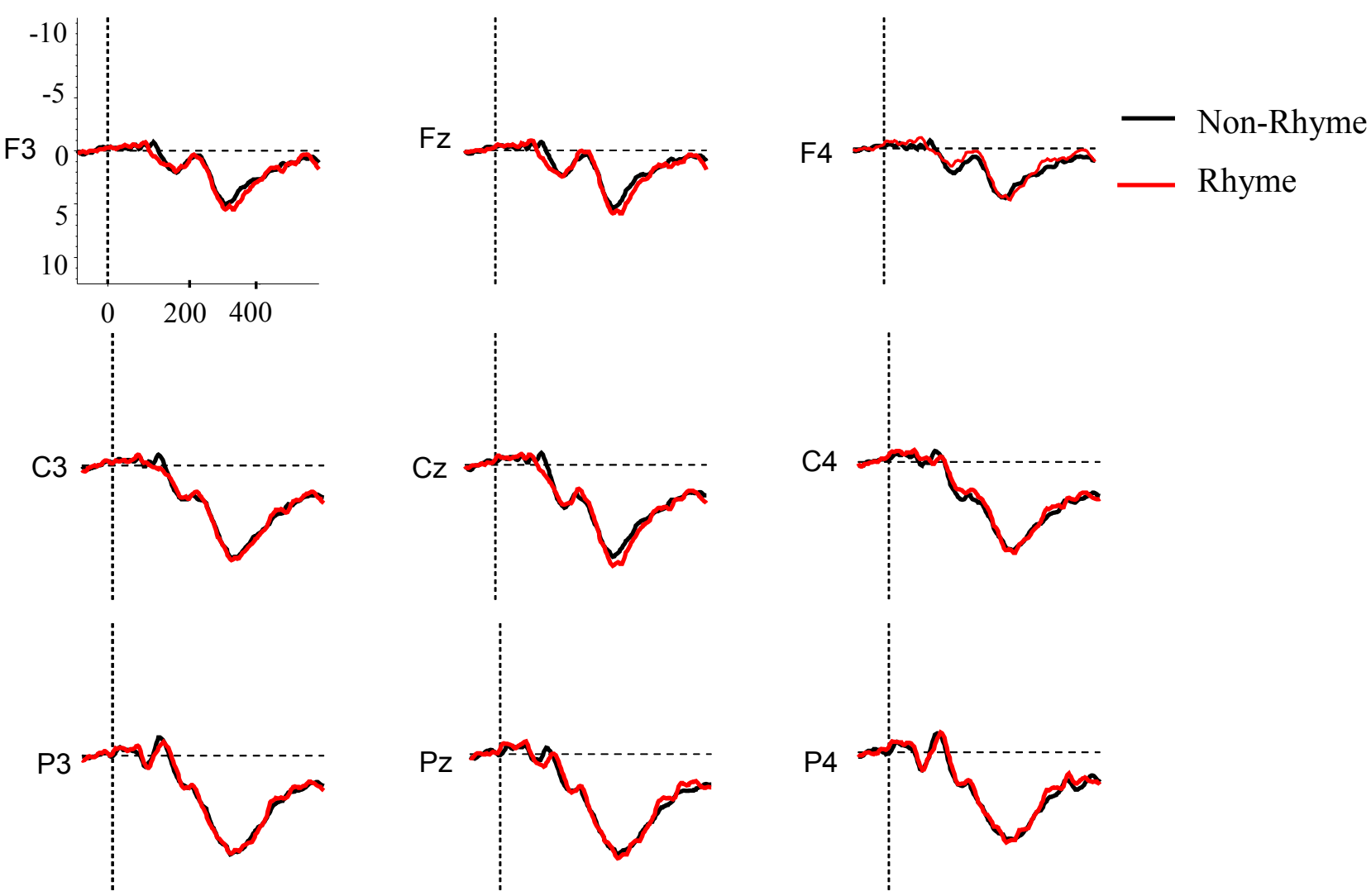

Figure 13: ERPs for the Condition Letter (repetition). No topographical maps are displayed, because no further information can be acquired from it. 


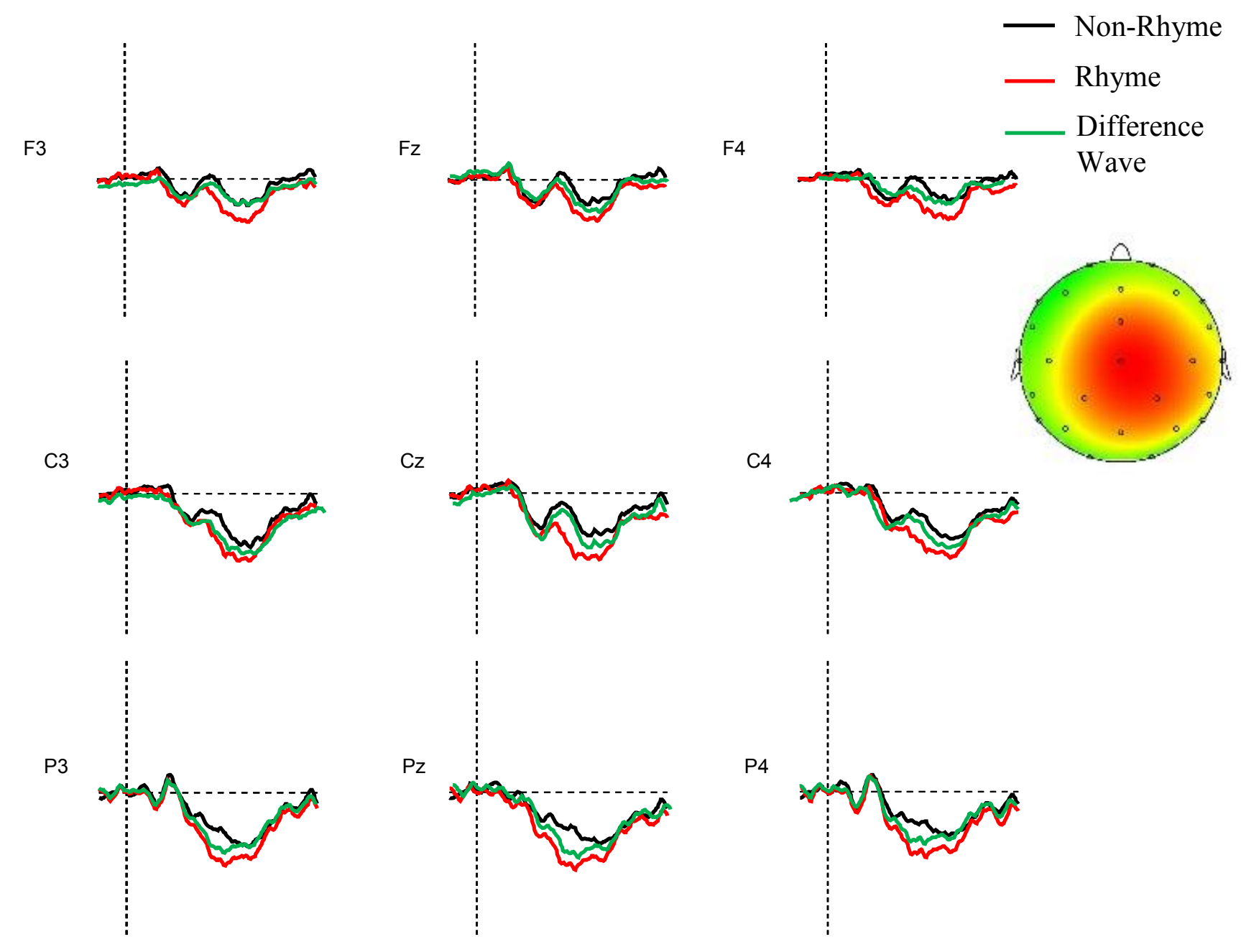

Figure 14: ERPs for the Condition Letter (vowel) and topographical map (430-480 ms). 


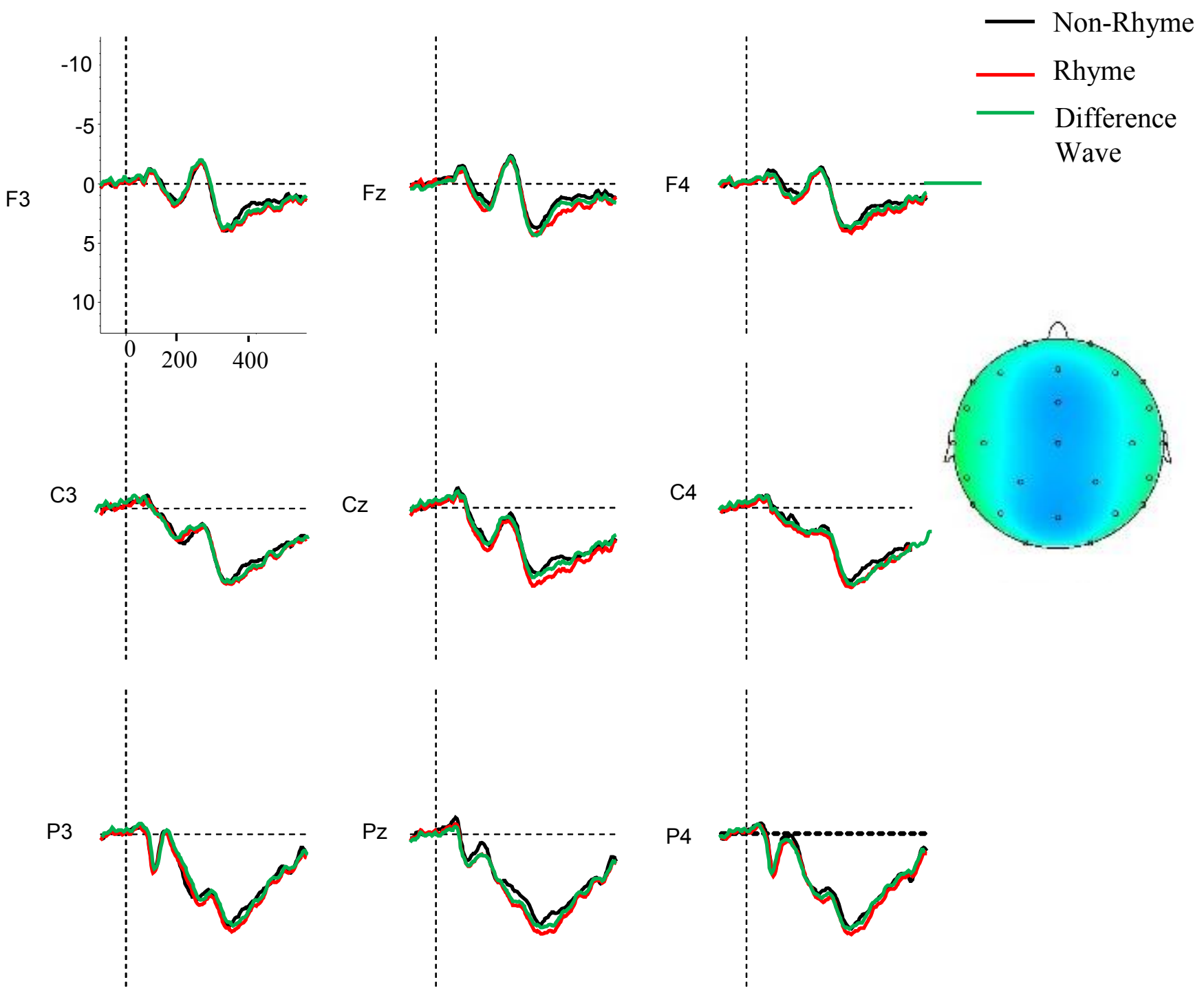

Figure 15: ERPs for the Condition Word (repetition) and top topographical map (430-480 ms). 


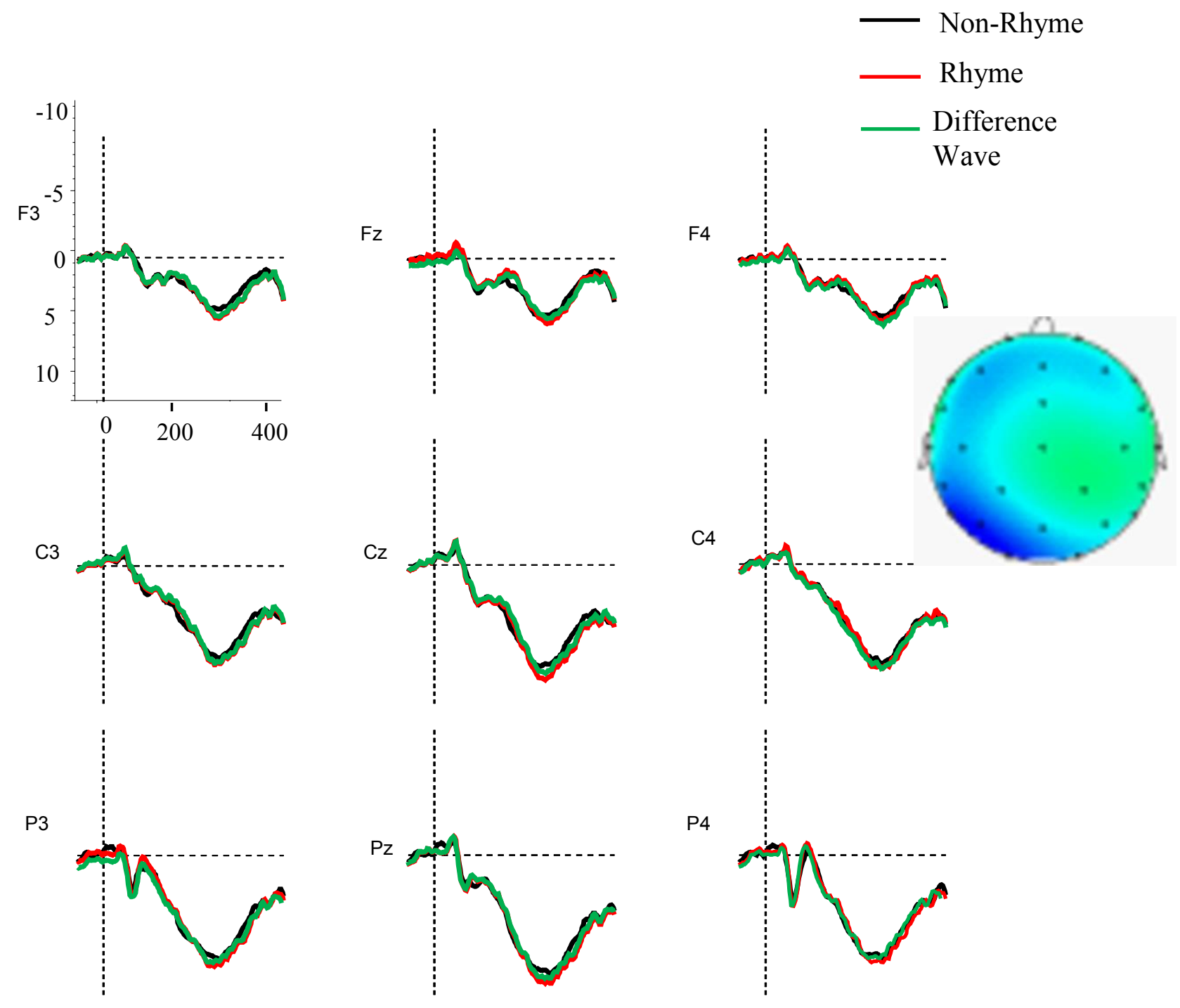

Figure 16: ERPs for the Condition Word (Pseudo-Word) and topographical map (410-460 ms).

For the conditions "letter" and "vowel" there was an marginal significant difference between rhyme vs. non-rhyme $\left(\mathrm{F}_{(1,21)}=3.95 ; p<.1, \eta^{2}=.16\right)$. There was a highly significant main effect for ELECTRODE $\left(\mathrm{F}_{(1,21)}=15.64 ; p<.01, \eta^{2}=.43\right)$. The interaction RHYME x ELECTRODE was also significant $\left(\mathrm{F}_{(1,21)}=4.25 ; p<.05, \eta^{2}=.17\right)$.

The phonological mapping hypothesis states that the left-lateralization of the N170-component depends on the degree of phonological processing. Thus, it was hypothesized that the N170 amplitude should be more left-lateralized in the single letter, detect vowel-condition (block 2) compared to the single letter, detect repetition condition (block 1). This hypothesis rests on the assumption that the single letter, detect vowel and the words conditions require more phonological processing compared to the respective control conditions. In line with this 
reasoning, the present result showed that the $\mathrm{N} 450$ rhyme effect at $\mathrm{FCz}$ (or $\mathrm{Cz}$ ) is larger for the single letter, detect vowel condition relative to the single letter, detect repetition condition and for the words, detect word repetition condition relative to the word, detect pseudo-word condition.

\section{The N170-amplitude reflects specialization for letter and word processing}

To confirm that the N170 reflects specialization for print processing, the present study compared the amplitude of the N170 for single letters with single symbols and for words with symbol strings, respectively.

A three-way ANOVA with the factors ELECTRODE (P7, P8) x CONDITION (6) x RHYME (2) yielded a non-significant three-way interaction $\left(\mathrm{F}_{(5,105)}=1.24, p=.301, \eta^{2}=.06\right)$. The twoway interactions ELECTRODE x CONDITION $\left(\mathrm{F}_{(5,105)}=4.36, p<.01, \eta^{2}=.17\right)$ and CONDITION

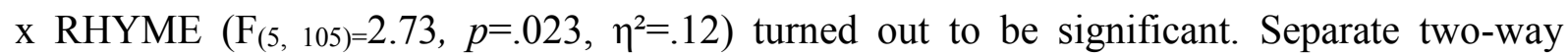
ANOVAs for P7 and P8 electrodes were computed to better understand the nature of the twoway interactions. For P7, the two-way ANOVA CONDITION (6) x RHYME (2) yielded significant results $\left(\mathrm{F}_{(5,105)}=3.55, p=.01, ; \eta^{2}=0.58\right)$. Furthermore, main effects of CONDITION $\left(\mathrm{F}_{(5,105)}=13.07, p<.01 ; \eta^{2}=1.12\right)$ and $\operatorname{RHYME}\left(\mathrm{F}_{(1,21)}=9.88, p<.01 ; \eta^{2}=0.97\right)$ were obtained. For $\mathrm{P} 8$, there were significant main effects for $\operatorname{CONDITION}\left(\mathrm{F}_{(5,105)}=3.35, p=.02 ; \eta^{2}=.57\right)$, as well as $\operatorname{RHYME}\left(\mathrm{F}_{(1,21)}=16.4, p=.003 ; \eta^{2}=.82\right) \quad$.

Several post-hoc $t$-tests were carried out, without alpha accumulation correction (Perneger, 1998). N170-amplitude of single letters (blocks 1 and 2, respectively) was compared with N170-amplitude of single symbols (block 6) and N170-amplitude for words (blocks 3 and 4, respectively) were compared with N170-amplitude for symbol strings (block 5). 
Table 7: T-tests for comparing different blocks. Linguistic stimuli vs. non- linguistic stimuli (rhyme condition).

\begin{tabular}{|c|c|c|c|c|c|c|}
\hline & & $\begin{array}{l}\text { T- } \\
\text { value }\end{array}$ & $d f$ & $\begin{array}{l}p(2- \\
\text { tailed })\end{array}$ & Cohen's $d$ & Comparision \\
\hline Letters (rep.) & P7 & -3.4 & 21 & $<.01$ & -.76 & Letter $>$ Symbol \\
\hline $\begin{array}{l}\text { vs. Single } \\
\text { Symbol }\end{array}$ & P8 & -2.4 & 21 & .03 & -.54 & Letter $>$ Symbol \\
\hline Letter (Vowel) & P7 & -4.3 & 21 & $<.01$ & -.96 & Letter $>$ Symbol \\
\hline $\begin{array}{l}\text { vs. Single } \\
\text { Symbol }\end{array}$ & P8 & -3.8 & 21 & $<.01$ & -.85 & Letter $>$ Symbol \\
\hline Words (rep.) & P7 & -4.04 & 21 & $<.01$ & -.9 & Word $>$ Symbol String \\
\hline $\begin{array}{l}\text { vs. Symbol } \\
\text { String }\end{array}$ & P8 & -1.4 & 21 & .18 & -.31 & $\begin{array}{l}\text { Word }>\text { Symbol } \\
\text { Strings } \\
\text { (not significant) }\end{array}$ \\
\hline Word (Pseudo) & P7 & -4.7 & 21 & $<.01$ & .94 & Pseudo $>$ String \\
\hline $\begin{array}{l}\text { vs. Symbol } \\
\text { String }\end{array}$ & P8 & -2.8 & 21 & .04 & -.63 & Pseudo $>$ String \\
\hline
\end{tabular}

Table 8: T-tests for comparing different blocks. Linguistic stimuli vs. non- linguistic stimuli (non-rhyme condition).

\begin{tabular}{|c|c|c|c|c|c|c|}
\hline & & $\begin{array}{l}\text { T- } \\
\text { value }\end{array}$ & $d f$ & $\begin{array}{l}p(2- \\
\text { tailed })\end{array}$ & Cohens $d$ & Comparision \\
\hline \multirow{2}{*}{$\begin{array}{l}\text { Letters (rep.) } \\
\text { vs. Single } \\
\text { Symbol }\end{array}$} & P7 & -2.04 & 21 & .05 & -.46 & $\begin{array}{l}\text { Letter }>\text { Symbol } \\
\text { (not significant) }\end{array}$ \\
\hline & P8 & 0.51 & 21 & .61 & .11 & $\begin{array}{l}\text { Letter }>\text { Symbol } \\
\text { (not significant) }\end{array}$ \\
\hline Letter (Vowel) & P7 & -3.5 & 21 & $<.01$ & -.78 & Letter $>$ Symbol \\
\hline $\begin{array}{l}\text { vs. Single } \\
\text { Symbol }\end{array}$ & P8 & -0.5 & 21 & .66 & -.11 & $\begin{array}{l}\text { Letter }>\text { Symbol } \\
\text { (not significant) }\end{array}$ \\
\hline Words (rep.) & P7 & -5.4 & 21 & $<.01$ & -.92 & Word $>$ String \\
\hline $\begin{array}{l}\text { vs. Symbol } \\
\text { String }\end{array}$ & P8 & -2.1 & 21 & .05 & -.47 & $\begin{array}{l}\text { word }>\text { Symbol Strings } \\
\text { (not significant) }\end{array}$ \\
\hline Word (Pseudo) & P7 & -6.4 & 21 & $<.01$ & -.96 & Pseudo $>$ String \\
\hline $\begin{array}{l}\text { vs. Symbol } \\
\text { String }\end{array}$ & P8 & -1.9 & 21 & .07 & -.42 & $\begin{array}{l}\text { Pseudo }>\text { String } \\
\text { (not significant) }\end{array}$ \\
\hline
\end{tabular}


The results of the tables (Table 8 and Table 9) show especially for the rhyme condition that linguistic stimuli evoke a larger N170 amplitude compared to non-linguistic stimuli. Letters and words are processed similarly.

\section{Is the N170 component left lateralized for phonological processing?}

To test the hypothesis of a stronger left-lateralization of N170-amplitude with increasing phonological processing, absolute mean amplitudes of the N170 component were analyzed by comparing the letter condition at P7 vs. P8. T-tests showed that there are no laterality differences for any condition, neither for rhyming nor for non-rhyming stimuli.

As alternative to compute total mean amplitudes, it is also possible to determine a lateralization index. This index (Table 9) was computed for relevant conditions by the following method: i.e. two different sub-indices were computed by the following equation: [P7(letter) - P7 (symbol)] and [P8(letter) - P8 (symbol)]. Those indices (P7 and P8) were then compared in a t-test. 
Table 9: Multiple T-tests to compare the differences in laterality N170 index between stimuli for the rhyme condition.

\begin{tabular}{|c|c|c|c|c|}
\hline N170 Index & T-value & $d f$ & $p$ (2-tailed) & Cohen's $d$ \\
\hline $\begin{array}{l}\text { P7(Letters)-P7(Symbol) } \\
\text { vs. } \\
\text { P8 (Letters) -(P8 Symbol) }\end{array}$ & -0.73 & 21 & .48 & -.15 \\
\hline $\begin{array}{l}\text { P7(Letters/Vowel)-P7(Symbol) } \\
\text { vs. } \\
\text { P8 (Letters/Vowel) - } \\
\text { (P8 Symbol) }\end{array}$ & -.78 & 21 & .44 & -.17 \\
\hline $\begin{array}{l}\text { P7(Word/Rep)- } \\
\text { P7(Symbol Strings) } \\
\text { vs. } \\
\text { P8 (Word/Rep) - } \\
\text { P8 (Symbol Strings) }\end{array}$ & -1.7 & 21 & .09 & -.36 \\
\hline $\begin{array}{l}\text { P7(Pseudo Word)-P7(Symbol } \\
\text { Strings) vs. } \\
\text { P8 (Pseudo Word) -(P8 Symbol } \\
\text { Strings) }\end{array}$ & -2.4 & 21 & $.03 *$ & -.51 \\
\hline
\end{tabular}

Table 10: Multiple T-tests to compare the differences in laterality N170 index between stimuli for the non-rhyme condition.

\begin{tabular}{lllll}
\hline N170 Index & T-value & $d f$ & $p$ (2-tailed) & Cohen's $d$ \\
\hline P7(Letters)-P7(Symbol) & -2.3 & 21 & .03 & -.49 \\
vs. & & & & \\
P8 (Letters) -(P8 Symbol) & & & & \\
& & & & -.58 \\
P7(Letters/Vowel)-P7(Symbol) vs. & -2.7 & 21 & .01 & \\
P8 (Letters/Vowel) - & & & & -.69 \\
(P8 Symbol) & & & & \\
P7(Word/Rep)- & -2.8 & 21 & .01 & \\
P7(Symbol Strings) & & & & \\
vs. & & & & -.81 \\
P8 (Word/Rep)- \\
P8 (Symbol Strings)
\end{tabular}


Multiple t-tests showed that for the rhyme condition a marginal tendency towards significance for [P7(Word/Rep)- P7(Symbol Strings) vs. P8 (Word/Rep) -P8 (Symbol Strings)] and a significant difference between [P7(Pseudo Word)-P7(Symbol Strings) vs. P8 (Pseudo Word) (P8 Symbol Strings)] (see Table 9). For non-rhyme multiple t-tests revealed significant differences for all conditions (see Table 10).

Figure 17 shows an overview of the electrodes for the conditions letter (repetition), letter (vowel) and single symbol and Figure 18 for the conditions words, pseudo-words and symbol strings.
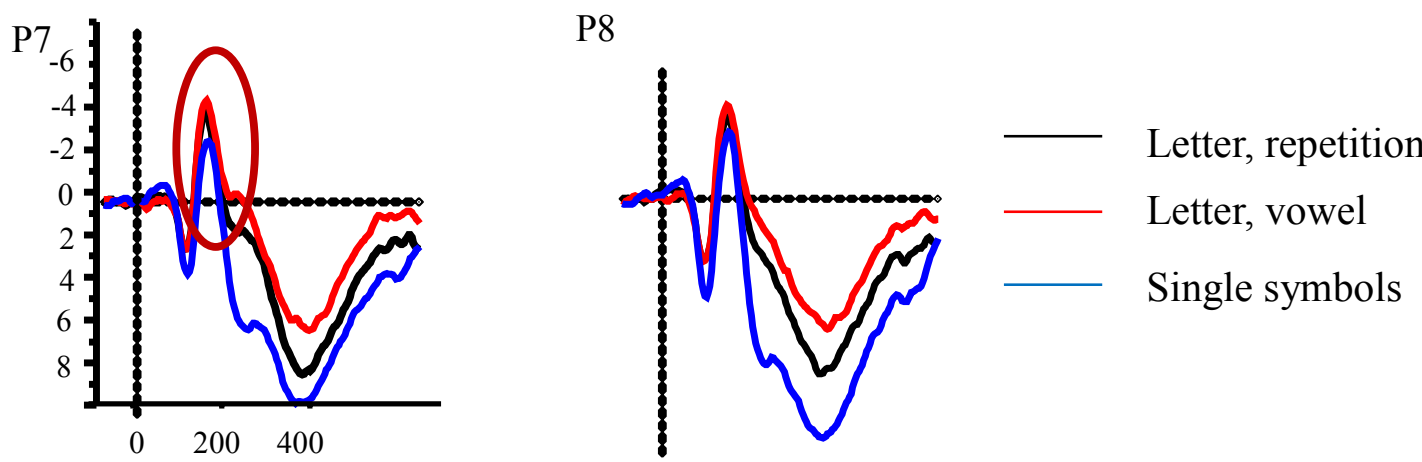

Figure 17: N170 component for letters (repetition, vowels) vs. single symbols.

P7

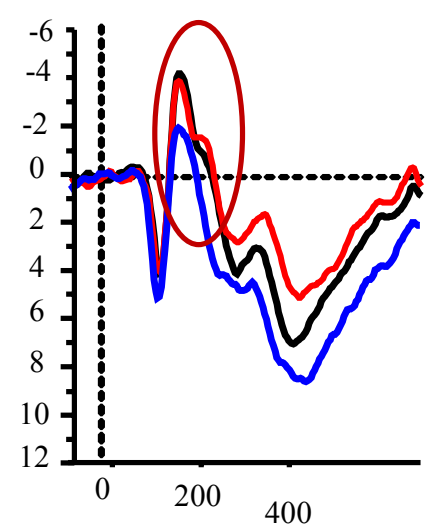

P8

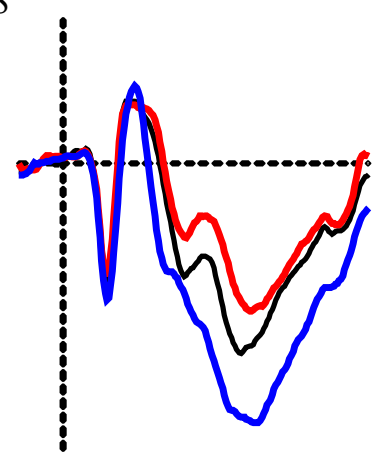

Words

Pseudo-words

Symbol strings

Figure 18: The N170 component for words, pseudo-words vs. symbol strings. 
The results verify only a part of the hypothesis: for rhymes, the N170 index has a tendency for a larger amplitude difference for words (rep.) vs. symbol stings and pseudo-words vs. symbol strings are clearly left lateralized, while for non-rhyme the N170 index shows more /also significant effects in the non-rhyme conditions (for all stimuli).

\subsubsection{Correlation of Reading Tests and N170 and N450}

\subsection{Saarbrücker Reading Test}

The mean of the general reading time of all participants was 318 seconds $(S D=57.9)$ with a range between 235 to 435 seconds. The mean of all mistakes which were made over all six texts was 16.2 mistakes $(S D=9.4$; range: 3 to 44$)$.

\subsection{Salzburger Reading Test}

The mean reading time of finished items in the Salzburger Reading Test for all participants was $61.7 \mathrm{~s}$ ( $S D=10.9$; range: 38-77). The Salzburger Reading Test is aiming at reading comprehension. Therefore, the Saarbrücker Reading Tests was additionally used for reading speed measures.

\subsection{Correlation of the N450 Amplitude with Reading Speed}

There were no significant correlations with the N450 amplitude-index at electrodes $\mathrm{FCz}, \mathrm{Cz}$ and CP2 with the Saarbrücker Reading Test.

\subsection{Correlation of the N170-Lateralization Index with Reading Speed}

In the Saarbrücker Reading Texts, there were negative correlations for the letter (vowel) condition $(r=-.48, p<.03)$ and the pseudo-word condition $(r=-.5, p<.017)$. The correlation for words $(r=-.13)$ and letters (repetition) $(r=-.2)$ were not significant. 


\subsubsection{Discussion}

The purpose of the third study was to investigate if a stronger phonological activation is related to a left-lateralization of the word-specific N170 component. To this end, single letters, words and pseudo-words were presented and the degree of activation of phonological representations was manipulated by means of different task requirements. When participants were asked to respond to rhymes, phonological representations were activated to a larger degree. This is indicated by a larger N450-rhyme effect for single letters (vowel) that required a rhymejudgment compared to single-letters that required a detection of stimulus repetition. Hence, the experimental manipulation was successful: the conditions that were planned to evoke a stronger phonological activation actually produced enhanced activation. This was demonstrated by the N450 rhyme effect.

In the conditions in which a stronger phonological activation appeared, a possibly stronger left lateralized N170 could be either determined by a) an absolute amplitude or b) a difference amplitude (i.e. [letter/words - single symbol/symbol stings]. However, no stronger lateralization could be found for absolute amplitudes. For the difference amplitudes, findings were different: For rhymes there was only a significant left lateralization for pseudo-words and only a tendency of significance for words. For the non-rhyme condition, all stimuli exposed a significant left lateralization. The N170 showed the expected specialization for wordprocessing: The N170-amplitude was larger for single letters compared to single symbols and also larger for words and pseudo-words compared to symbol strings. However, the predictions of the phonological mapping hypothesis could not be supported by the data of the present study. In the following sections possible reasons for these discrepant findings are discussed.

\subsection{N450 - Rhyme Effect}

The experimental manipulation was successful: The manipulation triggered a stronger phonological activation and a clear N450 rhyme effect was evoked. For letters (vowel) and words there was a significant difference between rhyme and non-rhyme (more positive N450 for rhymes). For the letters (repetition) no N450 rhyme effect could be found, as expected. This finding is in line with other studies that investigated the N450 rhyme effect (Praamstra \& Stegeman, 1993; Wagensveld et al., 2012). Additionally, the present study shows that the N450 rhyme effect for letters (vowel) is mainly limited to the medial posterior electrodes FCz, C3, $\mathrm{C} 4$ and $\mathrm{CP} 2$. These results show that the activation is rather centro-parietal and slightly rightlateralized, which is in line with studies about processing visual stimuli with regard to rhyming 
and non-rhyming letters (Coch, George et al., 2008; Coch, Hart et al., 2008). In the word condition, the present study found a stronger activation at the electrodes $\mathrm{FCz}, \mathrm{Cz}$ and $\mathrm{Pz}$ for rhymes which was also found by previous studies (Wagensveld et al., 2012; Wagensveld et al., 2013). At the electrodes C4, CP1 and CP2 the effect was marginally significant, which could be due to the small sample size. For pseudo-words there was no difference in amplitudes in the N450 for rhyme vs. non-rhyme.

One reason why the present study did not produce a rhyme effect for pseudo-words might be that the participants could come up with a strategy which did not require pseudo-word reading. Importantly, these findings indicate that phonological processing is engaged to a larger degree in the conditions requiring vowel detection or the detection of pseudo-words between real words, respectively.

\subsection{N170 component}

The present study confirms that the N170 of words and single letters is specific, which is demonstrated by the significant difference of letters/words vs. single symbols/symbol strings. The result replicates and extends a series of previous studies (Appelbaum, Liotti, Perez, Fox, \& Woldorff, 2009; Bentin et al., 1996; Cohen et al., 2002; Maurer et al., 2008; EberhardMoscicka, Jost, Fehlbaum, Pfenninger, \& Maurer, 2016). To the best of my knowledge, this is the first study that shows that single letter processing is similar to word processing with respect to phonological processing as indexed by the N170 in adult proficient German readers.

\subsection{Does the Left-Lateralization of the N170 depend on the automatic activation of phonological Representations?}

For the rhyme condition, a relative left lateralization of the N170 for pseudo-words was detected and for words (repetition) a low tendency for a relative left lateralization was found. Surprisingly, after separating the rhyme and non-rhyme conditions statistically, more significant effects for non-rhyme compared to rhyme with regard to the left lateralization were found. For the non-rhyme condition there were significant differences for all stimuli (letter/rep, letter/vowel, words/rep and word/pseudo-words). The results indicate that rhyming and nonrhyming stimuli are primarily found to be left lateralized- despite of rhyming. Thus, the present study demonstrates that letters, words and pseudo-words might predominantly evoke a left lateralized activity. Studies combining fMRI with MEG (Dale et al., 2000) and EEG (Cohen et 
al., 2000) support the view that the word N170 originates predominantly from left inferior occipito-temporal regions, also known as the visual word form area. As there was no left lateralization for the rhyming condition for other stimuli than words (repetition) and pseudowords, other studies did not find a left lateralization either: according to Stevens et al. (2013) a right-lateralization of the N170 to single letters would be expected, which is localized bilaterally

- compared to symbols. For the processing of the letter (vowel) condition there is no leftlateralization or relative left-lateralization of the N170. The result of this study is not in line with Stevens et al. (2013), because they hypothesize that there is a stronger phonological activation in letter processing, as proposed by the phonological mapping hypothesis (Maurer \& McCandliss, 2007a).

One reason for the lack of a left-lateralization of the N170 with increasing phonological demands could be that the participants were highly proficient readers (students). There could be a variation of the N170 over the life span of an individual. In children the N170 lateralization begins to specify (to the left hemisphere). Possibly, in the course of the automatization process of reading the left lateralization of the N170 disappears. This could also be true for very proficient readers compared to children and readers that do not have that extent of reading practice. The condition letter (vowel) successfully elicited a phonological activation: a rhyming effect was found but no lateralization for the relevant stimuli. At this point of time no further studies investigated reading proficiency in regards of left lateralization of the N170 and its relation to phonological activation. A future experimental design would be necessary to study children and less proficient readers that represent a typical sample.

\section{Other reasons for a missing $\mathbf{N 1 7 0}$ left lateralization in rhyming}

Literature delivers very heterogenic evidence. We cannot be sure that reading proficiency is related with the $\mathrm{PMH}$. There are multiple causes why the study is only adding more confirmation to the heterogeneity of evidence. Different languages may lead to different causes of left lateralization because the visual characteristics of words differ immensely between the languages. Varga, Tóth, and Csépe (2018) highlight that there could be a) visual similarities in words in the lexicon, and b) that there is the need to decompose a word input into its letters/graphemes for the grapheme - phoneme conversion during learning to read. Varga et al. (2018) also mention, that the one-sided nature of visual N170 experiments does not allow wellgrounded conclusions about the underling developmental process of N170 effects. In the present study we have the limitation of a small and non-representative sample: participants were 
very proficient in reading (students). Another reason could be the variety of paradigms: different paradigms and methods lead to different ERPs or laterality effects.

One other problem seems to be the publication bias: a literature search with terms, such as "Phonological Mapping Hypothesis and N170" only studies that found evidence for the PMH are listed (Eberhard-Moscicka et al., 2016; Emmorey, Midgley, Kohen, Sehyr, \& Holcomb, 2017; Hsu, Tsai, Lee, \& Tzeng, 2009; Sacchi \& Laszlo, 2016; Varga et al., 2018). Studies that resulted in non-conforming evidence have probably not been published.

\subsection{Relation between the N170 lateralization and the N450 rhyme effect}

The present study could not replicate the results of Stevens et al. (2013), who found that the relative lateralization of the N170 correlates with the N450 rhyme component. Stevens et al. (2013) found a bilateral activation of the N170 for the letter processing and also a rhyme-effect of the N450 for letters. The present study could not give supporting evidence for the N450 for letters (repetition), which are the same stimuli as in Stevens et al. (2013). This might be due to the stimulus material or the language differences.

\subsubsection{Correlation of the Reading Speed with the N170 and N450 component}

There was no correlation of the N450 rhyme component with the reading speed. A conclusion could be that the differentiation between rhyme and non-rhyme does not require powerful phonological processing. Additionally, the correlation of the reading speed (Saarbrücker Reading Test) with the laterality index of the N170 for words (repetition) and pseudo-words was significant. This part of the results is confirming the findings from Maurer and McCandliss' studies: the phonological mapping hypothesis can explain the expertise in (fast) reading with the N170 component. The correlation of the reading speed did not get significant for letters (repetition) or words. Other evidence was not yet contributed to this field of research.

Thus, the phonological mapping hypothesis could not be confirmed in this study. The hypothesized correlation of the laterality index of the N170 with the reading speed and a hypothesized correlation of the N450-rhyme component with the reading speed could not be verified. 
Table 11: Overview of the correlations of the mean habitation index (Difference_N170) and the reading tests: Note: the amplitude difference was taken from amplitude of Block A minus Block B.

\begin{tabular}{lllll}
\hline & & $\begin{array}{l}\text { Diff_N170 } \\
\text { Letters }\end{array}$ & $\begin{array}{l}\text { Diff_N170 } \\
\text { Words }\end{array}$ & $\begin{array}{l}\text { Diff_N170 } \\
\text { Pseudo- } \\
\text { words }\end{array}$ \\
\hline $\begin{array}{l}\text { Saarbrücker } \\
\text { Reading Test }\end{array}$ & $\begin{array}{l}\text { Correlation } \\
\text { Pearson }\end{array}$ & .004 & -.002 & -.046 \\
& $\begin{array}{l}p \text {-value } \\
\text { (2-tailed) }\end{array}$ & .982 & .990 & .779 \\
\hline $\begin{array}{l}\text { Salzburger } \\
\text { Reading Test }\end{array}$ & $\begin{array}{l}\text { Correlation } \\
\text { Pearson }\end{array}$ & .111 & -.270 & -.046 \\
& $\begin{array}{l}p \text {-value } \\
(2-\text { tailed })\end{array}$ & .497 & .091 & .778 \\
\hline & & & & \\
\hline
\end{tabular}

\subsubsection{General Discussion}

In the first two studies massive repetition was used to analyze habituation in children and adults to study the extent of reading automatization. In adults, a habituation of the N170 component and a left lateralization tendency for words and pseudo-words for fast readers and slow readers was observed, but there was only a significant difference for left lateralization specialization for fast readers (for pseudo-words). Children did not show any habituation (N170 amplitude difference between Block A and Block B) or lateralization effects.

Taken together, the present studies were conducted to investigate whether the habituation of the N170 component is a possible marker for the reading ability or even reading problems in adults (study 1) and in children (study 2). Only visual inspection showed a quick habituation in adults which shows the automatization of reading in general. Nevertheless, there was no correlation between reading speed and habituation of the ERP signal between fast and slow readers. Contrarily, amplitudes in children did not show such habituation of the ERPs, which demonstrates that the reading system has not automatized and developed yet. This result demonstrates that children - even when they already learned to read ( for 2 to 3 years) - do not have a neuronal established reading network that is as automatized and solid as in adults. They still need experience and practice in reading in order to develop the ERP patterns of adults. 
As mentioned before, a limitation of the adult study is the low variance of the reading performance of the participants. Additionally, further studies with a group with kindergarten children and students (also 2nd grade) with dyslexia are needed to compare the reading performance. Furthermore, it is also possible to use different analysis methods such as using the technique of moving averages or a single trial analysis.

Study 1 and study 2 investigated the N170 as a biological marker of reading problems. However, results demonstrate that the habituation of the N170 component is not suited as such a marker for reading problems as it cannot distinguish between a fast vs. slow reading performance in adults (or even reading problems in adults or children). The third study aimed to demonstrate that the left hemisphere is predominantly involved in phonological processing which is reflected by a larger left N170 amplitude. It could only be confirmed that the N450 amplitude for the rhyme condition is more positive than for the non-rhyme condition. This is true for letters (vowel) and words (repetition). For the non-rhyme condition all stimuli yielded a left-lateralization (difference amplitude). A left lateralization of the N170, depending on the extent of the automatic activation of phonological representations, could only be proven partially.

Likewise, the correlation between the laterality index of the N170 and the N450-rhyme component could not be verified. The assumption, that highly proficient readers had stronger automatic activation of phonological representations, was found only to be true partly. The reading speed did not correlate with the N450 amplitude (rhyme vs. non-rhyme) and the laterality index of the N170 only correlated for letters (vowel) and pseudo-words with the reading speed.

The participants were high performing in reading (students). Those students have a small range with regard to their reading ability and they are very homogeneous in their socialization. In contrast to the general population they have advanced compensatory strategies in reading, they read often / daily and have to comprehend large amounts of texts which are additionally complex. Thus, the group of high performing students has a lot of practice in reading. The data showed a significant N450 rhyme effect (block 2) that implies a phonological activation. Nevertheless, the left lateralization of the N170 hypothesized by the phonological mapping hypothesis did occur partly. If the PMH is not true the phonological activation does not appear mainly in the left VWFA. Phonological processing seems to be a more distributed network than originally assumed by Maurer and McCandliss (2007a). 
The N170 reflects the perceptual expertise of special stimulus classes, in this specific case: the expertise of words. The mentioned expertise could not be as distinct as in adults yet for words. The latter interpretation is in line with the non-existent correlation of N170 habituation and the reading speed. It is also is line with the results of experiment three (phonological mapping hypothesis).

Generally, the data do not confirm the phonological mapping hypothesis, even though rhyming condition worked well, no overall lateralization could be found. One reason for the results could be the highly proficient reading sample, who were mainly high performing students.

\subsubsection{Conclusion}

In each of the three studies of the present thesis the N170 amplitude was supposed to serve as an index for different purposes: In the first two studies the habituation of the N170 amplitude served as an index for the ability to read. It was hypothesized that it could even be a marker for reading problems, such as dyslexia or even serve as a diagnostic instrument. In the third study, the N170 amplitude was supposed to be an index with regard to phonological processing/activation and whether it is linked with the left-lateralization of the N170 amplitude. In summary, the initial hypotheses could not be verified.

Nevertheless, the first two studies give important insights into habituation differences between children and adults. When children had two to three years of reading instructions at school, their reading system is not as specified and automatized as in adults, whose N170 amplitude habituate compared to the one of children's.

The third study showed that in high performing readers, such as students, phonological activation does not seem to be connected to the left VWFA, measured by the left-lateralized N170 amplitude. In contrast to the MMN, the N170 seems to be more fragile over life time, while the MMN is more constant.

The studies were important to understand the nature of the N170 and its relation to reading proficiency and to phonological activation (in regard to the left lateralization of the ERP). The studies scrutinized only a small part of the whole picture in order to find a) an index/marker for reading speed or even for reading problems like dyslexia and b) an index for the phonological processing and its consequences to the left lateralization of the N170 amplitude (phonological mapping hypothesis). A future prospect would be to test kindergarten children and less 
proficient adult readers for dissolving the question whether the N170 amplitude develops differently in these target groups.

To summarize, the N170 has been investigated intensively in the present thesis, but it could not be conclusively clarified if it stands for automatization processes of reading or for the extent of phonological processing/activation. In the conducted studies, it could not be dissolved if the latter is the case. The data indicate that the N170 is not suited as a biomarker for reading problems- neither the habituation, nor the left-lateralization of the N170. Nevertheless, they gave interesting insights into the nature of neurophysiological reading indices but still give scope for further research. 


\section{Appendix}

\subsection{Study 1 (N170-Adults)}

Table 12: Below the stimuli are depicted (standard and deviant). The task was to react to the deviant immediately.

\begin{tabular}{lll}
\hline Condition & Standard & Deviant \\
\hline Letter & a & c \\
Words & Preis & Spiel \\
Pseudo Word & Frand & Kleuf \\
Symbols & $\square \triangle \triangle \square \square$ & $\Delta \square Q \diamond \bigcirc$
\end{tabular}




\subsection{Study 2 (N170-Children)}

Table 13: Below the stimuli are depicted (standard and deviant). The task was to react to the deviant immediately.

\begin{tabular}{lll}
\hline Condition & Standard & Deviant \\
\hline Letter & A & C \\
Words & PREIS & SPIEL \\
Pseudo Word & FRAND & KLEUF \\
Symbol & & \\
\hline
\end{tabular}




\subsection{Study 3}

Table 14: Stimuli in Block 3 - Task: Reaction to word repetition.

\begin{tabular}{ll}
\hline $\mathrm{a}$ & Strand \\
$\mathrm{b}$ & Zeh \\
$\mathrm{c}$ & Tee \\
$\mathrm{d}$ & Fee \\
$\mathrm{e}$ & Klee \\
$\mathrm{f}$ & Knall \\
$\mathrm{g}$ & See \\
$\mathrm{h}$ & Sand \\
$\mathrm{i}$ & Schiff \\
$\mathrm{j}$ & Mann \\
$\mathrm{k}$ & Wund \\
\hline
\end{tabular}

\begin{tabular}{ll}
\hline $\mathrm{l}$ & Boot \\
$\mathrm{m}$ & Frau \\
$\mathrm{n}$ & Haus \\
$\mathrm{o}$ & Schutt \\
$\mathrm{p}$ & Dreh \\
$\mathrm{s}$ & Seil \\
$\mathrm{t}$ & Schnee \\
$\mathrm{u}$ & Bahn \\
$\mathrm{v}$ & Baum \\
$\mathrm{w}$ & Reh \\
$\mathrm{z}$ & Tier \\
\hline
\end{tabular}

Table 15: Stimuli in Block 4 - Task: Reaction to pseudo-words.

\begin{tabular}{ll}
\hline $\mathrm{p}_{\mathrm{a}}$ & Gnee \\
$\mathrm{p}_{\mathrm{b}}$ & Pfahr \\
$\mathrm{p}_{\mathrm{c}}$ & Niff \\
$\mathrm{p}_{\mathrm{d}}$ & Tutt \\
$\mathrm{p}_{\mathrm{e}}$ & Tiek \\
$\mathrm{p}_{\mathrm{f}}$ & Kreh \\
$\mathrm{p}_{\mathrm{g}}$ & Schrall \\
\hline
\end{tabular}


Table 16: Stimuli of Block 5 - Task: Reaction on the repetition of the symbol strings.

\begin{tabular}{|c|c|c|c|}
\hline & \multirow[b]{2}{*}{ \#*\&\%§ } & \multirow[b]{2}{*}{1} & \multirow[b]{2}{*}{ \#* §* } \\
\hline a & & & \\
\hline b & $* \&) \S /$ & $\mathrm{m}$ & $* \# * \%$ \\
\hline $\mathrm{c}$ & \#\#)\& & $\mathrm{n}$ & $\S \S / *$ \\
\hline d & $\sim \mid \& \%\}$ & o & \&?\#\#* \\
\hline e & $\&()$ & $\mathrm{p}$ & $\% \% \S$ \\
\hline $\mathrm{f}$ & $\{\S ! /)$ & $\mathrm{S}$ & $\sim$ \#\% \\
\hline $\mathrm{g}$ & $\sim ? / \%$ & $\mathrm{t}$ & $* \# \%$ \\
\hline $\mathrm{h}$ & $\#^{*} \sim \backslash \&$ & $\mathrm{u}$ & $/ \& \% \S$ \\
\hline $\mathrm{i}$ & $* \# \# \S$ & $\mathrm{v}$ & )$(\& \%$ \\
\hline $\mathrm{j}$ & $\S \% \& /$ & w & $\S \S ? !$ \\
\hline $\mathrm{k}$ & \#\&\&!? & $\mathrm{z}$ & $? /)(\&$ \\
\hline
\end{tabular}


Table 17: Stimuli in Block 6 - Task: reaction on the repetition of the single symbols
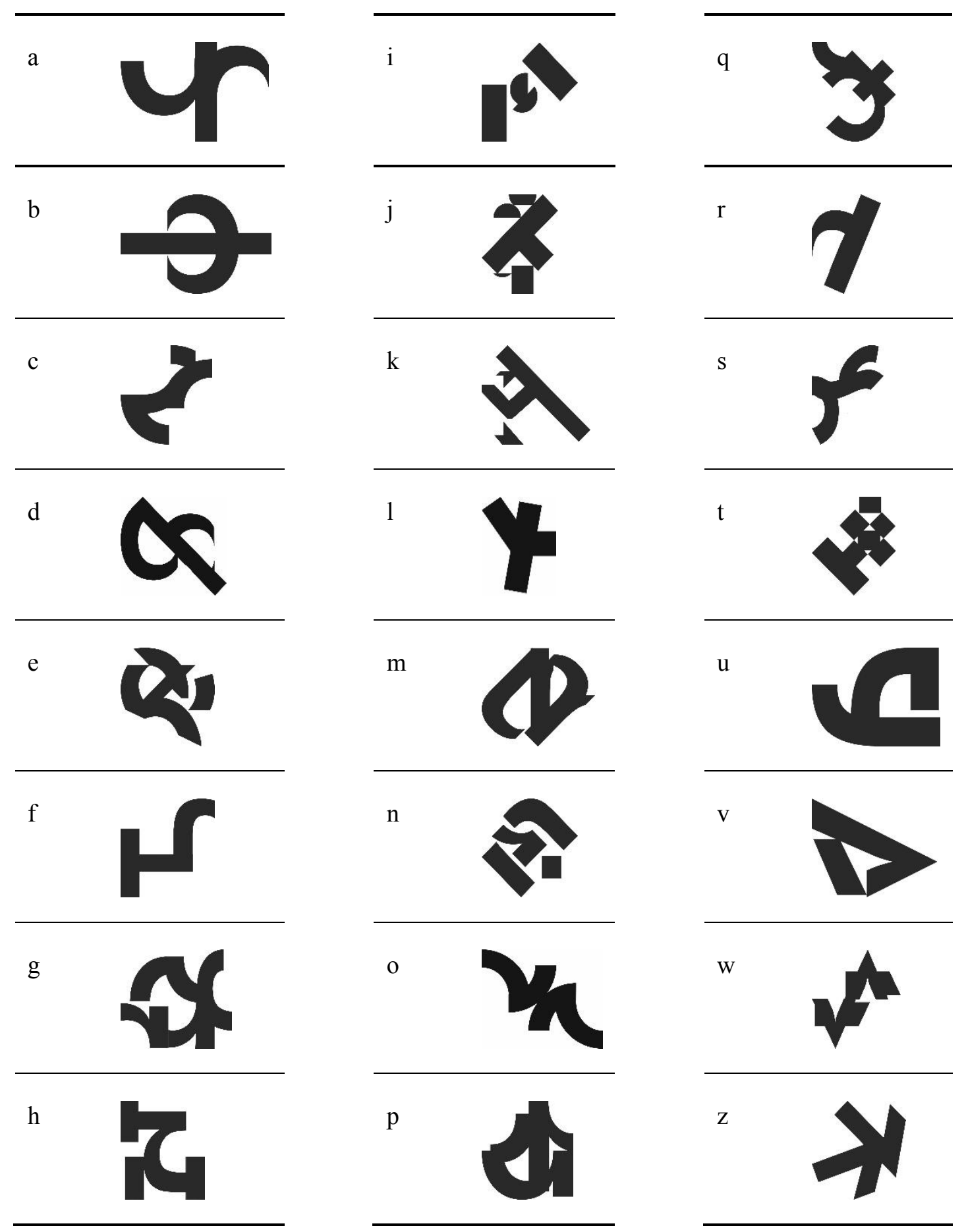


\section{A.1 List of Figures}

Figure 1: A schematic overview of some language-related ERPs.

Figure 2: Spatial-chronologically organization of the auditory sentence processing. On the right side of the time line the sentence processing model of Angela Friederici (Friederici, 2002) is depicted. On the left side, other language related ERPs and their function are summarized in regards to the time line. Figure adapted from Jäncke (2013), Lehrbuch Kognitive Neurowissenschaften, p.637.

Figure 3 left: Lateral view of the left hemisphere. The indicated area shows the position of the VWFA. Reprinted from list of brain pictures In Venngage. Retrieved January 29, 2018 from: https://infograph.venngage.com/p/212935/12-majorlandmarks-of-the-brain; Figure 3 right: Horizontal view of the brain, sight from beyond, again the VWFA is indicated by a red circle, please note that the VWFA is located below the cerebellum. Reprinted from a list of figures of the brain. Retrieved January 29, 2018 from:

https://faculty.washington.edu/chudler/gif/colorb9.gif.

Figure 4: Development of the N170 in kindergarten children and children and second graders. Reprinted from "Coarse neural tuning for print peaks when children learn to read" adapted figure of Maurer, 2006, NeuroImage, Volume 33 (2), $749-758$.

Figure 5: Approximated N170 amplitude over the life span based on publication by Maurer (2006). The amplitude probably rises until the age of $9 / 10$ years and then lowers with age.

Figure 6: Schematic view of one trial for adults. Children had shorter trials. One trial is programmed in three thirds (Block A, B \& C). The mean amplitudes of those 3 blocks enabled analyzing the habituation. In the following table the standards and the deviants are listed, which were put in for the placeholder that are displayed in the figure as "Standard or Deviant".

Figure 7: Graphic of the used electrodes (marked in fat script) ........................................ 42

Figure 8: Adults: ERPs of Fast and Slow Readers at Electrode Positions P7/P8................ 47

Figure 9: Children: ERPs at electrode positions P7/P8.

Figure 10: An example from the sequence of the condition material for task 1: Participants had to press a response key to an immediate repetition of a letter. Stimulus duration: $500 \mathrm{~ms}$, ISI: $500 \mathrm{~ms}$. 
Figure 11: Schematic figure of a trial (symbol strings displayed): Participants had to press a response key to an immediate repetition of a letter. Stimulus duration: 500 ms, ISI: $500 \mathrm{~ms}$

Figure 12: Symbol created symbol from a cut letter.

Figure 13: ERPs for the Condition Letter (repetition). No topographical maps are displayed, because no further information can be acquired from it.

Figure 14: ERPs for the Condition Letter (vowel) and topographical map (430-480 ms).. 73

Figure 15: ERPs for the Condition Word (repetition) and top topographical map (430$480 \mathrm{~ms})$.

Figure 16: ERPs for the Condition Word (Pseudo-Word) and topographical map (410$460 \mathrm{~ms})$. 75

Figure 17: N170 component for letters (repetition, vowels) vs. single symbols. 80

Figure 18: The N170 component for words, pseudo-words vs. symbol strings. 80

\section{A.2 List of Tables}

Table 1: Overview of effect sizes and studies in Bishop's review (2007).

Table 2: Overview over some recent studies (2007-2015) that examine the MMN in regards to reading or language problems. Note: $\mathrm{F}=$ frequency; $\mathrm{T}=$ temporal (non-speech); $\mathrm{S}=$ speech, *at least 1 dyslexic parent.

Table 3: Stimuli for adults and children.

Table 4: Mean Amplitudes for Letters, Words and Pseudo Words.

Table 6: Overview over the blocks, the used stimuli and the task/ instructions. 65

Table 7: T-test for the different electrodes and conditions: rhyme vs. non-rhyme:

Table 8: T-tests for comparing different blocks. Linguistic stimuli vs. non- linguistic stimuli (rhyme condition).

Table 9: T-tests for comparing different blocks. Linguistic stimuli vs. non- linguistic stimuli (non-rhyme condition).

Table 10: Multiple T-tests to compare the differences in laterality N170 index between stimuli for the rhyme condition.

Table 11: Multiple T-tests to compare the differences in laterality N170 index between stimuli for the non-rhyme condition. 
Table 12: Below the stimuli are depicted (standard and deviant). The task was to react to

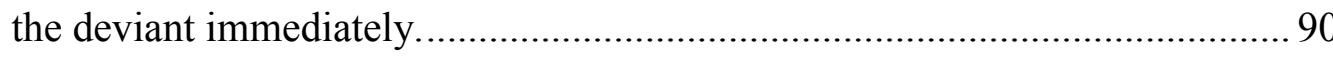

Table 13: Below the stimuli are depicted (standard and deviant). The task was to react to

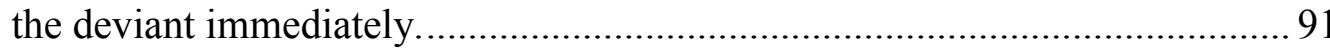

Table 14: Stimuli in Block 3 - Task: Reaction to word repetition.................................... 92

Table 15: Stimuli in Block 4 - Task: Reaction to pseudo-words...................................... 92

Table 16: Stimuli of Block 5 - Task: Reaction on the repetition of the symbol strings. .... 93

Table 17: Stimuli in Block 6 - Task: reaction on the repetition of the single symbols ...... 94

\section{A.3 List of Abbreviations}

ELAN Early Left Anterior Negativity

ERP Event Related Potential

MMN Mismatch Negativity

PMH Phonological Mapping Hypothesis

VWFA Visual Word Form Area 


\section{References}

Ackerman, P. T., Dykman, R. A., \& Oglesby, D. M. (1994). Visual event-related potentials of dyslexic children to rhyming and nonrhyming stimuli. Journal of Clinical and $\begin{array}{llll}\text { Experimental Neuropsychology, } & 138-154 .\end{array}$ https://doi.org/10.1080/01688639408402624

Aghababian, V., \& Nazir, T. A. (2000). Developing normal reading skills: Aspects of the visual processes underlying word recognition. Journal of Experimental Child Psychology, 76(2), 123-150. https://doi.org/10.1006/jecp.1999.2540

Ahmmed, A. U., Clarke, E. M., \& Adams, C. (2008). Mismatch negativity and frequency representational width in children with specific language impairment. Developmental Medicine \& Child Neurology, 50(12), 938-944. https://doi.org/10.1111/j.14698749.2008.03093.x

Association for Computational Linguistics (Ed.) (2013). Word surprisal predicts N400 amplitude during reading. : 878-883. Sofia. keien DOI oder ISBN vorhanden

Baldeweg, T., Richardson, A., Watkins, S., Foale, C., \& Gruzelier, J. (1999). Impaired auditory frequency discrimination in dyslexia detected with mismatch evoked potentials. Annals of Neurology, 45, 495-503. https://doi.org/10.1002/15318249(199904)45:4\%3C495::aid-ana11\%3E3.0.co;2-m

Barnea, A., Lamm, O., Epstein, R., \& Pratt, H. (1994). Brain potentials from dyslexic children recorded during short-term memory tasks. The International Journal of Neuroscience, 74, 227-237. https://doi.org/10.3109/00207459408987241

Bartha-Doering, L., Deuster, D., Giordano, V., Am Zehnhoff-Dinnesen, A., \& Dobel, C. (2015). A systematic review of the mismatch negativity as an index for auditory sensory memory: From basic research to clinical and developmental perspectives. Psychophysiology, 52(9), 1115-1130. https://doi.org/10.1111/psyp.12459

Bentin, S., Mouchetant-Rostaing, Y., Giard, M. H., Echallier, J. F., \& Pernier, J. (1999). ERP manifestations of processing printed words at different psycholinguistic levels: Time course and scalp distribution. Journal of Cognitive Neuroscience, 11, 235-260. https://doi.org/10.1162/089892999563373 
Bentin, S. (1987). Event-related potentials, semantic processes, and expectancy factors in word recognition. Brain and Language, 31(2), 308-327. https://doi.org/10.1016/0093934X(87)90077-0

Bentin, S. (1989). Electrophysiological studies of visual word perception, lexical organization, and semantic processing: A tutorial review. Language and Speech, 32, 205220. https://doi.org/10.1177/002383098903200302

Bentin, S., Allison, T., Puce, A., Perez, E., \& McCarthy, G. (1996). Electrophysiological Studies of Face Perception in Humans. Journal of Cognitive Neuroscience, 8(6), 551565. https://doi.org/10.1162/jocn.1996.8.6.551

Bergmann, J., Hutzler, F., Klimesch, W., \& Wimmer, H. (2005). How is dysfluent reading reflected in the ERP? Journal of Neurolinguistics, 18(2), 153-165. https://doi.org/10.1016/j.jneuroling.2004.11.004

Bishop, D. V. M. (2007). Using mismatch negativity to study central auditory processing in developmental language and literacy impairments: Where are we, and where should we be going? Psychological Bulletin, 133(4), 651-672. https://doi.org/10.1037/00332909.133.4.651

Boddy, J. (1986). Event-Related Potentials in Chronometric Analysis of Primed Word Recognition with Different Stimulus Onset Asynchronies. Psychophysiology, 23, 232245. https://doi.org/10.1111/j.1469-8986.1986.tb00624.x

Boltzmann, M., \& Rüsseler, J. (2013). Training-related changes in early visual processing of functionally illiterate adults: Evidence from event-related brain potentials. $B M C$ Neuroscience, 14, 154. https://doi.org/10.1186/1471-2202-14-154

Bonte, M. L., \& Blomert, L. (2004). Developmental dyslexia: Erp correlates of anomalous phonological processing during spoken word recognition. Brain Research. Cognitive Brain Research, 21(3), 360-376. https://doi.org/10.1016/j.cogbrainres.2004.06.010

Brandeis, D., Vitacco, D., \& Steinhausen, H. C. (1994). Mapping brain electric micro-states in dyslexic children during reading. Acta Paedopsychiatrica, 56, 239-247. PMID: 8079644

Breznitz, Z., \& Leikin, M. (2000). Syntactic processing of Hebrew sentences in normal and dyslexic readers: Electrophysiological evidence. The Journal of Genetic Psychology, 161(3), 359-380. https://doi.org/10.1080/00221320009596718 
Brunelliere, A., Hoen, M., \& Dominey, P. F. (2005). ERP correlates of lexical analysis: N280 reflects processing complexity rather than category or frequency effects. NeuroReport, 16(13), 1435-1438. https://doi.org/10.1097/01.wnr.0000177008.98860.69

Cao, F., Rickles, B., Vu, M., Zhu, Z., Chan, D. H. L., Harris, L. N., Perfetti, C. A. (2013). Early stage visual-orthographic processes predict long-term retention of word form and meaning: A visual encoding training study. Journal of Neurolinguistics, 26(4), 440-461. https://doi.org/10.1016/j.jneuroling.2013.01.003

Cao, X., Ma, X., \& Qi, C. (2015). N170 adaptation effect for repeated faces and words. Neuroscience, 294, 21-28. https://doi.org/10.1016/j.neuroscience.2015.03.009

Cao, X., Li, S., Zhao, J., Lin, S.'e., \& Weng, X. (2011). Left-lateralized early neurophysiological response for Chinese characters in young primary school children. Neuroscience Letters, 492(3), 165-169. https://doi.org/10.1016/j.neulet.2011.02.002

Cao, X.-H., Jiang, B., Li, C., \& He, Z.-Q. (2014). Rapid adaptation effect of N170 for printed words. Perceptual and Motor Skills, 119(1), 191-202. https://doi.org/10.2466/24.22.PMS.119c15z6

Chapman, R. M., McCrary, J. W., \& Chapman, J. A. (1978). Short-term memory: The "storage" component of human brain responses predicts recall. Science (New York, N.Y.), 202, 1211-1214. https://doi.org/10.1126/science.725596

Cheour, M., Ceponiene, R., Lehtokoski, A., Luuk, A., Allik, J., Alho, K., \& Näätänen, R. (1998). Nature Neuroscience, 1(5), 351-353. https://doi.org/10.1038/1561

Coch, D., George, E., \& Berger, N. (2008). The case of letter rhyming: An ERP study. Psychophysiology, 45(6), 949-956. https://doi.org/10.1111/j.1469-8986.2008.00701.x

Coch, D., Hart, T., \& Mitra, P. (2008). Three kinds of rhymes: An ERP study. Brain and Language, 104(3), 230-243. https://doi.org/10.1016/j.bandl.2007.06.003

Coch, D., Mitra, P., George, E., \& Berger, N. (2011). Letters rhyme: Electrophysiological evidence from children and adults. Developmental Neuropsychology, 36(3), 302-318. https://doi.org/10.1080/87565641.2010.549985

Cohen, J. (2013). Statistical Power Analysis for the Behavioral Sciences (2nd ed.). Hoboken: $\begin{array}{llll}\text { Taylor and from } & \text { Francis. }\end{array}$ http://gbv.eblib.com/patron/FullRecord.aspx?p=1192162 
Cohen, J., \& Polich, J. (1997). On the number of trials needed for P300. International Journal of Psychophysiology, 25(3), 249-255. https://doi.org/10.1016/S01678760(96)00743-X

Cohen, L., Dehaene, S., Naccache, L., Lehéricy, S., Dehaene-Lambertz, G., Hénaff, M.-A., \& Michel, F. (2000). The visual word form area. Brain, 123(2), 291-307. https://doi.org/10.1093/brain/123.2.291

Comerchero, M. D., \& Polich, J. (1999). P3a and P3b from typical auditory and visual stimuli. Clinical Neurophysiology, 110(1), 24-30. https://doi.org/10.1016/S01685597(98)00033-1

Cycowicz, Y. M., Friedman, D., \& Rothstein, M. (1996). An ERP developmental study of repetition priming by auditory novel stimuli. Psychophysiology, 33, 680-690. https://doi.org/10.1111/j.1469-8986.1996.tb02364.x

Dale, A. M., Liu, A. K., Fischl, B. R., Buckner, R. L., Belliveau, J. W., Lewine, J. D., \& Halgren, E. (2000). Dynamic Statistical Parametric Mapping. Neuron, 26(1), 55-67. https://doi.org/10.1016/S0896-6273(00)81138-1

Dambacher, M., Kliegl, R., Hofmann, M., \& Jacobs, A. M. (2006). Frequency and predictability effects on event-related potentials during reading. Brain Research, 1084(1), 89-103. https://doi.org/10.1016/j.brainres.2006.02.010

Deacon, D., Breton, F., Ritter, W., \& Vaughan, H. G., JR (1991). The relationship between N2 and N400: Scalp distribution, stimulus probability, and task relevance. Psychophysiology, 28, 185-200. https://doi.org/10.1111/j.1469-8986.1991.tb00411.x

Dehaene-Lambertz, G. (1997). Electrophysiological correlates of categorical phoneme perception in adults. NeuroReport, 8, 919-924. https://doi.org/10.1097/00001756199703030-00021

Donchin, E., \& Isreal, J. B. (1980). Event-related Potentials and Psychological Theory. In H. H. Kornhuber (Ed.), Progress in Brain Research: Vol. 54. Motivation, motor and sensory processes of the brain: electrical potentials, behaviour and clinical use: Proceedings of the 5th International Symposium on Electrical Potentials Related to Motivation Motor and Sensory Processes of the Brain (MOSS V) held at Ulm-Reisensburg May 14 - 181979 ; with 35 tables. International Symposium on Electrical Potentials Related to Motivation, Motor and Sensory Processes of the Brain (Vol. 54, pp. 697-715). Amsterdam: Elsevier North-Holland Biomedical Press. https://oi.org/10.1016/S00796123(08)61692-1 
Duncan, C. C., Rumsey, J. M., Wilkniss, S. M., Denckla, M. B., Hamburger, S. D., \& OdouPotkin, M. (1994). Developmental dyslexia and attention dysfunction in adults: Brain potential indices of information processing. Psychophysiology, 31, 386-401. https://doi.org/10.1111/j.1469-8986.1994.tb02447.x

Duncan-Johnson, C. C., \& Donchin, E. (1982). The P300 component of the event-related brain potential as an index of information processing. Biological Psychology, 14(1-2), 152. https://doi.org/10.1016/0301-0511(82)90016-3

Dunn, B. R., Dunn, D. A., Languis, M., \& Andrews, D. (1998). The relation of ERP components to complex memory processing. Brain and Cognition, 36(3), 355-376. https://doi.org/10.1006/brcg.1998.0998

Dunn, M., Gomes, H., \& Sebastian, M. J. (1996). Prototypicality of responses of autistic, language disordered, and normal children in a word fluency task. Child Neuropsychology, 2(2), 99-108. https://doi.org/10.1080/09297049608401355

Eberhard-Moscicka, A. K., Jost, L. B., Fehlbaum, L. V., Pfenninger, S. E., \& Maurer, U. (2016). Temporal dynamics of early visual word processing - Early versus late N1 sensitivity in children and adults. Neuropsychologia, 91, 509-518. https://doi.org/10.1016/j.neuropsychologia.2016.09.014

Enoki, H., Sanada, S., Yoshinaga, H., Oka, E., \& Ohtahara, S. (1993). The effects of age on the N200 component of the auditory event-related potentials. Brain Research. Cognitive Brain Research, 1, 161-167. https://doi.org/10.1016/0926-6410(93)90023-x

Erez, A., \& Pratt, H. (1992). Auditory event-related potentials among dyslexic and normalreading children: $3 \mathrm{clt}$ and midline comparisons. The International Journal of Neuroscience, 63, 247-264. https://doi.org/10.3109/00207459208987200

Escera, C., Leung, S., \& Grimm, S. (2014). Deviance detection based on regularity encoding along the auditory hierarchy: Electrophysiological evidence in humans. Brain Topography, 27(4), 527-538. https://doi.org/10.1007/s10548-013-0328-4

Fawcett, A. J., Chattopadhyay, A. K., Kandler, R. H., Jarrat, J. A., Nicolson, R. I., \& Proctor, M. (1993b). Temporal information processing in the nervous system. In P. Tallal, A. M. Galaburda, \& R. R. Llinas (Eds.), Event-related potentials and dyslexia (Vol. 682, pp. 342-345). https://doi.org/10.1111/j.1749-6632.1993.tb22988.x

Fitzgerald, P. G., \& Picton, T. W. (1983). Event-related potentials recorded during the discrimination of improbable stimuli. Biological Psychology, 17(4), 241-276. https://doi.org/10.1016/0301-0511(83)90003-0 
Friederici, A. D. (2002). Towards a neural basis of auditory sentence processing. Trends in cognitive sciences, 6(2), 78-84. https://doi.org/10.1016/S1364-6613(00)01839-8

Friederici, A. D., \& Frisch, S. (2000). Verb Argument Structure Processing: The Role of Verb-Specific and Argument-Specific Information. Journal of Memory and Language, 43(3), 476-507. https://doi.org/10.1006/jmla.2000.2709

Friederici, A. D., \& Weissenborn, J. (2007). Mapping sentence form onto meaning: The syntax-semantic interface. Brain Research, 1146, 50-58. https://doi.org/10.1016/j.brainres.2006.08.038

Friedman, D., \& Simpson, G. V. (1994). ERP amplitude and scalp distribution to target and novel events: Effects of temporal order in young, middle-aged and older adults. Cognitive Brain Research, 2(1), 49-63. https://doi.org/10.1016/0926-6410(94)90020-5

Friedman, D., Vaughan, H. G., \& Erlenmeyer-Kimling, L. (1981). Multiple Late Positive Potentials in Two Visual Discrimination Tasks. Psychophysiology, 18(6), 635-649. https://doi.org/10.1111/j.1469-8986.1981.tb01838.x

Gauthier, I., Curran, T., Curby, K. M., \& Collins, D. (2003). Perceptual interference supports a non-modular account of face processing. Nature Neuroscience, 6(4), 428-432. https://doi.org/10.1038/nn1029

Gehring, W. J., Gratton, G., Coles, M. G., \& Donchin, E. (1992). Probability effects on stimulus evaluation and response processes. Journal of Experimental Psychology: Human Perception and Performance, 18(1), 198-216. https://doi.org/10.1037/00961523.18.1.198

Goswami, U., \& Bryant, P. (1994). Phonological skills and learning to read (Repr. in paperback). Essays in developmental psychology. Hove: Erlbaum. keine doi vorhanden

Griffiths, Y. M., \& Snowling, M. J. (2002). Predictors of exception word and nonword reading in dyslexic children: The severity hypothesis. Journal of Educational Psychology, 94(1), 34-43. https://doi.org/10.1037/0022-0663.94.1.34

Grossi, G., Coch, D., Coffey-Corina, S., Holcomb, P. J., \& Neville, H. J. (2001). Phonological processing in visual rhyming: A developmental erp study. Journal of Cognitive Neuroscience, 13(5), 610-625. https://doi.org/10.1162/089892901750363190

Hackley, S. A., Woldorff, M., \& Hillyard, S. A. (1990). Cross-modal selective attention effects on retinal, myogenic, brainstem, and cerebral evoked potentials. Psychophysiology, 27, 195-208. https://doi.org/10.1111/j.1469-8986.1990.tb00370.x 
Hagoort, P., \& Kutas, M. (1995 // 2000). Electrophysiological insights into language deficits. In F. Boller \& J. Grafman (Eds.), Handbook of neuropsychology // Section 1: introduction; section 2: attention (2nd ed., pp. 105-134). Amsterdam: Elsevier. keine ISBN vorhanden

Hahne, A., \& Friederici, A. D. (1999). Electrophysiological Evidence for Two Steps in Syntactic Analysis: Early Automatic and Late Controlled Processes. Journal of Cognitive Neuroscience, 11(2), 194-205. https://doi.org/10.1162/089892999563328

Halgren, E., Marinkovic, K., \& Chauvel, P. (1998). Generators of the late cognitive potentials in auditory and visual oddball tasks. Electroencephalography and Clinical Neurophysiology, 106, 156-164. https://doi.org/10.1016/s0013-4694(97)00119-3

Halgren, E., \& Marinkovic, K. (1995). Neurophysiological networks integrating human emotions. keine DOI oder ISBN vorhanden

Hämälainen, J. A., Salminen, H. K., \& Leppänen, P. H. T. (2013). Basic auditory processing deficits in dyslexia: Systematic review of the behavioral and event-related potential/ field evidence. Journal of Learning Disabilities, 46(5), 413-427. https://doi.org/10.1177/0022219411436213

Harter, Anllo-Vento, L., Wood, F. B., \& Schroeder, M. M. (1988). Separate brain potential characteristics in children with reading disability and attention deficit disorder: Color and letter relevance effects. Brain and Cognition, 7, 115-140. https://doi.org/10.1016/02782626(88)90023-1

Harter, Diering, S., \& Wood, F. B. (1988). Separate brain potential characteristics in children with reading disability and attention deficit disorder: Relevance-independent effects. Brain and Cognition, 7, 54-86. https://doi.org/10.1016/0278-2626(88)90021-8

Hasko, S., Groth, K., Bruder, J., Bartling, J., \& Schulte-Körne, G. (2014). What does the brain of children with developmental dyslexia tell us about reading improvement? Erp evidence from an intervention study. Frontiers in Human Neuroscience, 8, 441. https://doi.org/10.3389/fnhum.2014.00441

Heim, S., Eulitz, C., Kaufmann, J., Füchter, I., Pantev, C., Lamprecht-Dinnesen, A., .. . Elbert, T. (2000). Atypical organisation of the auditory cortex in dyslexia as revealed by MEG. Neuropsychologia, 38(13), 1749-1759. https://doi.org/10.1016/S00283932(00)00075-0

Helenius, P., Tarkiainen, A., Cornelissen, P., Hansen, P. C., \& Salmelin, R. (1999). Dissociation of normal feature analysis and deficient processing of letter-strings in 
dyslexic adults. Cerebral Cortex (New York, N.Y. : 1991), 9, 476-483. https://doi.org/10.1093/cercor/9.5.476

Hennighausen, K., Remschmidt, H., \& Warnke, A. (1994). Visually evoked potentials in boys with developmental dyslexia. European Child \& Adolescent Psychiatry, 3(2), 72 81. https://doi.org/10.1007/BF01977669

Herning, R. I., Speer, M., \& Jones, R. T. (1987). Event-related potentials to spoken equations: Is the N400 really a late N200? Electroencephalography and Clinical Neurophysiology. Supplement, 40, 394-398. PMID: 3480153

Hillyard, S. A., \& Kutas, M. (1983). Electrophysiology of cognitive processing. Annual Review of Psychology, 34, 33-61. https://doi.org/10.1146/annurev.ps.34.020183.000341

Hillyard, S. A., Squires, K. C., Bauer, J. W., \& Lindsay, P. H. (1971). Evoked Potential Correlates of Auditory Signal Detection. Science, 172(3990), 1357-1360. https://doi.org/10.1126/science.172.3990.1357

Hillyard, S. A., \& Picton, T. W. (1987). Electrophysiology of cognition. Comprehensive Physiology. https://doi.org/10.1002/cphy.cp010513

Holcomb, P. J., Ackerman, P. T., \& Dykman, R. A. (1985). Cognitive event-related brain potentials in children with attention and reading deficits. Psychophysiology, 22, 656-667. https://doi.org/10.1111/j.1469-8986.1985.tb01663.x

Holcomb, P. J., Ackerman, P. T., \& Dykman, R. A. (1986). Auditory event-related potentials in attention and reading disabled boys. International Journal of Psychophysiology : Official Journal of the International Organization of Psychophysiology, 3, 263-273. https://doi.org/10.1016/0167-8760(86)90035-8

Holcomb, P. J., \& McPherson, W. B. (1994). Event-related brain potentials reflect semantic priming in an object decision task. Brain and Cognition, 24(2), 259-276. https://doi.org/10.1006/brcg.1994.1014

Holcomb, P. J., \& Neville, H. J. (1990). Auditory and Visual Semantic Priming in Lexical Decision: A Comparison Using Event-related Brain Potentials. Language and Cognitive Processes, 5(4), 281-312. https://doi.org/10.1080/01690969008407065

Holopainen, I. E., Korpilahti, P., Juottonen, K., Lang, H., \& Sillanpää, M. (1997). Attenuated auditory event-related potential (mismatch negativity) in children with developmental dysphasia. Neuropediatrics, 28(5), 253-256. https://doi.org/10.1055/s-2007-973709 
Holopainen, I. E., Korpilahti, P., Juottonen, K., Lang, H., \& Sillanpää, M. (1998). Abnormal frequency mismatch negativity in mentally retarded children and in children with developmental dysphasia. Journal of Child Neurology, 13(4), 178-183. https://doi.org/10.1177/088307389801300406

Humphrey, D. G., \& Kramer, A. F. (1994). Toward a psychophysiological assessment of dynamic changes in mental workload. Human Factors: The Journal of the Human Factors and Ergonomics Society, 36, https://doi.org/10.1177/001872089403600101

Hyde, M. (1997). The N1 response and its applications. Audiology \& Neuro-Otology, 2, 281-307. https:// doi.org/10.1159/000259253

Iragui, V. J., Kutas, M., Mitchner, M. R., \& Hillyard S. A. (1993). Effects of aging on eventrelated brain potentials and reaction times in an auditory oddball task. Psychophysiology, 30(1), 10-22. https://doi.org/10.1111/j.1469-8986.1993.tb03200.x

Jäncke, L. (2013). Lehrbuch Kognitive Neurowissenschaften (1. Aufl.). Bern: Huber. Retrieved from http://elibrary.hogrefe.de/9783456950044/I

Jednorog, K., Marchewka, A., Tacikowski, P., Heim, S., \& Grabowska, A. (2011). Electrophysiological evidence for the magnocellular-dorsal pathway deficit in dyslexia. Developmental Science, 14(4), 873-880. https://doi.org/10.1111/j.14677687.2011.01037.x

Jednoróg, K., Marchewka, A., Tacikowski, P., \& Grabowska, A. (2010). Implicit phonological and semantic processing in children with developmental dyslexia: Evidence from event-related potentials. Neuropsychologia, 48(9), 2447-2457. https://doi.org/10.1016/j.neuropsychologia.2010.04.017

Johannes, S., Mangun, G. R., \& Münte, T. F. (1994b). Cerebral lateralization in constitutional dyslexia. Electrophysiologic findings. Der Nervenarzt, 65, 859-864. PMID: 7854508

Johnson, R. (1986). A triarchic model of P300 amplitude. Psychophysiology, 367-384. https://doi.org/10.1111/j.1469-8986.1986.tb00649.x

Johnson, R. (1988). The amplitude of the P300 component of the event-related potential: Review and synthesis. In P. Ackles, J. R. Jennings, \& Coles. M. G. H (Eds.), Advances in psychophysiology: A research annual (pp. 69-138). Greenwich, CT. keine DOI oder ISBN vorhanden 
Johnson, R., JR (1989). Developmental evidence for modality-dependent P300 generators: A normative study. Psychophysiology, 26, 651-667. https://doi.org/10.1111/j.14698986.1989.tb03167.x

Johnstone, S. J., Barry, R. J., Anderson, J. W., \& Coyle, S. F. (1996a). Age-related changes in child and adolescent event-related potential component morphology, amplitude and latency to standard and target stimuli in an auditory oddball task. International Journal of Psychophysiology : Official Journal of the International Organization of Psychophysiology, 24, 223-238. https://doi.org/10.1016/s0167-8760(96)00065-7

Johnstone, S. J., Barry, R. J., Anderson, J. W., \& Coyle, S. F. (1996b). Age-related changes in child and adolescent event-related potential component morphology, amplitude and latency to standard and target stimuli in an auditory oddball task. International Journal of Psychophysiology, 24(3), 223-238. https://doi.org/10.1016/S0167-8760(96)00065-7

Kast, M., Elmer, S., Jancke, L., \& Meyer, M. (2010). Erp differences of pre-lexical processing between dyslexic and non-dyslexic children. International Journal of Psychophysiology : Official Journal of the International Organization of Psychophysiology, 77(1), 59-69. https://doi.org/10.1016/j.ijpsycho.2010.04.003

Kiehl, K. A., Laurens, K. R., \& Liddle, P. F. (2002). Reading Anomalous Sentences: An Event-Related fMRI Study of Semantic Processing. NeuroImage, 17(2), 842-850. https://doi.org/10.1006/nimg.2002.1244

Kim, K. H., Yoon, H. W., \& Park, H. W. (2004). Spatiotemporal brain activation pattern during word/picture perception by native Koreans. Neuroreport, 15, 1099-1103. https://doi.org/10.1097/00001756-200405190-00003

Knight, R. (1996). Contribution of human hippocampal region to novelty detection. Nature, 383(6597), 256-259. https://doi.org/10.1038/383256a0

Korinth, S. P., Sommer, W., \& Breznitz, Z. (2013). Neuronal response specificity as a marker of reading proficiency: two-fold nature of the N170 revealed after massive repetition. NeuroReport, 24(2), 96-100. https://doi.org/10.1097/WNR.0b013e32835d20b1

Korpilahti, P., \& Lang, H. A. (1994). Auditory ERP components and mismatch negativity in dysphasic children. Electroencephalography and Clinical Neurophysiology, 91, 256264. https://doi.org/10.1016/0013-4694(94)90189-9 
Kramer, A. F., Strayer, D. L., \& Buckley, J. (1991). Task Versus Component Consistency in the Development of Automatic Processing: A Psychophysiological Assessment. Psychophysiology, 28(4), 425-437. https://doi.org/10.1111/j.1469-8986.1991.tb00726.x

Kraus, N., McGee, T., Carrell, T. D., King, C., Tremblay, K., \& Nicol, T. (1995). Central auditory system plasticity associated with speech discrimination training. Journal of Cognitive Neuroscience, 7(1), 25-32. https://doi.org/10.1162/jocn.1995.7.1.25

Kujala, T., Karma, K., Ceponiene, R., Belitz, S., Turkkila, P., Tervaniemi, M., \& Naatanen, R. (2001). Plastic neural changes and reading improvement caused by audiovisual training in reading-impaired children. Proceedings of the National Academy of Sciences of the United States of America, 98(18), 10509-10514. https://doi.org/10.1073/pnas.181589198

Kujala, T., \& Näätänen, R. (2001). The mismatch negativity in evaluating central auditory dysfunction in dyslexia. Neuroscience \& Biobehavioral Reviews, 25(6), 535-543. https://doi.org/10.1016/S0149-7634(01)00032-X

Kutas, M., \& Federmeier, K. D. (2011). Thirty years and counting: Finding meaning in the N400 component of the event-related brain potential (ERP). Annual Review of Psychology, 62, 621-647. https://doi.org/10.1146/annurev.psych.093008.131123

Kutas, M., van Petten, C., \& Besson, M. (1988). Event-related potential asymmetries during the reading of sentences. Electroencephalography and Clinical Neurophysiology, 69, 218-233. https://doi.org/10.1016/0013-4694(88)90131-9

Lachmann, T., Berti, S., Kujala, T., \& Schröger, E. (2005). Diagnostic subgroups of developmental dyslexia have different deficits in neural processing of tones and phonemes. International Journal of Psychophysiology, 56(2), 105-120. https://doi.org/10.1016/j.ijpsycho.2004.11.005

Lau, E., Stroud, C., Plesch, S., \& Phillips, C. (2006). The role of structural prediction in rapid syntactic analysis. Brain and Language, 98(1), 74-88. https://doi.org/10.1016/j.band1.2006.02.003

Licht, R., Bakker, D. J., Kok, A., \& Bouma, A. (1992). Grade-related changes in eventrelated potentials (ERPs) in primary school children: Differences between two reading tasks. Journal of Clinical and Experimental Neuropsychology, 14(2), 193-210. https://doi.org/10.1080/01688639208402823 
Liu, W., Wu, X., Zhou, D., \& Gong, Q. (2019). Reading deficits correlate with cortical and subcortical volume changes in a genetic migration disorder. Medicine, 98(36), e17070. https://doi.org/10.1097/MD.0000000000017070

Lohvansuu, K., Hämälainen, J. A., Tanskanen, A., Ervast, L., Heikkinen, E., Lyytinen, H., \& Leppänen, P. H. T. (2014). Enhancement of brain event-related potentials to speech sounds is associated with compensated reading skills in dyslexic children with familial risk for dyslexia. International Journal of Psychophysiology : Official Journal of the International Organization of Psychophysiology, 94(3), 298-310. https://doi.org/10.1016/j.ijpsycho.2014.10.002

Lovio, R., Näätänen, R., \& Kujala, T. (2010). Abnormal pattern of cortical speech feature discrimination in 6-year-old children at risk for dyslexia. Brain Research, 1335, 53-62. https://doi.org/10.1016/j.brainres.2010.03.097

Lovrich, D., Cheng, J. C., \& Velting, D. M. (1996). Late cognitive brain potentials, phonological and semantic classification of spoken words, and reading ability in children. Journal of Clinical and Experimental Neuropsychology, 18(2), 161-177. https://doi.org/10.1080/01688639608408272

Lovrich, D., Cheng, J. C., Velting, D. M., \& Kazmerski, V. (1997). Auditory ERPs during rhyme and semantic processing: Effects of reading ability in college students. Journal of Clinical and Experimental Neuropsychology, 19(3), 313-330. https://doi.org/10.1080/01688639708403861

Lovrich, D., \& Stamm, J. S. (1983). Event-related potential and behavioral correlates of attention in reading retardation. Journal of clinical and experimental neuropsychology, 5, 13-37. https://doi.org/10.1080/01688638308401148

Luck, S. J., \& Hillyard, S. A. (1994). Electrophysiological correlates of feature analysis during visual search. Psychophysiology, 31, 291-308. https://doi.org/10.1111/j.14698986.1994.tb02218.x

Lyytinen, H., Erskine, J., Hämäläinen, J., Torppa, M., \& Ronimus, M. (2015). DyslexiaEarly Identification and Prevention: Highlights from the Jyväskylä Longitudinal Study of Dyslexia. Current Developmental Disorders Reports, 2(4), 330-338. https://doi.org/10.1007/s40474-015-0067-1

Martin, F., \& Lovegrove, W. J. (1988). Uniform-field flicker masking in control and specifically-disabled readers. Perception, 17, 203-214. https://doi.org/10.1068/p170203 
Maurer, U., Brem, S., Bucher, K., \& Brandeis, D. (2005). Emerging neurophysiological specialization for letter strings. Journal of Cognitive Neuroscience, 17, 1532-1552. https://doi.org/10.1162/089892905774597218

Maurer, U., Brem, S., Bucher, K., Kranz, F., Benz, R., Steinhausen, H.-C., \& Brandeis, D. (2007). Impaired tuning of a fast occipito-temporal response for print in dyslexic children learning to read. Brain, 130(12), 3200-3210. https://doi.org/10.1093/brain/awm193

Maurer, U., Brem, S., Kranz, F., Bucher, K., Benz, R., Halder, P., Brandeis, D. (2006). Coarse neural tuning for print peaks when children learn to read. NeuroImage, 33(2), 749-758. https://doi.org/10.1016/j.neuroimage.2006.06.025

Maurer, U., \& McCandliss, B. D. (2007b). The development of visual expertise for words: the contribution of electrophysiology. Single Word Reading. ASIN: B009E2W4IG

Maurer, U., Schulz, E., Brem, S., der Mark, S. V., Bucher, K., Martin, E., \& Brandeis, D. (2011). The development of print tuning in children with dyslexia: Evidence from longitudinal ERP data supported by fMRI. NeuroImage, 57, 714-722. https://doi.org/10.1016/j.neuroimage.2010.10.055

Maurer, U., Zevin, J. D., \& McCandliss, B. D. (2008). Left-lateralized N170 effects of visual expertise in reading: evidence from Japanese syllabic and logographic scripts. Journal of Cognitive Neuroscience, 20, 1878-1891. https://doi.org/10.1162/jocn.2008.20125

Maurer, U., Blau, V. C., Yoncheva, Y. N., \& McCandliss, B. D. (2010). Development of visual expertise for reading: Rapid emergence of visual familiarity for an artificial script. Developmental Neuropsychology, 35(4),

$404-422$. https://doi.org/10.1080/87565641.2010.480916

Maurer, U., Brandeis, D., \& McCandliss, B. D. (2005). Fast, visual specialization for reading in English reveal by the topography of the N170 ERP response. Behavioral and Brain Functions, 1(1), 13. https://doi.org/10.1186/1744-9081-1-13

Maurer, U., Schulz, E., Brem, S., van der Mark, S., Bucher, K., Martin, E., \& Brandeis, D. (2011). The development of print tuning in children with dyslexia: Evidence from longitudinal ERP data supported by fMRI. NeuroImage, 57(3), 714-722. https://doi.org/10.1016/j.neuroimage.2010.10.055

McCarthy, G., \& Nobre, A. C. (1993). Modulation of semantic processing by spatial selective attention. Electroencephalography and Clinical Neurophysiology/Evoked Potentials Section, 88(3), 210-219. https://doi.org/10.1016/0168-5597(93)90005-A 
McDonough, B. E., Warren, C. A., \& Don, N. S. (1992). Event-related potentials in a guessing task: The gleam in the eye effect. The International Journal of Neuroscience, 65, 209-219. https://doi.org/10.3109/00207459209003295

McPherson, W. B., Ackerman, P. T., Holcomb, P. J., \& Dykman, R. A. (1998). Event-related brain potentials elicited during phonological processing differentiate subgroups of reading disabled adolescents. Brain and Language, 62(2), 163-185. https://doi.org/10.1006/brln.1997.1893

McPherson, W. B., Ackerman, P. T., Oglesby, D. M., \& Dykman, R. A. (1996). Eventrelated brain potentials elicited by rhyming and non-rhyming pictures differentiate subgroups of reading disabled adolescents. Integrative Physiological and Behavioral Science : the Official Journal of the Pavlovian Society, 31, 3-17. https://doi.org/10.1007/bf02691478

Meng, X., Tian, X., Jian, J., \& Zhou, X. (2007). Orthographic and phonological processing in Chinese dyslexic children: An ERP study on sentence reading. Brain Research, 1179, 119-130. https://doi.org/10.1016/j.brainres.2007.08.046

Menning, H., Roberts, L. E., \& Pantev, C. (2000). Plastic changes in the auditory cortex induced by intensive frequency discrimination training. NeuroReport, 11. https://doi.org/10.1097/00001756-200003200-00032

Miles, J., \& Stelmack, R. M. (1994). Learning disability subtypes and the effects of auditory and visual priming on visual event-related potentials to words. Journal of Clinical and $\begin{array}{llll}\text { Experimental Neuropsychology, } & \text { 43-64. }\end{array}$ https://doi.org/10.1080/01688639408402616

Molenaar, P. C.M., Wijker, W., \& Molen, M. W. (1989). Age-changes in scalp distributions of cognitive event-related potentials elicited in an oddball task. Journal of Psychophysiology, 3, 179-189. keine DOI oder ähnliches aufindbar

Molfese, P. J., Fletcher, J. M., \& Denton, C. A. (2013). Adequate versus inadequate response to reading intervention: An event-related potentials assessment. Developmental Neuropsychology, 38(8), 534-549. https://doi.org/10.1080/87565641.2013.825260

Näätänen, R., \& Alho, K. (1995). Mismatch negativity to change in complex spectrotemporal sound pattern: A new way to study neural learning in the human brain. Electroencephalography and Clinical Neurophysiology. Supplement, 44, 179-184. PMID: 7649019 
Näätänen, R., Lehtokoski, A., Lennes, M., Cheour, M., Huotilainen, M., Iivonen, A., Alho, K. (1997). Language-specific phoneme representations revealed by electric and magnetic brain responses. Nature, 385(6615), 432-434. https://doi.org/10.1038/385432a0

Näätänen, R., \& Picton, T. (1987). The N1 Wave of the Human Electric and Magnetic Response to Sound: A Review and an Analysis of the Component Structure. Psychophysiology, 24(4), 375-425. https://doi.org/10.1111/j.1469-8986.1987.tb00311.x

Näätänen, R., Schröger, E., Karakas, S., Tervaniemi, M., \& Päävilainen, P. (1993). Development of a memory trace for a complex sound in the human brain. NeuroReport, 4. https://doi.org/10.1097/00001756-199305000-00010

Naylor, C. E., Wood, F. B., \& Harter, M. R. (1995). Event related potentials in adults diagnosed as reading disabled in childhood. The International Journal of Neuroscience, 80, 339-352. https://doi.org/10.3109/00207459508986108

Neuhoff, N., Bruder, J., Bartling, J., Warnke, A., Remschmidt, H., Muller-Myhsok, B., \& Schulte-Körne, G. (2012). Evidence for the late MMN as a neurophysiological endophenotype for dyslexia. PloS One, 7(5), e34909. https://doi.org/10.1371/journal.pone.0034909

Neville, H. J., Coffey, S. A., Holcomb, P. J., \& Tallal, P. (1993). The neurobiology of sensory and language processing in language-impaired children. Journal of Cognitive Neuroscience, 5(2), 235-253. https://doi.org/10.1162/jocn.1993.5.2.235

Niznikiewicz, M., \& Squires, N. K. (1996). Phonological processing and the role of strategy in silent reading: Behavioral and electrophysiological evidence. Brain and Language, 52(2), 342-364. https://doi.org/10.1006/brln.1996.0016

Nobre, A. C., \& McCarthy, G. (1995). Language-related field potentials in the anteriormedial temporal lobe: II. Effects of word type and semantic priming. J. Neurosci., 15, 1090. https://www.ncbi.nlm.nih.gov/pmc/articles/PMC6577813/

Nordt, M., Hoehl, S., \& Weigelt, S. (2016). The use of repetition suppression paradigms in developmental cognitive neuroscience. Cortex; a Journal Devoted to the Study of the Nervous System and Behavior, 80, 61-75. https://doi.org/10.1016/j.cortex.2016.04.002

Oades, R. D., Dittmann-Balcar, A., \& Zerbin, D. (1997). Development and topography of auditory event-related potentials (ERPs): Mismatch and processing negativity in individuals 8-22 years of age. Psychophysiology, 34, 677-693. https://doi.org/10.1111/j.1469-8986.1997.tb02143.x 
Oades, R. D., Zerbin, D., \& Dittmann-Balcar, A. (1995). The topography of event-related potentials in passive and active conditions of a 3-tone auditory oddball test. The International Journal of Neuroscience, 81, 249-264. https://doi.org/10.3109/00207459509004890

Oliveira, J. C., Murphy, C. F. B., \& Schochat, E. (2013). Processamento auditivo (central) em crianças com dislexia: avaliação comportamental e eletrofisiológica. Brain research, 25(1), 39-44. https://doi.org/10.1590/S2317-17822013000100008

Ortiz Alonso, T., Navarro, M., \& Vila Abad, E. (1990). P300 component of the auditory event-related potentials and dyslexia. Functional Neurology, 5, 333-338. PMID:2093051

Palmer, B., Nasman, V. T., \& Wilson, G. F. (1994). Task decision difficulty: Effects on ERPs in a same-different letter classification task. Biological Psychology, 38(2-3), 199214. https://doi.org/10.1016/0301-0511(94)90039-6

Papagiannopoulou, E. A., \& Lagopoulos, J. (2017). P300 event-related potentials in children with dyslexia. Annals of Dyslexia, 67(1), 99-108. https://doi.org/10.1007/s11881-016$0122-6$

Perneger, T. V. (1998). What's wrong with Bonferroni adjustments. BMJ (Clinical Research Ed.), 316(7139), 1236-1238. https://doi.org/10.1136/bmj.316.7139.1236

Picton, T. W. (1995). The neurophysiological calculation of auditory discrimination. Ear and Hearing, 1-5. https://doi.org/10.1016/j.clinph.2010.03.011

Polich, J. (1985). Semantic categorization and event-related potentials. Brain and Language, 26(2), 304-321. https://doi.org/10.1016/0093-934X(85)90045-8

Polich, J. (1987). Task difficulty, probability, and inter-stimulus interval as determinants of P300 from auditory stimuli. Electroencephalography and Clinical Neurophysiology/Evoked Potentials Section, 68(4), 311-320. https://doi.org/10.1016/0168-5597(87)90052-9

Polich, J. (1989). Habituation of P300 from auditory stimuli. Psychobiology, 17, 19-28.

Polich, J., \& HEINE, M. R. D. (1996). P300 topography and modality effects from a singlestimulus paradigm. Psychophysiology, 33(6), 747-752. https://doi.org/10.1111/j.14698986.1996.tb02371.x

Posner, M. I., \& McCandliss, B. D. (1999). Brain circuitry during reading. Converging methods for understanding reading and dyslexia, 305-337. ISBN-10: 026211247 
Potts, G. F., Hirayasu, Y., O'Donnell, B. F., Shenton, M. E., \& McCarley, R. W. (1998). High-density recording and topographic analysis of the auditory oddball event-related potential in patients with schizophrenia. Biological Psychiatry, 44, 982-989. https://doi.org/10.1016/s0006-3223(98)00223-6

Praamstra, P., \& Stegeman, D. (1993). Phonological effects on the auditory N400. Brain research. Cognitive brain research, 1. https://doi.org/10.1016/0926-6410(93)90013-U

Raney, G. E. (1993). Monitoring changes in cognitive load during reading: An event-related brain potential and reaction time analysis. Journal of Experimental Psychology: Learning, Memory, and Cognition, 19(1), 51-69. https://doi.org/10.1037/02787393.19.1.51

Rinker, T., Kohls, G., Richter, C., Maas, V., Schulz, E., \& Schecker, M. (2007). Abnormal frequency discrimination in children with SLI as indexed by mismatch negativity (MMN). Neuroscience Letters, 413(2), 99-104. https://doi.org/10.1016/j.neulet.2006.11.033

Rinne, T., Alho, K., Alku, P., Holi, M., Sinkkonen, J., Virtanen, J., Näätänen, R. (1999). Analysis of speech sounds is left-hemisphere predominant at $100-150 \mathrm{~ms}$ after sound onset. NeuroReport, 10, 1113-1117. : htttp://10.1097/00001756-199904060-00038

Rispens, J. E. (2004). Syntactic and Phonological Processing in Developmental Dyslexia (Thesis). University of Groningen, Groningen.

Ritter, W., Simson, R., Vaughan, H. G., \& Macht, M. (1982). Manipulation of event-related potential manifestations of information processing stages. Science, 218, 909-911. htttp://10.1126/science.7134983

Ruchkin, D.S., Sutton, S., \& Stega, M. (1980). Emitted P300 and slow wave event-related potentials in guessing and detection tasks. Electroencephalography and Clinical Neurophysiology, 49(1-2), 1-14. https://doi.org/10.1016/0013-4694(80)90346-6

Rugg, M. D. (1984a). Event-related potentials and the phonological processing of words and non-words. Neuropsychologia, 22, 435-443. htttp://10.1016/0028-3932(84)90038-1

Rugg, M. D. (1984b). Event-related potentials in phonological matching tasks. Brain and Language, 23, 225-240. htttp:// 10.1016/0093-934x(84)90065-8

Rugg, M. D., \& Barrett, S. E. (1987). Event-related potentials and the interaction between orthographic and phonological information in a rhyme-judgment task. Brain and Language, 32, 336-361. htttp://10.1016/0093-934x(87)90132-5 
Rugg, M. D., \& Doyle, M. C. (1992). Event-related potentials and recognition memory for low- and high-frequency words. Journal of Cognitive Neuroscience, 4(1), 69-79. https://doi.org/10.1162/jocn.1992.4.1.69

Rugg, M. D. (1987). Dissociation of semantic priming, word and non-word repetition effects by event-related potentials. The quarterly journal of Experimental Psychology, 39, 123148. https://doi.org/10.1080/02724988743000060

Rüsseler, J., Johannes, S., Kowalczuk, J., Wieringa, B. M., \& Münte, T. F. (2003). Developmental dyslexics show altered allocation of attention in visual classification tasks. Acta Neurologica Scandinavica, 107(1), 22-30. https://doi.org/10.1034/j.16000404.2003.02060.x

Rüsseler, J., Probst, S., Johannes, S., \& Münte, T. (2003). Recognition memory for highand low-frequency words in adult normal and dyslexic readers: An event-related brain potential study. Journal of Clinical and Experimental Neuropsychology, 25(6), 815-829. https://doi.org/10.1076/jcen.25.6.815.16469

Rüsseler, J., Becker, P., Johannes, S., \& Münte, T. F. (2007). Semantic, syntactic, and phonological processing of written words in adult developmental dyslexic readers: An event-related brain potential study. BMC Neuroscience, 8, 52. https://doi.org/10.1186/1471-2202-8-52

Rüsseler, J., Kowalczuk, J., Johannes, S., Wieringa, B. M., \& Münte, T. F. (2002). Cognitive brain potentials to novel acoustic stimuli in adult dyslexic readers. Dyslexia, 8(3), 125142. https://doi.org/10.1002/dys.221

Salmelin, R., Service, E., Kiesila, P., Uutela, K., \& Salonen, O. (1996). Impaired visual word processing in dyslexia revealed with magnetoencephalography. Annals of Neurology, 40(2), 157-162. https://doi.org/10.1002/ana.410400206

Schlaggar, B. L., \& McCandliss, B. D. (2007). Development of Neural Systems for Reading. Annual Review of Neuroscience, 30(1), 475-503. https://doi.org/10.1146/annurev.neuro.28.061604.135645

Schulte-Körne, G., Bartling, J., Deimel, W., \& Remschmidt, H. (2004a). Motion-onset VEPs in dyslexia. Evidence for visual perceptual deficit. NeuroReport, 15, 1075-1078.https:// 10.1097/00001756-200404290-00029 
Schulte-Körne, G., Bartling, J., Deimel, W., \& Remschmidt, H. (2004b). Visual evoked potential elicited by coherenty moving dots in dyslexic children. Neuroscience Letters, 357(3), 207-210. https://doi.org/10.1016/j.neulet.2003.12.098

Schulte-Körne, G., Deimel, W., Bartling, J., \& Remschmidt, H. (1999). Pre-attentive processing of auditory patterns in dyslexic human subjects. Neuroscience Letters, 276, 41-44. https://doi.org/10.1016/S0304-3940(99)00785-5

Schulte-Körne, G., Deimel, W., Bartling, J., \& Remschmidt, H. (2001). Speech perception deficit in dyslexic adults as measured by mismatch negativity (MMN). International Journal of Psychophysiology, 40(1), 77-87. https://doi.org/10.1016/S01678760(00)00152-5

Schulz, E., Maurer, U., van der Mark, S., Bucher, K., Brem, S., Martin, E., \& Brandeis, D. (2008). Impaired semantic processing during sentence reading in children with dyslexia: Combined fMRI and ERP evidence. NeuroImage, 41(1), 153-168. https://doi.org/10.1016/j.neuroimage.2008.02.012

Share, D. L. (1999). Phonological recoding and orthographic learning: A direct test of the self-teaching hypothesis. Journal of Experimental Child Psychology, 72(2), 95-129. https://doi.org/10.1006/jecp.1998.2481

Sharma, M., Purdy, S. C., Newall, P., Wheldall, K., Beaman, R., \& Dillon, H. (2006). Electrophysiological and behavioral evidence of auditory processing deficits in children with reading disorder. Clinical Neurophysiology, 117(5), 1130-1144. https://doi.org/10.1016/j.clinph.2006.02.001

Shaul, S. (2008). Event-Related Potentials in the Study of Dyslexia. In Z. Breznitz (Ed.), Brain Research in Language (pp.51-92). Boston, MA: Springer US. https://doi.org/10.1007/978-0-387-74980-8_2

Shaywitz, B. A., Shaywitz, S. E., Pugh, K. R., Mencl, W.E., Fulbright, R. K., Skudlarski, P., Gore, J. C. (2002). Disruption of posterior brain systems for reading in children with developmental dyslexia. Biological psychiatry, 52(2), 101-110. https://doi.org/10.1016/S0006-3223(02)01365-3

Shaywitz, S. E. (1998). Dyslexia. The New England Journal of Medicine, 338(5), 307-312. https://doi.org/10.1056/NEJM199801293380507

Shiran, A., \& Breznitz, Z. (2011). The effect of cognitive training on recall range and speed of information processing in the working memory of dyslexic and skilled readers. Journal of Neurolinguistics, 24(5), 524-537. https://doi.org/10.1016/j.jneuroling.2010.12.001 
Shtyrov, Y., Kujala, T., Palva, S., Ilmoniemi, R. J., \& Naatanen, R. (2000). Discrimination of speech and of complex nonspeech sounds of different temporal structure in the left and right cerebral hemispheres. NeuroImage, 12(6), 657-663. https://doi.org/10.1006/nimg.2000.0646

Silva, P. B., Ueki, K., Oliveira, D. G., Boggio, P. S., \& Macedo, E. C. (2016). Early Stages of Sensory Processing, but Not Semantic Integration, Are Altered in Dyslexic Adults. Frontiers in Psychology, 7, 430. https://doi.org/10.3389/fpsyg.2016.00430

Silva-Pereyra, J., Rivera-Gaxiola, M., Fernandez, T., Diaz-Comas, L., Harmony, T., Fernandez-Bouzas, A., Marosi, E. (2003). Are poor readers semantically challenged? An event-related brain potential assessment. International Journal of Psychophysiology: Official Journal of the International Organization of Psychophysiology, 49, 187-199. https://doi.org/10.1016/S0167-8760(03)00116-8

Simos, P. G., Breier, J. I., Fletcher, J. M., Bergman, E., \& Papanicolaou, A. C. (2000). Cerebral mechanisms involved in word reading in dyslexic children: A magnetic source imaging approach. Cerebral Cortex (New York, N.Y. : 1991), 10, 809-816. https://doi.org/10.1093/cercor/10.8.809

Smith, M. E. (1993). Neurophysiological Manifestations of Recollective Experience during Recognition Memory Judgments. Journal of Cognitive Neuroscience, 5(1), 1-13. https://doi.org/10.1162/jocn.1993.5.1.1

Squires, N. K., Squires, K. C., \& Hillyard, S. A. (1975). Two varieties of long-latency positive waves evoked by unpredictable auditory stimuli in man. Electroencephalography and Clinical Neurophysiology, 38, 387-401. https://doi.org/10.1016/00134694(75)90263-1

Stein, J. (2018). The current status of the magnocellular theory of developmental dyslexia. Neuropsychologia. Advance online publication. https://doi.org/10.1016/j.neuropsychologia.2018.03.022

Stelmack, R. M., Saxe, B. J., Noldy-Cullum, N., Campbell, K. B., \& Armitage, R. (1988). Recognition memory for words and event-related potentials: A comparison of normal and disabled readers. Journal of Clinical and Experimental Neuropsychology, 10(2), 185200. https://doi.org/10.1080/01688638808408235

Stevens, C., McIlraith, A., Rusk, N., Niermeyer, M., \& Waller, H. (2013). Relative laterality of the N170 to single letter stimuli is predicted by a concurrent neural index of implicit 
processing of letter names. Neuropsychologia, 51(4), 667-674. https://doi.org/10.1016/j.neuropsychologia.2012.12.009

Stoodley, C. J., Hill, P. R., Stein, J. F., \& Bishop, D. V. M. (2006). Auditory event-related potentials differ in dyslexics even when auditory psychophysical performance is normal. Brain Research, 1121(1), 190-199. https://doi.org/10.1016/j.brainres.2006.08.095

Tanaka, J. W., \& Curran, T. (2001). A neural basis for expert object recognition. Psychological Science, 12, 43-47.

Tarkiainen, A. (1999). Dynamics of letter string perception in the human occipitotemporal cortex. Brain, 122(11), 2119-2132. https://doi.org/10.1093/brain/122.11.2119

Taroyan, N. A. (2015). Seeing is knowing? Visual word recognition in non-dyslexic and dyslexic readers: An ERP study. Visual Cognition, 23(5), 577-596. https://doi.org/10.1080/13506285.2015.1055852

Taylor, M. J., \& Keenan, N. K. (1990). Event-related potentials to visual and language stimuli in normal and dyslexic children. Psychophysiology, 27, 318-327. https://doi.org/10.1111/j.1469-8986.1990.tb00389.x

Taylor, M. J., \& Keenan, N. K. (1999). ERPs to orthographic, phonological, and semantic tasks in dyslexic children with auditory processing impairment. Developmental Neuropsychology, 15(2), 307-326. https://doi.org/10.1080/87565649909540751

Taylor, M. J., Smith, M. L., \& Iron, K. S. (1990). Event-related potential evidence of sex differences in verbal and nonverbal memory tasks. Neuropsychologia, 28(7), 691-705. https://doi.org/10.1016/0028-3932(90)90124-7

Townsend, D. J., \& Bever, T. G. (Eds.). (2001). A Bradford book. Sentence comprehension: The integration of habits and rules. Cambridge, Mass.: MIT Press. ISBN-10: 0262700808

Tremblay, K., Kraus, N., \& McGee, T. (1998a). The time course of auditory perceptual learning: neurophysiological changes during speech-sound training. NeuroReport, 9 . 10.1097/00001756-199811160-00003

Uwer, R., Albrecht, R., \& Suchodoletz, W. von (2002). Automatic processing of tones and speech stimuli in children with specific language impairment. Developmental Medicine \& Child Neurology, 44(8), 527-532. https://doi.org/10.1111/j.1469-8749.2002.tb00324.x

Van Petten, C., \& Kutas, M. (1991). Influences of semantic and syntactic context on openand closed-class words. Memory \& Cognition, 19(1), 95-112. https://doi.org/10.3758/BF03198500 
Van Zuijen, T. L., Plakas, A., Maassen, B. A. M., Been, P., Maurits, N. M., Krikhaar, E., van der Leij, A. (2012). Temporal auditory processing at 17 months of age is associated with preliterate language comprehension and later word reading fluency: An ERP study. Neuroscience Letters, 528(1), 31-35. https://doi.org/10.1016/j.neulet.2012.08.058

Vaughan Jr, H. G., \& Kurtzberg, D. (Eds.) (1992). Electrophysiologic Indices of Human Brain Maturation and Cognitve Development. Developmental Behavioral Neuroscience. ISBN-10: 0805809775

Verbaten, M. N., Huyben, M. A., \& Kemner, C. (1997). Processing capacity and the frontal P3. International Journal of Psychophysiology : Official Journal of the International Organization of Psychophysiology, 25, 237-248. https://doi.org/10.1016/S01678760(96)00748-9

Wagensveld, B., Segers, E., van Alphen, P., Hagoort, P., \& Verhoeven, L. (2012). A neurocognitive perspective on rhyme awareness: The N450 rhyme effect. Brain Research, 1483, 63-70. https://doi.org/10.1016/j.brainres.2012.09.018

Wagensveld, B., van Alphen, P., Segers, E., Hagoort, P., \& Verhoeven, L. (2013). The neural correlates of rhyme awareness in preliterate and literate children. Clinical Neurophysiology : Official Journal of the International Federation of Clinical Neurophysiology, 124(7), 1336-1345. https://doi.org/10.1016/j.clinph.2013.01.022

Wijers, A. A., Lange, J. J.A.N., Mulder, G., \& Mulder, L. J. M. (1997). An ERP study of visual spatial attention and letter target detection for isoluminant and nonisoluminant stimuli. Psychophysiology, 34(5), 553-565. https://doi.org/10.1111/j.14698986.1997.tb01742.x

Wilson, G. F., Swain, C. R., \& Ullsperger, P. (1998). ERP components elicited in response to warning stimuli: The influence of task difficulty. Biological Psychology, 47(2), 137158. https://doi.org/10.1016/S0301-0511(97)00021-5

Winkler, I., Kujala, T., Tiitinen, H., Sivonen, P., Alku, P., Lehtokoski, A., Näätänen, R. (1999). Brain responses reveal the learning of foreign language phonemes. Psychophysiology, 36, 638-642. DOI: https://doi.org/10.1111/1469-8986.3650638

Zhao, P., Li, S., Zhao, J., Gaspar, C. M., \& Weng, X. (2015). Training by visual identification and writing leads to different visual word expertise N170 effects in preliterate Chinese children. Developmental Cognitive Neuroscience, 15, 106-116. https://doi.org/10.1016/j.den.2015.09.002 